Illinois State University

ISU ReD: Research and eData

Theses and Dissertations

3-21-2016

\title{
Too Little Stem Workforce In The United States: Framing The Discourse In A Global Setting
}

Patrice-Andre P. Prud'homme

Illinois State University, zzaells@gmail.com

Follow this and additional works at: https://ir.library.illinoisstate.edu/etd

Part of the Education Policy Commons, Higher Education Administration Commons, and the Higher Education and Teaching Commons

\section{Recommended Citation}

Prud'homme, Patrice-Andre P., "Too Little Stem Workforce In The United States: Framing The Discourse In A Global Setting" (2016). Theses and Dissertations. 595.

https://ir.library.illinoisstate.edu/etd/595

This Dissertation is brought to you for free and open access by ISU ReD: Research and eData. It has been accepted for inclusion in Theses and Dissertations by an authorized administrator of ISU ReD: Research and eData. For more information, please contact ISUReD@ilstu.edu. 


\title{
TOO LITTLE STEM WORKFORCE IN THE UNITED STATES: FRAMING THE DISCOURSE IN A GLOBAL SETTING
}

\author{
Patrice-Andre P. Prud'homme
}

\section{Pages}

Policymakers and industry leaders are claiming that the U.S. has an insufficient number of STEM graduates. As the rhetoric of a shortage of skilled scholars and employees in STEM-related fields expands, there is a plethora of publications that refers to a phenomenon dating back to the 1950s. Nonetheless, this new paradigm presents a critical challenge to policies and programs that surround STEM education in countries around the world. While STEM, including the underlying human capital component is a major factor of economic growth in the United States, it is also in Australia and Germany. The policy analysis study is presented as a systematic investigation, critically examining how the contemporary discussion around STEM and skills shortages is articulated within an analytical framework that tends to differ. The policy analysis has proven useful to identify how the rhetoric reflects the real situation and how solutions are sought out relative to the national and international contexts.

KEYWORDS: Australia, Germany, Education Policy, Higher Education, Immigration, MINT, Skills Mismatch, Skills Shortage, STEM, STEM Shortage, United States 
TOO LITTLE STEM WORKFORCE IN THE UNITED STATES:

FRAMING THE DISCOURSE IN A GLOBAL SETTING

PATRICE-ANDRE P. PRUD'HOMME

A Dissertation Submitted in Partial

Fulfillment of the Requirements

for the Degree of

DOCTOR OF PHILOSOPHY

Department of Educational Administration and Foundations

ILLINOIS STATE UNIVERSITY

2016 
(C) 2016 Patrice-Andre P. Prud'homme 
TOO LITTLE STEM WORKFORCE IN THE UNITED STATES:

FRAMING THE DISCOURSE IN A GLOBAL SETTING

PATRICE-ANDRE P. PRUD'HOMME

COMMITTEE MEMBERS:

Elizabeth.T. Lugg, Chair

Paul J. Baker

Diane R. Dean

William J. F. Hunter 


\section{ACKNOWLEDGMENTS}

My sincere gratitude goes to my advisor and chair, Dr. Elizabeth Lugg, who has guided me and supported my ambition in writing this education policy analysis. I also want to express my sincere gratitude to the faculty members of my committee, who have provided a very strong support to my study.

I extend my gratitude to the people I interviewed, who kindly shared their expertise in making this study more credible. Their participation has been very much appreciated.

This dissertation is dedicated to my wife and my sons, whose incredible patience and love have made this unique experience possible.

P-A. P. P. 


\section{CONTENTS}

Page

ACKNOWLEDGMENTS $\quad$ i

CONTENTS

TABLES vii

FIGURES viii

CHAPTER

I. INTRODUCTION 1

Statement of the Problem $\quad 5$

Purpose of the Study 6

$\begin{array}{ll}\text { Research Questions } & 6\end{array}$

$\begin{array}{ll}\text { Abbreviations } & 7\end{array}$

$\begin{array}{ll}\text { Definitions of Terms } & 10\end{array}$

$\begin{array}{ll}\text { Limitations of the Study } & 12\end{array}$

Significance of the Study 14

$\begin{array}{ll}\text { Organization of the Dissertation } & 15\end{array}$

$\begin{array}{ll}\text { II. } & \text { METHODOLOGY } \\ \end{array}$

Document Analysis $\quad 20$

$\begin{array}{ll}\text { Interviews } & 25\end{array}$

$\begin{array}{ll}\text { Policy Analysis } & 28\end{array}$

III. CHRONOLOGICAL HISTORY OF STEM 32

$\begin{array}{ll}\text { Overview } & 32\end{array}$

$\begin{array}{ll}\text { The United States } & 32\end{array}$

Science in the early years of the twentieth century 32

American scientists as 'agents of change', 1930s 34

A transitional period for American science, late 1930s-1945 35 
American science: The human resource capacity, post WWII years

Emerging needs of technically trained personnel, late 1950s-1960s

Anti-science idiosyncrasies of two presidencies

The changing landscape of science (and the world)

Is American science and technology in decline?

Australia

The call for more trained personnel

The 1960s to the mid-1980s

The late 1980s

The turn of the twenty-first century

Stability in the 'rules of the game'

Germany

The years following World War II 55

The decision to invest in higher education 58

The production of scientific and scholarly talents 59

Summary

60

IV. CRITICAL REVIEW OF THE STEM SHORTAGE DISCOURSE IN THE UNITED STATES

What is Meant by STEM in the Educational Context?

Understanding STEM

Defining STEM

The Ambiguity with Labeling STEM

The Need to Establish a Clear Vision

71

Summary

Major Tenets (Grounding) of the Discourse

How is the STEM Shortage Discourse Framed?

Economic principles

The lack of supply

Market indicators 
The picture of STEM workforce shortages

Wages are lagging behind $\quad 89$

Unemployment rates are lower than expected 91

The changing demographics 93

$\begin{array}{ll}\text { Political Framework } & 97\end{array}$

Federal government STEM programs 97

The immigration of STEM workers 101

The power of lobbying 106

There is a lack of evidence despite current beliefs $\quad 108$

The U.S. innovative leadership 110

$\begin{array}{ll}\text { Summary } & 111\end{array}$

$\begin{array}{ll}\text { Conclusion } & 112\end{array}$

V. CRITICAL REVIEW OF THE STEM SHORTAGE DISCOURSE IN AUSTRALIA AND GERMANY 115

$\begin{array}{ll}\text { Australia } & 116\end{array}$

Introduction 116

Placing STEM in Context 117

Major Tenets 119

How is the discourse framed? 119

Economic concepts 121

Supply 121

Demand 123

$\begin{array}{ll}\text { Market indicators } & 123\end{array}$

Wages and unemployment rates 123

$\begin{array}{ll}\text { Demographics } & 125\end{array}$

$\begin{array}{ll}\text { Political Framework } & 126\end{array}$

Industry 126

Immigration 127

Programs, participation and STEM in society 127

iv 
Germany

Introduction

Placing MINT in Context

How is the discourse framed?

Supply

Market indicators

Demographics

Political Framework

Industry

Programs and education

Conclusion

VI. DISCUSSION AND IMPLICATION

Research Questions

Significance of Evidence

Implications

Recommendations

173

Future Research 
APPENDIX A: Interview Questionnaire 


\section{TABLES}

Table $\quad$ Page

1. Numbers of Higher Education Graduates in the Federal Republic of Germany: 1960-1996 58

2. Classification of STEM, STEM-Related, and Non-STEM Occupations 67

3. Distribution of Workers in S\&E Occupations, by Race and Ethnicity: 1993-2010 (Percent) 96

4. Share of Degree Holders Working in and out of their Fields 105 


\section{FIGURES}

$\begin{array}{lll}\text { Figure } & \text { Page }\end{array}$

1. Employment growth dropped during the recession but will come back by 2018

2. Bureau of Labor Statistics' projected increases in employment for S\&E and selected other occupations: 2010-2020

3. Growth of U.S. baccalaureate and first professional degrees from 1990 to 1988

4. Millions of 22-year-olds in the U.S. population

5. Fields of study at West German universities and technical colleges, 1951-1991*

6. STEM employment by type of STEM occupation, May 2014

7. Average hourly wages for STEM workers with only a bachelor's degree in 2012 dollars

8. Average hourly wages for STEM workers with only a bachelor's degree or higher in 2012 dollars

9. Unemployment and underemployment of young college graduates, 1994-2013*

10. Unemployed and job openings, by industry (in thousands)

11. Average hourly wage in computer and mathematical occupations, workers with at least a bachelor's degree, 2000-2011 (2012 dollars)

12. Unemployment rates of all workers and workers in computer and mathematical occupations, 2000-2011 (relative to unemployment rates at full employment) 
13. Share of total employment, science and engineering degrees, and STEM employment by sex

14. Women's employment in STEM occupations: 1970 to 2011

15. Racial and ethnic representation in the STEM workforce

16. Full attribution cost — education and related spending per undergraduate completion at public four-year institutions, by discipline, 2009

17. Percentage of non-U.S. citizens (bachelor's degree or higher)

18. Growth in STEM employment 2000 to 2012

19. STEM jobs distribution and the question of degree specificity by native and immigrant

20. Proportions of assessed occupations in shortage, Australia, 2007 to $2015(\%)$

21. Higher education revenue by source, 1907-2012 


\section{CHAPTER I}

\section{INTRODUCTION}

Policies that surround Science, Technology, Engineering, and mathematics (STEM) shortages are emerging around the world with the intent to provide a skilled workforce to meet demand within the context of a more integrated global economy. Globalization presents new challenges in that it does not eliminate the adaptability and flexibility relative to contextual social, economic and political forces that apply in each nation. While this study aims to focus on the current rhetoric of STEM shortages in the United States, it also incorporates Australia and Germany as frames of reference, taking into consideration the role played by their national values in the context of the global STEM conversation.

The advent of the importance placed on American science has earlier beginnings than World War II as new relations between science and government had already emerged in the 1920s. In the 1920s, industrial and government research laboratories expanded rapidly, followed by increasing investments in research and development in the 1930s-1940s. It was also a critical period in history, when German scientists migrated to the United States. As the United States developed its hegemonic position as an industrialized core nation after World War II (Wallerstein, 1974), the U.S. economy was also becoming more dependent on science education for prosperity and innovation to drive its economic strength in absorbing and creating new technologies. At the close of 
World War II, U.S. government had recommended increasing its human resource capacity in science and engineering to sustain its hegemonic position in promoting scientific research and fulfilling its obligations to the public (Bush, 1945; President's Scientific Research Board, 1947a). Germany was rebuilding after the destruction of the war; its education system remained under the Humboldtian model. Australia addressed the losses of the war through the Commonwealth Reconstruction Training Scheme. In the 1950s-1960s, the U.S. federal government undertook comprehensive measures by boosting educational programs to meet critical national needs in teaching technological and science literacy skills to move the American economy ahead and assure its security. The high level of anxiety that had been raised by the Cold War and the launching of Sputnik I triggered a sense of emergency in the United States. As a result, science and engineering education and technology deployment were expanded (National Academy of Sciences, 1995) and federal appropriations had already tripled by 1958 (Atkinson \& Blanpied, 2008). The needs of technically trained personnel emerged rapidly even though the immigration of scientists from Europe had already begun before World War II in supporting defense research. Australia had responded by resuming large-scale immigration.

The current rhetoric of STEM shortage in the United States is not a new phenomenon; it dates back to the 1950s. As science, technology and innovation are more integrated globally within the context of an emerging global economy, the projected demand for STEM job vacancies tends to indicate a steady growth to the end of this decade. However, these projections tend to vary in which professions are represented and period of time (Carnevale, Smith, \& Melton, 2011, Figure 1; NSF, 2014b, Figure 2). 
Associated with the lack of reliability in projecting future demands (Freeman, 2006b), this new paradigm presents a critical challenge in guiding policies and programs that surround STEM education in the United States, Australia and Germany.

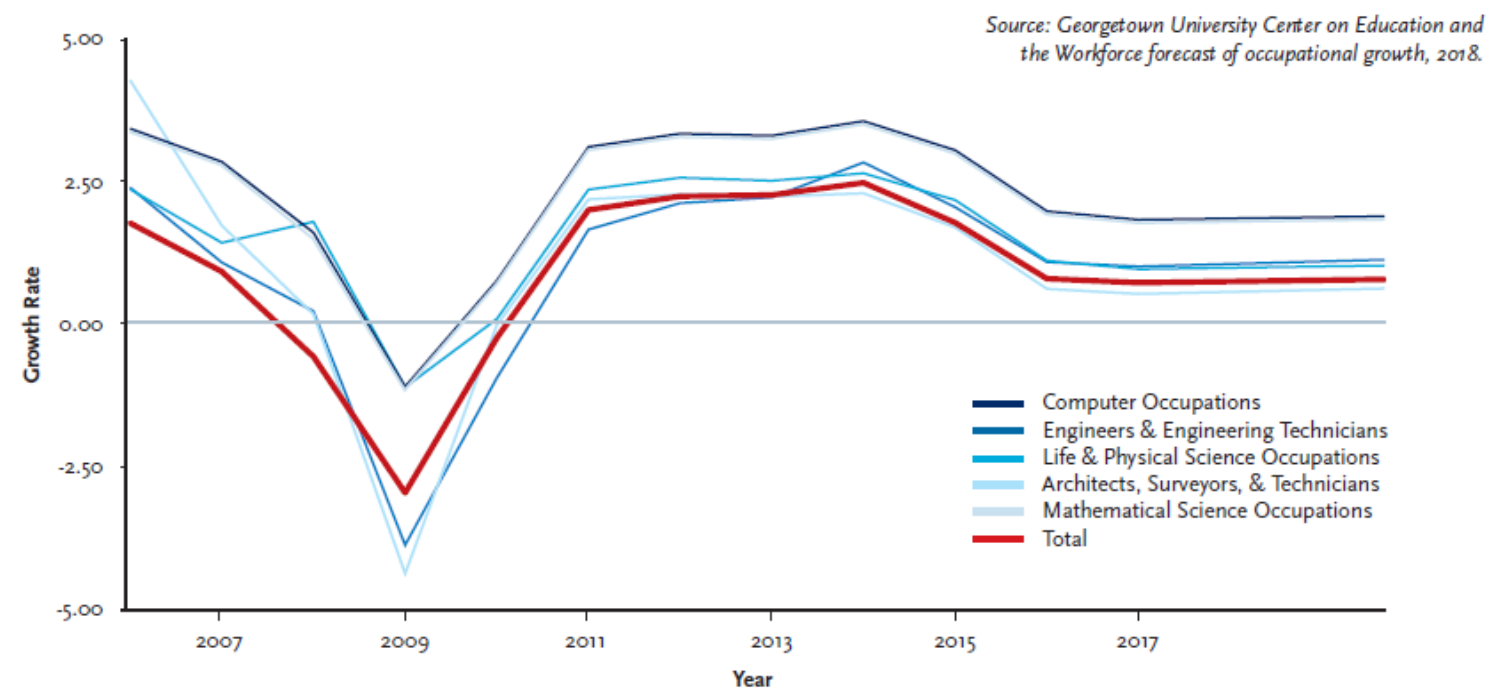

Figure 1. Employment growth dropped during the recession but will come back by 2018 . Adapted from "STEM," by A. P. Carnevale, N. Smith, and M. Melton, 2011, Georgetown University: Center on Education and the Workforce, p. 19.

Although politicians, corporate leaders and lobbyists have expressed numerous concerns about shortages in STEM fields in the United States, those issues are also raising vibrant discussions in Australia and Germany. Nevertheless, researchers in the United States maintain that no clear evidence can substantially support the claims brought forward and that more scientists and engineers graduate from U.S. universities than positions can guarantee their employment (Atwater \& Jones, 2004; Teitelbaum, 2008, 2014a, 2014b). At the same time, observations are that employers cannot fill positions with high-skilled workers to meet demand in rapidly advancing careers in STEM fields. Anft (2013) thinks that Americans are not told the truth about the real problem. In 
Germany, shortages of skilled workers in Mathematics, Information technology, Natural Science and Technology (MINT) fields are also a concern. Aside from those key STEM destinations, STEM shortages do exist in Australia as well.

\section{All Occupations $\square$ S\&E Occupations $\square$ other Selected Occupations}

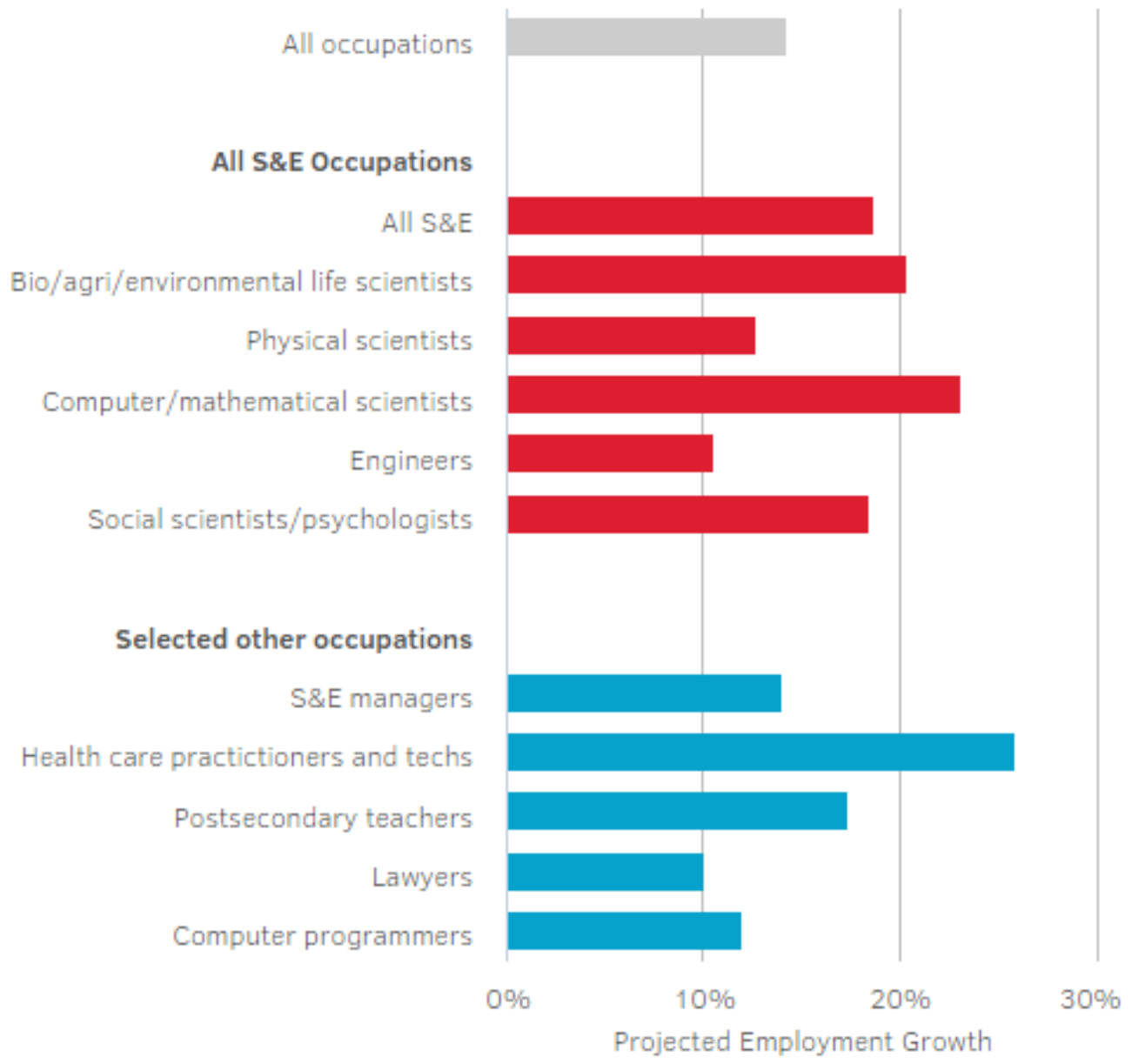

Figure 2. Bureau of Labor Statistics' projected increases in employment for S\&E and selected other occupations: 2010-2020. Adapted from "What does the S\&E job market look like for U.S. graduates?" by National Science Foundation. STEM Education Data, 2014. 
Note. $\mathrm{S} \& \mathrm{E}=$ science and engineering. Physical scientists $=$ chemists, physicists, astronomers, and earth/ocean/atmospheric scientists.

This policy study examines the current rhetoric of STEM workforce shortages in the United States, with consideration to STEM education policies and programs within the context of higher education. The analysis draws on the literature with a focus on the United States to determine what evidence, if any, suggests that there is too little STEM workforce in the United States. Through the examination of two other countries, namely Australia and Germany, which are also affected by shortages in STEM (or MINT) fields, the analysis adds substantive evidence to frame the policy discourse on STEM shortage in the United States beyond its national boundaries in that it is not an isolated phenomenon. The analysis takes into consideration how the importance of science, engineering and innovation translate within the global connection that exists among those three nations. Lastly, the analysis includes additional evidence from researchers and experts to develop ideas and recommendations for a deeper understanding of the debate on STEM workforce in the United States.

\section{Statement of the Problem}

Within the context of current political and economic forces, STEM is a commonly addressed subject worldwide. In the United States, opinions about STEM education programs in generating a capacity in human capital differ. While the rhetoric of a STEM shortage frames the need for more graduates, researchers and pundits think otherwise. The current discourse is not a new phenomenon, but its context is now embracing new global dimensions. The continuing importance placed on committing resources to STEM education at both the P12 and higher education level despite the disagreement in the 
global discourse, has created the issue of whether such delegation of finite resources is defensible.

\section{Purpose of the Study}

The purpose of the study was to examine the current rhetoric of a shortage in STEM scholars and employees in the United States with an understanding of historical developments presented as an overview; to define and place STEM education in its appropriate context; to elaborate on the current beliefs that drive STEM education policies and programs in higher education; to take into consideration international perspectives from Australia and Germany and the global connection that exists between the three countries; to draw implications about STEM education and shortages and policy recommendations that arise as the educational system of each country is only one part of the larger global market competitive landscape.

\section{Research Questions}

1. What is the history of STEM education, beginning with an examination of American science since the early 1920s and including a historical outline on the perspective of science in Australia and Germany?

2. What is meant by STEM education and does a definition of STEM exist?

a. How does its interpretation differ based on national context?

3. What are the major tenets of the rhetoric of a shortage in STEM scholars and employees in the United States?

4. How does the rhetoric of a STEM workforce shortage play out in the United States from the perspective of the U.S. economy and its dependence on STEM workers to keep its vibrancy and the bipartisan theme in public policy 
discussions?

a. How much leverage does this claim have with research suggesting there is little shortage in STEM occupations in the United States?

5. What are the main characteristics that surround the debate of the shortage of skilled workers in Australia and Germany?

6. What critical implications and recommendations can be drawn out from the current discourse on STEM shortage in the United States with consideration to Australia and Germany?

\author{
Abbreviations \\ ABS: Australian Bureau of Statistical (U.S.) \\ ACAlliance: American Competitiveness Alliance \\ ACS: American Community Survey \\ ACOLA: Australian Council of Learned Academies \\ ACWIA: American Competitiveness and Workforce Improvement Act \\ AEC: Atomic Energy Commission (U.S.) \\ AiGroup: Australian Industry Group \\ AIR: American Institutes for Research \\ $A R C$ : Australian Research Council \\ ASTA: Australian Science Teachers Association \\ AWPA: Australian Workforce and Productivity Agency \\ BA: Bundesagentur für Arbeit (German Federal Employment Agency) \\ BHEF: Business Higher Education Forum \\ $B I B B$ : Federal Institute for Vocational Education and Training (GE)
}


$B L S$ : Bureau of Labor Statistics (U.S.)

BMWi: Federal Ministry of Economics and Technology (GE)

CEDEFOP: European Center for the Development of Vocational Training

CPI: Consumer Price Index

CRTS: Commonwealth Reconstruction Training Scheme (AU)

CSIR: Commonwealth Scientific and Industrial Research (AU)

CSIRO: Commonwealth Scientific and Industrial Research Organisation (AU)

CTEC: Commonwealth Tertiary Education Commission (AU)

$D G B$ : German Trade Union Confederation

DHS: Department of Homeland Security (U.S.)

DIW: Deutsches.Institut für Wirtschaftsforschung e.V. (Institute for Economic Research)

DOD: Department of Defense (U.S.)

DOE: Department of Education (U.S.)

DOL: Department of Labor (U.S.)

FDZ: Research Data Centre (GE)

GAO: Government Accountability Office (U.S.)

GDP: Gross Domestic Product

GDR: German Democratic Republic

GI Bill: Servicemen's Readjustment Act of 1944 (U.S)

HECS: Higher Education Contribution Scheme (AU)

$I A B$ : InstitutfürArbeitsmarkt- und Berufsforschung (Institute for Employment Research)

ICE: Immigration and Customs Enforcement (U.S.)

ICT: Information and Communications Technology 
IES: Institute of Education Sciences (U.S.)

IRB: Institutional Review Board

ITAA: Information Technology Association of America

ITIF: Information Technology and Innovation Foundation (U.S.)

$I W$ : Institut der deutschen Wirtschaft Köln (Cologne Institute for Economic Research)

JEC: Joint Economic Committee (U.S.)

MINT: Mathematics, Information technology, Natural Science and Technology

NAA: National Archives of Australia

NAS: National Academy of Sciences (U.S.)

NCEE: National Council on Economic Education (U.S.)

NRC: National Research Council (U.S.)

NDEA: National Defense Education Act (U.S.)

$N S F$ : National Science Foundation (U.S.)

NSTC: National Science and Technology Council (U.S.)

OECD: Organization for Economic Co-operation and Development

OMB: Office of Management and Budget (U.S.)

PMSEIC: Prime Minister's Science, Engineering and Innovation Council (AU)

SESTAT: Scientists and Engineers Statistical Data System (U.S.)

SOC: Standard Occupational Classification (U.S.)

SOL: Skills Occupation List (AU)

STEM: Science, Technology, Engineering, and Mathematics

VDI: Verein Deutscher Ingenieure (Association of German Engineers) 


\section{Definitions of Terms}

Aggregate demand: The demand for the Gross Domestic Product (GDP) of a country (Investopedia)

Commonwealth Reconstruction Training Scheme: The CRTS was introduced in March 1944. Individuals who served in Australia's armed services during World War II could get educational and vocational training. Individuals who chose full-time training received free tuition and fees as well as living allowances. One of three categories - professional, vocational or rural training were offered (NAA, 2015).

Demand: For economists, demand refers to the amount of a good or service that people are both willing and able to buy (The Economist). Demand can also describe a consumer's desire and willingness to pay a price for a specific good or service (Investopedia)

GI Bill: Officially known as the Servicemen's Readjustment Act of 1944, the GI Bill provided vocational rehabilitation and stipends for tuition and living expenses to veterans of World War II to attend college or trade schools.

Humboldtian model: A model created by Wilhelm von Humboldt (1767-1835) in the early nineteenth century. The model was founded on two comprehensive philosophies, the commitment of universities to scholarly learning (or Wissenschaft) and the development of the individual intellectually (or Bildung).. In the United States, for example, the Humboldtian ideal shaped the research universities. MINT: Mathematics, Information Technology, Natural Science and Technology Shortage: Shortage is a broad term, which measurement is affected by several factors related to macroeconomic indicators, demographics, infrastructure, competitiveness, 
politics, institutions, innate abilities, personal characteristics (Cohen \& Zaidi, 2002).

Arrow and Capron (1959) define shortage based on the concept of a dynamic shortage in which demand for skills grows faster than supply, creating "a situation in which there are unfilled vacancies in positions where salaries are the same as those currently being paid in others of the same type and quality" ( p. 301). "In general, a shortage in an occupation is the aggregation of hard-to-fill vacancies across firms" (Shah \& Burke, 2003, p. 7). In practical terms, shortages are interpreted in terms of difficulties in filling vacancies despite all reasonable efforts, not only in terms of the number of workers, but also in terms of the quality and type of skills and attributes possessed by workers to undertake a certain job (Cappelli, 2015; Shah \& Burke, 2003).

STEM: The grouping of the four de facto core disciplines, known as Science, Engineering, Technology, and Mathematics is heterogeneous in its nature and its representation by most jurisdictions, internationally (Freeman, Marginson \& Tytler, 2015).

Supply: The amount of a good or service available at any particular price (The Economist). Supply can also be described as the total amount of a specific good or service available to consumers (Investopedia).

Science: It represents a theoretical or intellectual understanding acquired by study, which can expand to a particular area of knowledge in any branch of learning or trained skill. In essence, one can develop expertise in one or more branches in the learning of science such as natural or physical science (Oxford Dictionary)

Technology: It is the branch of knowledge dealing with the mechanical arts and applied sciences. It can also be the technological knowledge that derive from the practical side of 
scientific and technical knowledge (Oxford Dictionary)

Engineering: It is the branch of science and technology that focuses on the development and modification of processes that use specialized skills (Oxford Dictionary)

Mathematics: It is referred to the disciplines of the quadrivium originally, in a collective fashion before evolving to represent the science of space, methods and the like (Oxford Dictionary)

\section{Limitations of the Study}

This study has intended to focus primarily upon issues related to shortage in STEM scholars and employees in the United States. The document analysis focuses on major historical facts from the early 1920s. An examination of STEM education follows, beginning with the pivotal governmental reports written after World War II to the current beliefs that relate to STEM education policies and programs in higher education. Within the process of gathering documents, the researcher was confronted to make the decision in deciding which documents was the most important and relevant to best conduct the policy analysis. It has been almost impossible to list all possible materials as access to resources may be limited somehow and "because public policies and debates over them continually change, making earlier accounts less useful” (Kraft \& Furling, 2004, p. 5). Also, limitations that apply with bias and ideology are worth mentioning. Yin (1994) speaks about 'biased selectivity' in document analysis, which may translate into an incomplete selection of documents, thus in alignment with a particular agenda. Documents such as "brochures, [blogs, editorials and the like] that promote educational programs ... usually do not provide balanced information about effectiveness or credibility" (Owen, 2014, p. 11). Those types of documents may provide insufficient 
details as they are written for some purpose independent of a research agenda (Bowen, 2009). However, documents can also be written with a research agenda and must be approached for what they were intended to accomplish.

Within the framework of this policy analysis, data and statistical analyses collected attempted to provide the most recent information on political, social and economic positions that shape the current rhetoric of a STEM shortage in the United States within the context of higher education. Economic information focused on the issue of supply and demand and the relationship of those economic principles with claims brought forth by proponents of shortages. Similar to the document analysis method, the researcher was faced with the decision to identify the most important and relevant data sources for the study. Limitations in data interpreted on a broad definition of STEM and inconsistencies in dates, degree data and other pertinent information referenced in statistical survey data were taken into consideration.

Interpretive interviewing has presented limitations in that "an interview [is] a 'coelaborated' act on the part of both parties .... [that] it [may] be difficult to separate out 'external' information from what [either party has] contributed" (Miles \& Huberman, 1994, p. 8). Miles and Huberman (1994) argue that researchers have their own understanding and convictions, which cannot exclude that they are not affected by what they observe, hear or read in their field of study.

This study takes into consideration two other OECD countries, Australia and Germany, where similar limitations of fit data for analysis and documentation may occur. For Australia, access to some dated documents has been a limitation. For Germany, and because some of the publications were in German, a minimum of resources written in 
German was first assessed and translated if proved relevant to inform research after taking into consideration differences in opinions about skills shortage (Fachkräftemangel) or labor shortage (Arbeitskräftemangel). The translation of these selected texts served the purpose of having Germany as a foil in the study. One other limitation to the study was the absence of interviews to report about Germany and Australia for any additional information about how shortages in STEM (or MINT) fields are negotiated across each of the two countries' economy. Incorporating both Australia and Germany was intentional nonetheless, as both nations were used as a foil in the study. Essentially, the researcher has highlighted policies and programs that surround STEM, science and technology, education, and innovation in both countries and how these issues are handled differently from country to country.

While this topic is of high interest to policymakers, industry and university leaders, some information may have lost some degree of relevance by the time this study was completed. Nonetheless, one immediate limitation of this study has been the lack of consistent and cogent evidence, with which researchers and pundits in STEM fields are concerned.

\section{Significance of the Study}

The study is a stepping stone, adding to the knowledge base by getting closer to answering whether it is the lack of evidence that has been feeding the current belief of widespread labor market shortages in science and engineering occupations or whether the shortage is, in fact, ongoing. Through conducting interviews of researchers and experts, their opinions contributed greatly in the following ways: (1) to develop a more thorough policy analysis with regards to how U.S. research universities constitute the core of U.S. 
science and technology system; and (2) how science and engineering workforce and related labor markets represent an integral part of the education system in the United States, in supporting scientific and technological innovation in face of global competitiveness.

\section{Organization of the Dissertation}

The dissertation is organized in six chapters. In this introductory Chapter One, a brief introduction to the study was presented, including a description of the problem statement, purpose and research questions of the study. Additionally, limitations to the study were identified as well as the values that the study presents.

In Chapter Two, I describe how the public policy analysis was performed and presented as "a systematic investigation of alternative policy options and the assembly and integration of the evidence for and against each option” (Ukeles, 1977, p. 223), focusing on the interpretive synthesis of qualitative research, which in turn was based on a blended methodology, including document analysis and interviews, and policy analysis. The premise of the policy analysis was to question the current claim that there are too few STEM graduates in the United States. Interviews of experts and researchers in STEMrelated fields have helped ground the policy analysis and gain a deeper understanding of the primary causes of the public policy discourse in the United States. Additionally, I present an examination of the current situation in Australia and Germany, after first explaining why those two countries were selected, with the main purpose being to place the study within the perspective of the global setting, yet recognizing that "STEM policies must be consonant with the national and local contexts" (Marginson, Tytler, Freeman, and Roberts, 2013). 
In Chapter Three, I describe a chronological history of STEM -an overviewto progressively turn to STEM education policy as the use of the acronym STEM began in the 1990s in the United States. Despite the emphasis placed on the United States, the chapter is also including a historical perspective of STEM in Australia and Germany, serving as a frame of reference. This was necessary to set the stage for later comparisons of STEM in the global context.

In Chapter Four, I attempt to explain why STEM is critical for the United States and how the need to understand what is meant by STEM in the educational context is fundamental. The second part provides an understanding of the major tenets of the policy discourse on STEM shortage in the United States and how the current claims are framing the needs for more graduates in STEM educational programs. The third part examines how the issue of STEM education programs and policies surrounding it relates to higher education administration.

In Chapter Five, I examine the current situation in Australia and Germany in their response to the shortage of skilled workers in STEM or MINT-related fields. The understanding of those acronyms needed to be understood in their national context, but also taking into account that education for the science, technology and innovation workforce in the future must not ignore the increasing dimension of the international experience and interconnectedness of markets around the world. The examination helped frame the policy analysis more broadly, emphasizing the fact that STEM shortages in the United States are not an isolated problem.

In Chapter Six, I synthesize the best evidence on the status of the current claim that there are too few STEM graduates in the United States, taking into account the global 
connections that may exist with Australia and Germany. In this concluding Chapter Six, most interview materials gathered from researchers and experts are included in order to support the framing of the dialog surrounding STEM education as described in the methodology chapter, Chapter Two. The policy analysis continues with implications for practice and research; implications might arise through the historiography of educational programs and policies, and document analysis of the respective countries. I continue with recommendations on how further actions about STEM education in the United States could be taken at the federal and state levels within the global setting, acknowledging that this phenomenon is not isolated. Lastly, I identify areas of future research study before concluding. 


\section{CHAPTER II}

\section{METHODOLOGY}

This public policy analysis was performed based on the four elements by Crotty (1998). In applying the research approach proposed by Crotty (1998), these four elements inform each other. They are as follows:

a) What methods are used?

b) What methodology is employed?

c) What theoretical perspective supports the methodology?

d) What epistemology informs the theoretical perspective?

First, in answering what methods to use, Crotty (1998) defines those methods as "the techniques or procedures used to gather and analyze data related to some research questions or hypothesis" (p. 3). For my study, I used two primary research methods of analysis, document analysis and interviews.

Second, the methodology employed is a policy analysis, which can be described as "the strategy, plan of action, process or design" (Crotty, 1998, p. 3). "Policy analysis is an applied social science discipline which uses multiple methods of inquiry and argument to produce and transform policy-relevant information that may be used in political settings to resolve policy problems" (Dunn, 1981, p. 35). The policy analysis ${ }^{1}$ is meant to gather more information and relevant data from experts and researchers to build an understanding of the policy issue as accurate as possible in order to establish a learned

\footnotetext{
${ }^{1}$ The policy issue addressed in this study focuses on higher education, with STEM graduates with at least a bachelor's degree or higher not P12
} 
decision as indicated in the policy and draw conclusions regarding the advocacy of the policy. Kraft and Furling (2004) describe policy analysis as "an attempt to dissect problems and solutions in what is usually described as a rational manner" (p. 25). One of the primary functions of policy analysis is also "to satisfy the need for pertinent information and thoughtful, impartial assessments in the policy process" (Kraft \& Furling, 2004, p. 103).

Third, interpretivism is the theoretical perspective that has supported my study in that it helped explore "culturally derived and historically situated interpretations of the social life-world" (Crotty, 1998, p. 67). By theoretical perspective, it is meant to be the philosophical stance informing the methodology and thus providing a context for the process and grounding its logic and criteria" (Crotty, 1998, p. 3). Interpretivism is "a line of inquiry" (Miles \& Huberman, 1994, p. 8), it is “often linked to the thought of Max Weber (1864-1920), who suggests that in the human [and social] sciences we are concerned with Verstehen (understanding) .... [compared to] the explicative approach (Erklären, explaining), focused on causality, that is found in the natural sciences" (Crotty, 1998, p. 67). Along those lines, "the evidentiary material that the researcher analyzes is constructed by participants in the event or setting being studied" (Yanow, 2007, p. 409).

Fourth, the epistemology that informs the theoretical perspective is social constructivism (Crotty, 1998). The intent was "to look for the complexity of views rather than narrowing meanings into a few categories or ideas" (Creswell, 2009, p. 8). In this study, the researcher is placing the discourse surrounding STEM in the constructivist framework to perform the policy analysis.

With this in mind, the study also comprises an examination of the current 
situation in Australia and Germany for the reason that education for the science, technology and innovation workforce in the future must not ignore the increasing dimension of the international experience and interconnectedness of markets around the world. Most importantly, the credibility of the policy analyst would be affected should the analysis had looked at only one side of the issue as this issue is not known only to be true in the United States. Through use of data on the current situation of those two OECD countries, which are also facing a skilled workforce shortage in STEM (or MINT), the examination of those data has helped frame the policy analysis from a broader perspective. The examination has provided close knowledge, necessary to more effectively develop a more comprehensive mapping of the differences and similarities between the three nations to understand governmental strategies and programs in those areas of study, objectively and contextually relative to the social, cultural, economic and political landscape.

Both countries display different strengths in their approach to higher education and their economic position in the world. While Australia sees its global presence essential to the knowledge economy, its close proximity to the South Asian market offers great opportunities. Germany is a leading economy in Western Europe. As research and innovation are highly priced, the German education system has had a great impact on the American university research system as it had on the Australian system as well. Nonetheless, the shortage of STEM skilled talent in both countries is critical.

\section{Document Analysis}

The document analysis was "a systematic procedure for reviewing or evaluating documents [in] both printed and electronic [form]" (Bowen, 2009, p. 27). The document 
analysis is based on the research of primary information and collection of data, including bibliographies from readings. This method of research is used to address research questions one through five.

Question 1 sets the stage, for later comparisons of STEM in the global context, about the current beliefs of a shortage in STEM scholars and employees in perspective to historical developments since the early years of the twentieth century. Question 2 is fundamental in that it attempts to define what STEM is whether it is possible to draw reasonable boundaries in defining it in order to best set the public policy. It is followed by question 2a to understand STEM education in its appropriate context, which is important to make a global connection with Australia and Germany. Question 3 identifies what the major principles of the rhetoric of a shortage in STEM scholars and employees are. This examination of the rhetoric is essential in that it helps understand how the STEM shortage discourse is framed, prior to placing the discourse in the context of the public policy, which is addressed in question 4. Question 4 answers how the rhetoric of a STEM workforce shortage fit within the policy context by elaborating on the current beliefs that drive STEM education policies and programs and understanding how bipartisan discussions are articulated in light of a high dependency on STEM workers. With this in mind, question 4 a weighs the significance of what research findings show against the current claim and how the policy context of the current discourse stands out. Question 5 takes the global connection even further by taking into consideration how the shortage of skilled workers in Australia and Germany plays out.

The identification of relevant facts and statistical information guides a thorough examination of what the existing beliefs are and who the major players in STEM 
education policy are about the significant features of the problem presented in this study. The objective was to identify relevant historical background information since the 1920s to guide the investigation of the political, economic, social, and philosophical landscape in science and engineering, the mobilization of American science during World War II and how the relationship with the Federal government contributed to the great advances of science in post-war years. By means of the document analysis method, questions surrounding this study were answered by examining primary documents as valid and reliable sources of information. The researcher has ensured that the resource originates from authoritative and primary sources, taking into consideration the limitations that apply with bias and ideology. This study is grounded on the impartial assessment of evidence in order to perform an analytical and objective assessment of the issues.

In this study, the document analysis has drawn from a variety of resources. Initially, the examination of major events from the early 1920s to World War II sets the stage to understand how the relationship between industry and government contributed to growth of baccalaureates and professional degrees in science despite the fact that data on the production of scientists and engineers before World War II are not available (Atkinson, 1990). The historiography is not an exhaustive discussion. As World War II ended, important reports ${ }^{2}$ such as Science - the Endless Frontier by Vannevar Bush in 1945 and the Science and Public Policy by John Steelman in 1947 that connected research and development activities and the availability of trained personnel with today's rhetoric on STEM shortage was examined. The document analysis has helped generate

\footnotetext{
${ }^{2}$ These two reports are historical markers to the beginning of modern science policy
} 
the interview questions listed in the protocol submitted to the Institutional Review Board (IRB).

Before listing the type of documents that have been examined for this study, there are seminal documents, such as reports, books and articles that are worth mentioning. These works have been influential elements in this study. They have helped place the discourse on STEM shortages in the United States, including how the current narrative transpires in Australia and Germany, in the constructivist framework to perform the policy analysis. The document analysis is grounded on the following seminal resources (Appendix B):

For the United States,
a) Tapping America's Potential, July 2005
b) Rising Above the Gathering Storm, October 2005
c) Anthony Carnevale, Nicole Smith, and Michelle Melton (2011)
d) Hal Salzman
e) Michael S. Teitelbaum
f) Norman Matloff
g) Paula Stephan (2012)
h) Richard B. Freeman
i) Ron Hira
j) Yu Xie and Alexandra A. Killewald (2012)

For Australia,
a) Australia Industry Group (2012)

b) Simon Marginson

For Germany,

a) European Commission (2014). e-SKILLS in Europe

b) Karl Brenke

Aside from these seminal resources, printed or electronic resources include journal treatises; peer-reviewed articles; National Bureau of Economic Research reports; 
publications from the U.S. Congress; U.S. Government Printing Office; U.S. Senate; National Science Board open-books; National Science Foundation; National Academies Press; proceedings and reports from professional and research organizations; associations and societies; think tanks; including RAND Corporation; The Brookings Institution; Economic Policy Institute; and other related sources where reports indicate differences in opinions; public policy reports; Public Radio commentaries; new media articles to construct perspectives in opinions being shared. Statistical data were obtained or retrieved in part, from the American Community Survey - Census; National Science Board; National Science Foundation's Scientists and Engineers Statistical Data System (SESTAT); U.S. Department of Labor, Employment and training administration.

The document analysis continues with an examination of what is meant by STEM. It also includes information about two other OECD countries, Australia and Germany. The identification of major sources has helped frame the policy discourse on STEM shortage in the United States within the context of a global marketplace, setting the stage beyond its national boundaries in that it is not an isolated phenomenon. Information is primarily from authoritative and empirical sources for both countries within the constraint of their availability.

For Australia, printed or electronic resources include journal treatises; journal articles; reports from the Australian Bureau of Statistics; Australian Council of Learned Academies; Australian Academy of Science; Australian Industry Group; Australian Research Council; Australian Workforce and Productivity Agency; Department of Education and training; Office of the Chief Scientist; Tertiary education and training in Australia (2010) 
For Germany, printed or electronic resources include journal treatises; journal articles; reports from the Deutsche Bank Research; Federal Institute for Vocational Education and Training (BIBB); Federal Ministry of Economics and Technology (BMWi); Institute for Employment Research; DIW Berlin; German Institute for Economic Research, which is one of the leading economic research institutions; Institute for Employment Research (InstitutfürArbeitsmarkt- und Berufsforschung or IAB); Research Data Centre (FDZ) of the German Federal Employment Agency (Bundesagentur für Arbeit BA) at the Institute for Employment Research (IAB) is intended mainly to facilitate access to BA and IAB micro-data for non-commercial empirical research.

More broadly, other data were examined such as the main science and technology indicators of the OECD and Eurostat data (Statistical data).

\section{Interviews}

The decision to use interviews as part of a blended methodology was to help ground the document analysis and gain a deeper understanding of the primary causes of the public policy discourse, demonstrating whether there is too little STEM workforce in the United States. New data related to interviews have been included for the most part in Chapter Six as supplemental evidence to the study. Based on the principles of purposive sampling strategies (Patton, 1990), fourteen participants were purposely selected on the basis that they are experts and leading scholars in the field of study examined in this policy study. Two other experts in the field of study with an emphasis on economics accepted to participate in the interview after being introduced to me. Anthony P. Carnevale was kind to put me in contact with Nicole Smith, who kindly accepted to 
participate in my interview in place of Mr. Carnevale. Stephen Ezell introduced me to Adams Nager, who also accepted to participate jointly in the interview. Most individuals have held senior-level positions within higher education, prominent think tanks and the U.S. federal government. Although most of the individuals listed in the IRB were cited in the proposal to some degree, the decision to interview these individuals was to gain a deeper understanding of the primary causes of the public policy discourse in the United States besides conducting a systematic investigation solely from documents, which may have produced insufficient details. The researcher sought to elevate the credibility of the study by getting closer to experts' opinions on the subject, which in itself has been enriched by these individuals' insights, representing both sides of the aisle. Out of the fourteen individuals, four agreed to participate in the interview upon my request (Jonathan Rothwell, Hal Salzman, Ron Hira, Stephen Ezell) and two others participated in the interview after being placed in contact with me by colleagues within their organization (Adams Nager and Nicole Smith).

In this section, I introduce the six individuals I spoke to, as follows:

Adams Nager is an economic policy analyst at the Information Technology and Innovation Foundation (ITIF). His research focus includes, in part, the importance of STEM education and the immigration of high-skilled workers.

Hal Salzman is Professor of Planning and Public Policy at Rutgers University, Senior Faculty Fellow, John J. Heldrich Center for Workforce Development. He presented at a hearing before the United States Senate Judiciary Committee on immigration reforms on March 17, 2015 and 2016.

Jonathan Rothwell is a fellow, Metropolitan Policy Program at Brookings. His 
Brookings publications have included reports on hard-to-fill job vacancies, the value of STEM knowledge, and skill mismatch.

Nicole Smith is Research Professor and Chief Economist at the Georgetown University Center on Education and the Workforce. I had first reached out to Anthony P. Carnevale, who is the Director of the Georgetown University Center on Education and the Workforce. He asked if Nicole Smith could participate in my interview instead. As an economist, Nicole Smith provided insightful information to the study, bringing valuable perspectives on STEM shortages with a different lens.

Ron Hira is Associate Professor in Public Policy. He recently joined the Howard University Political Science Department. He presented at a hearing before the United States Senate Judiciary Committee on immigration reforms on March 17, 2015 and 2016.

Stephen Ezell is Vice President of Global Innovation Policy at the Information Technology and Innovation Foundation (ITIF). His focus is on science and technology policy, international competitiveness and manufacturing, in part.

The protocol for this study was submitted to the IRB at Illinois State University and was approved (Appendix A). Since all the interviews took place via telephone, the informed consent was acknowledged by each participant verbally. For the verbal informed consent, the researcher had obtained the permission to use a waiver of documentation of informed consent per federal guidelines 45 CFR 46.117. The informed consent included a synopsis of the research and described benefits and risks of the study (Rubin \& Rubin, 2005).

The interview protocol included thirteen questions, including subsets. It was developed based on prevalent themes in the literature to further explore the information 
discussed in the literature as supportive argument to the project outcomes. All elements of the interviews were audio-recorded. They have been transcribed and shared with each individual respectively to avoid any misinterpretation of the participant's opinion and any subjectivity on the researcher's part, and to ensure that participants are accurately quoted. Finally, transcripts have been analyzed and reported in my study accordingly.

\section{Policy Analysis}

The premise of the policy analysis was to question the current claim that there are too few STEM graduates in the United States. This methodology addressed research questions 4, 4a and 6, Question 4 and 4a were first documented from performing primary research methods of analysis, articulated within the document analysis. As a result, question 6 explore what policy recommendations can be made for the United States, taking into account the importance of national needs and wants within a global context relative to Australia and Germany.

The policy analysis is an important element in this study as it intends to analyze the current claim, specifically and STEM education programs that derive from it in generating a capacity in human capital. This policy issue is at utmost importance to education administrators in light of the large amount of funding that is directed to STEM programs. This issue draws on insights and intuitions in providing policy recommendations regarding the rhetoric of a shortage in STEM workforce in the United States with consideration to Australia and Germany, acknowledging that this phenomenon is not isolated.

The policy research process has drawn from the benefit of engaging with documents and people just as Bardach (2012) recommends. Further, the researcher has 
executed a modified plan of action based on the Eightfold Path suggested by Bardach (2012) as follows:

- Define the problem,

- Assemble the evidence,

- Construct the alternatives and synthesize data,

- Select the criteria (evaluating potential outcomes),

- Present cost - benefit scenario,

- Provide policy recommendations.

First, in defining the problem in this policy analysis, it is important to determine how STEM education in the United States warrants the attention of the public as it contributes largely for the American society to thrive in the knowledge economy and produces the assets for the industry, supporting societal needs at large (Perry, 2006). The examination of how science has evolved since the early 1920s, including the significant recognition of scientists as 'agents of change' in higher education (Guralnick, 1979) and the reports by Vannevar Bush and John Steelman, could help frame the higher education landscape in science and engineering over prominent historical events and understand public perceptions toward science.

Second, in analyzing the policy discourse of a shortage of STEM workforce, it is important to investigate how STEM is defined and if a definition of STEM exists and the type of disciplines the definition includes with consideration to selected criteria for defining STEM (or MINT) in a particular way. One could examine how the importance of defining STEM (or MINT) is critical to the public perception for data to be interpreted on an even playing field.

Third, the core of the problem pertains to the continuous rhetoric of a STEM workforce shortage presented as a bipartisan theme in public policy discussions. In the 
2013 ACOLA report for the Prime Minister's Science, Engineering and Innovation Council (PMSEIC), it was reported that Australia does not itself have a compulsory focus on disciplinary content. In asking what causes the current problem, one can examine what political, economic and social forces are at play, while science, technology and innovation have conflated into a market for techno-scientific ideas (Tyfield, 2012), transforming the idea of STEM education and its outcome in the marketplace. Also, the policy analysis would be to investigate the viewpoint of researchers and proponents of STEM shortage in light of a lack of consistent and cogent evidence. It forces us to ask whether it is a question of supply and demand and if the level of granularity in reports and statistics justifies their views? How do current beliefs frame the need to increase enrollment in higher education and what factors could be attributed to diversion? Are there significant trends that may predict that more data and analyses are needed for researchers to make their point against beliefs shared by industry leaders, lobbyists, foundations and universities? More importantly, issues of STEM skill shortages exist in Australia and Germany also. For Germany, manufacturing is a strong sector, however many of its graduates work outside the profession. In defining the problem, this policy analysis aims to frame the current issue with respect to the national context of those two countries, acknowledging that the researcher is not looking at the U.S. in isolation.

The policy analysis process continued with assembling the evidence, collecting data as facts and statistical information for further examination. Per the IRB protocol, data from interviewing the researchers and experts have supplemented the evidence gathered to be used as supportive argument to project outcomes. The next step consists of constructing alternatives and synthesizing data to assess how STEM fields are 
represented distinctively in the whole scheme of the STEM workforce. Such alternatives might be about possible policy that helps articulate supply and demand, including greater coordination of STEM workforce capacity between higher education and industry and greater control of $\mathrm{H}-1 \mathrm{~B}$ visa immigration that does undermine the livelihood of many American workers in STEM fields, by reassessing skill mismatch with demand and the type and level of STEM degrees being negotiated. In assessing potential outcomes, the analysis reflects on two evaluative criteria in light of maximizing public interest and value judgments (Bardach, 2012) such as the cost of educating graduates in STEM fields in the United States and the human capital and adequacy of skills that STEM education procures with benefits and opportunities incurred despite the competitive pressures of a global market. A cost-benefit scenario is presented with respect to political, economic and social boundaries. After thoroughly examining how pertinent the current rhetoric surrounding the STEM workforce is to the real situation, supported by metrics, recommendations are made, stating how further actions about STEM education in the United States could be taken at the federal and state levels within the global setting.

Lastly, the drawback of this policy analysis articulated around a blended methodology may be in its specificity, compared to methods used in quantitative or qualitative research in that the review of documents is not infinite, leading to new evidence and interpretations, and raising new sets of questions. Patton, Sawicki, and Clark (2016) state that, "there is no single, agreed-upon way" (p. 40) to conduct a policy analysis. The researcher has systematically reviewed supporting data to analyze the current discourse. 


\section{CHAPTER III \\ CHRONOLOGICAL HISTORY OF STEM \\ Overview}

This section presents a history of science in three countries, geographically dispersed yet connected by a vision. It documents how the United States and Australia have attained their own entities at a different time and place in history from the initial imprint of the British colonists. While a substantial number of German scientists migrated to Australia in the nineteenth century, the United States benefited from them in the twentieth century. Despite these external influences, those two settler nations built and adapted their educational system differently to meet their needs and wants as they were both benefiting from the European expansion. All three countries were affected by the Second World War and the concerns that arose in the 1950s with the shortage of scientists due to war casualties. From the more complex and diverse American higher education system and research, the more uniform Australian system burgeoned in the second half of the twentieth century, while Germany lost many scientists after World War II into the 1980s, to fundamentally invest in its university system at the turn of the twenty-first century.

\section{The United States}

Science in the early years of the twentieth century. As the balance of scientific power was shifting from Europe to the United States, so was the American science 
marked by "the advent of science-based university and the professionalization of the scientific community" (Owen, 1997, p. 832). It was not until the twentieth century that science emerged as a profession in the United States (Xie \& Killewald, 2012). The early twentieth century witnessed a rise of multidisciplinary universities and the success of scientists lay in their academic 'eclecticism' (Guralnick, 1979). By 1910, thousands of scientists were employed in higher education, now that scientific research had finally gained recognition as an academic end in a number of institutions (Guralnick, 1979). Gradually, science education grew to maturity, evolving from an avid development of science curriculum and lending itself to more opportunities for academic scientists to exercise more than their entrepreneurial roles. Already, in those early years demand from commerce, agriculture and literacy of the population was greater than the number of academic scientists qualified to work (Guralnick, 1979).

While Dewey had been defending science as a legitimate intellectual study in how it can provide the intellectual capacity for individuals, science education was becoming more important in its contribution to society helping people to understand their roles within it (DeBoer, 2000). In the early years of the twentieth century, the wealth and philanthropy from Carnegie and Rockefeller influenced science greatly and the resultant scientific advances benefited the enterprises of these wealthy industrialists. The Rockefeller Foundation, founded in 1913 had the biggest influence on science, establishing "a form of conspicuous consumption" as described by the historian Michael Dennis (Agar, 2012, p. 164). In the early 1920s, the Rockefeller Foundation was very much involved in building the research capacity of the American university. Agar (2012) recalls the time when the National Research Council was created during World War I in 
order to not have government interfere with science, reflecting Americans' suspicion of central government, portrayed by American scientist, George Ellery Hale.

American scientists as 'agents of change', 1930s. By the twentieth century, several state universities had established their credentials as leading research institutions, including the universities of California, Michigan, Wisconsin, Minnesota, and Illinois. After universities had joined federal government laboratories by World War I and scientific research took a 'professionalized' [emphasis added] stance, research laboratories expanded. Research laboratories owned by U.S. companies accounted for 1,600 in 1931 (National Academy of Sciences, 2010). Although, the industrial sector was becoming more prominent and dominating research, these laboratories would decline during the rest of the 1930s, to rebound financially by 1940 .

In the United States, higher education often was a site to support differences expressed with the creation of enclaves for basic research, which were preferred by many because they were not so easily subjected to unexpected economic variations, institutional affairs and the like (Reingold, 1979). Ideologically speaking, colleges and universities were more prepared than government entities or industries to offer American scientists professional opportunities. Despite efforts put forward by the American College in its support of American science, its role was underestimated in giving significant recognition to scientists as 'agents of change' in higher education (Guralnick, 1979).

While the creation of federal agencies led to a shift from little to big science in the 1930s (Xie \& Killewald, 2012), the type of research was also divided with basic research under private institutions like the Carnegie institution or the Battelle Foundation and applied research at universities and in the industrial-government sector. However, the 
division in the type of research did not happen without any political disagreement, particularly about the social sciences and how they fit in the political landscape of the 1930s (Atkinson \& Blanpied, 2008). Although listed as other sciences, social sciences would be made eligible for research support by the amended National Science Foundation Act of 1950 (Public Law 81-507).

A transitional period for American science, late 1930s-1945. Prior to the Second World War, the United States industry had relied mostly on basic research conducted in Europe. Because of the war devastation in Europe, the United States needed to rely on its resources to conduct basic research to restore the talent pool (Atkinson \& Blanpied, 2008) to be shared by the public and meet industry demands. With this mind, opinions already differed as the industrial sector was looking at basic research from an investment perspective while the federal government incentivized it as a public good. In Holton (2010), it reads:

World events of the 1930s and 1940s brought new imperatives for science education curriculum. Efforts to improve science curriculum were largely local before World War II. By the end of the conflict, U.S. citizens have become acutely aware of the part of mathematics, science, engineering, and technology and how important these disciplines were to the successful outcome of the war to the nation. (p. 768)

The 1930s were critical years, in that the influx of German immigrants led to the largest growing number of foreign-born scientists in United States history (Reingold, 1979). Under Section (4)d of the Immigration Act of 1924, university teachers were exempt from immigration quotas.

In 1940, the total expenditures for research and development in the United States was estimated to be approximately $\$ 345$ million, with the private industry accounting for the most of all three sectors with $\$ 234$ million, followed by the federal government ( $\$ 67$ 
million) and universities and colleges (\$31 million) (Atkinson \& Blanpied, 2008).

Science and engineering indicators published by the National Science Foundation (2000)

showed that in the years prior to World War II, the source of research funding for private universities came primarily from endowments and non-profit foundations; state universities were funded by state funds as the United States government provided virtually no support for research at the exception of federal contracts. Also, the industry received little government research and development money; it looked for technically trained personnel and faculty consultants at universities (National Academy of Sciences, 1995). Because of greater federal expenditures for research and development during the World War II, many academic researchers were mobilized to work on wartime research and development projects at their institutions and remunerated for their service. In contrast, scientists working on military projects during World War I had been military personnel.

American science: The human resource capacity, post WWII years. While the prospects of American science and engineering would be important for the future of the United States and its welfare in the years following World War II, other nations, including Australia had established by 1946 that it also needed to position itself in the world of research and science. In the United States, Vannevar Bush and John Steelman cogently argued in their report of 1945 and 1947 respectively that an increased support in both financial and human resources were necessary to expand American science. In his report Science - the Endless Frontier, Bush (1945) argued for the legitimacy of federal support for basic research and science education to step away from the fact that research universities had been on the periphery of the United States scientific enterprise prior to 
the World War II. Although Bush (1945) expressed the obligation for the Federal Government to fulfill its obligations to the public, he stated:

We therefore urge that the Federal Government take a more active interest in promoting scientific research, and in assuring that the Nation gain therefrom the benefits of increased security and increased welfare. We are convinced that the most effective way for the Federal Government to serve these purposes is to provide to our educational institutions and research institutes support for basic research and training for research. By so doing, the Government will increase the flow of new knowledge and the supply of young scientists trained in research. It is on this new knowledge that applied science must build, and it is from the ranks of those trained in research that the leaders in applied science must come. (p. 74)

At the same time, Bush (1945) recommended the creation of a new agency, the National Research Foundation, known today as the National Science Foundation (NSF), which would play an important role in basic research in universities. The National Science Foundation Act of 1950 (P.L. 81-507) aimed "to promote the progress of science; to advance the national health, prosperity, and welfare; to secure the national defense; and for other purposes" (p. 1). This post war science-government contract incentivized the continued efforts toward a national policy to promote basic research in universities and education in the sciences, including scholarships, graduate fellowships and independent research. The act would be amended ten years later (P.L. 86-550) with Congress authorizing the foundation " "... to initiate and support ... science education programs at all levels" (Atkinson \& Blanpied, 2008, p. 36). Enacted in 1960, the Pub. L. 86-550 authorized the selection of nationals for scholarships and fellowships (1959).

Although John Steelman had recommended augmenting national research and development and basic research expenditures within ten years, the availability of trained personnel was clearly the main limiting factor to developing research and development activities (President's Scientific Research Board, 1947a). In sum, both the Bush and 
Steelman reports confirmed that the human resource capacity for science and engineering needed to increase, particularly due to losses during World War II. Atkinson (1990) notes that despite the fact that data on the production of scientists and engineers before World War II are not available, the number of U.S. baccalaureates and first professional degrees from 1900 to 1988 rose at a 4.8 percent annual growth (Figure 3). While each war period indicates a rate lower that the annual growth after 1978, the number of degrees granted was above the annual growth rate on three separate occasions, a few years before the Great Depression, before the Korean War and approximately between 1972 and 1978 (Atkinson, 1990).

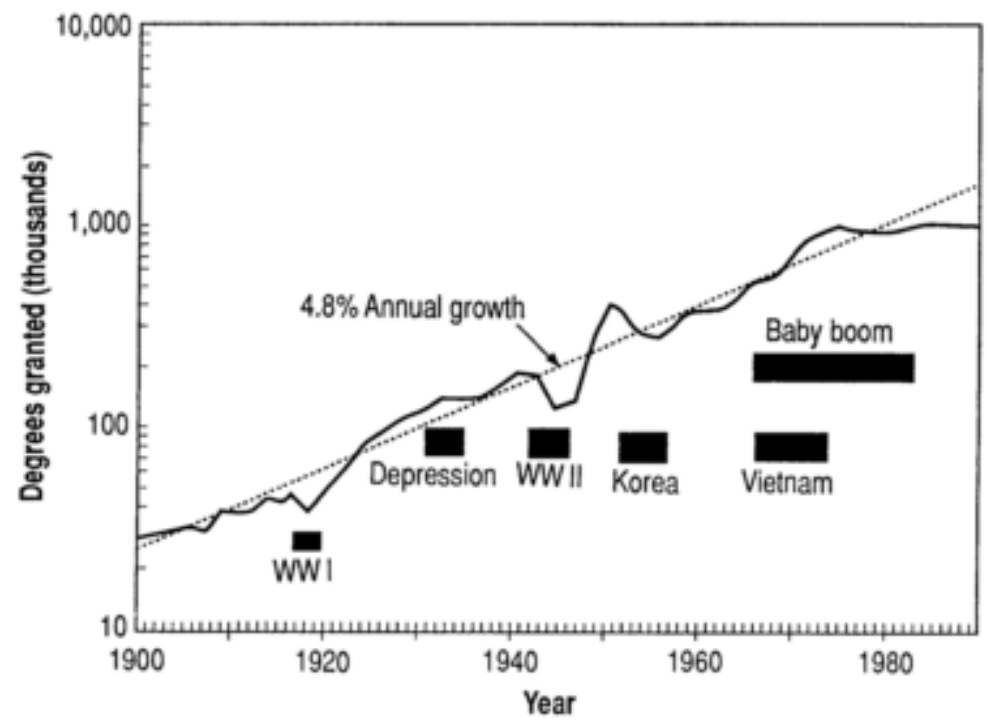

Figure 3. Growth of U.S. baccalaureate and first professional degrees from 1900 to 1988. The dotted line shows a $4.8 \%$ annual growth rate. The baby boom identifies the group at 22 years of age. Adapted from "Supply and demand for scientists and engineers: A national crisis in the making," by R. C. Atkinson, 1990, Science, 248, p. 426. Source. National Science Foundation. 
Not only had the war triggered a change in the relationship between science and society, in that scientific and technological developments were seen as essential to assuring national security, public perceptions toward science and its role was also critical to sustain the hegemonic position of the United States in the world. Although John R. Steelman emphasized in his report that "the security and prosperity of the United States depend[ed] ..., upon the rapid extension of scientific knowledge (President's Scientific Research Board, 1947a, p. 3), Steelman nonetheless insisted in the President's Scientific Research Board (1947b) that:

The production of professional scientists, [must take into consideration] the degree of comprehension of science by the general population. For in a democracy it is upon the popular attitude toward science that the attractiveness of the profession, the resulting selectivity ..., and the degree of support obtainable for their work will depend. (p. 113)

In Vannevar Bush's opinion, scientists needed to have an independent voice in future national defense projects, however they remained suspicious of government support for science, questioning whether it could affect the direction and purpose of their work (Sapolsky, 1979). The perception of scientists supporting public investments in academic science began to be more visible after 1960 when military sponsorship for academic science was fading in favor to the National Institutes of Health and the National Science Foundation, to ultimately lead to a more insatiable quest for resource funding from the perspective of scientists and universities (Sapolsky, 1979).

Emerging needs of technically trained personnel, late 1950s-1960s. The Morrill Act of 1862 (12 Stat. 503) contributed largely in transforming higher education and articulating the creation of the American research university system. The influential Humboldtian education ideal led to the development of the idea of advanced studies and 
the creation of doctoral programs with research laboratories (Atkinson \& Blanpied, 2008). At the same time, science and engineering programs burgeoned in many states. The act helped stimulate public support for higher education. The elective curriculum by President Charles W. Eliot led universities to enter the world of active business, increasing their contribution from knowledge economy in sciences and other disciplines to help the industry. Now, with the research university system in place, federal funding has greatly contributed to make STEM education more robust and at the same time boost research and development services on a large scale (Butz et al., 2004).

The National Science Foundation had an important role in basic research in universities, and its role would be suddenly intensified by an approximate $250 \%$ research budget increase as the Soviet Union launched the first satellite, Sputnik I into orbit on October 1957 (Atkinson \& Blanpied, 2008). Not only had the United States entered a technological race a few years earlier with the Cold War, the Sputnik I launch caused a high level of anxiety, making the United States question its technical superiority engendering the fear that the nation was not addressing the education of its future scientists and engineers. Shortly after the event, the United States research and development, science and engineering education and technology deployment were expanded (National Academy of Sciences, 1995). At the same time, federal appropriations for the National Science Foundation research and development, mathematics and science education, not excluding other governmental agencies would rise rapidly over the 1960 s. They had already more than tripled to $\$ 137.3$ million one year after Sputnik I (Atkinson \& Blanpied, 2008).

Soon after the Sputnik I launch, the National Defense Education Act (NDEA) 
was created by Congress in 1958 to give the National Science Foundation more capacity to fund science education and related educational research. The NDEA Act expanded the role of the federal government in curriculum development and provided loans and fellowships for science, math and the like at the undergraduate and graduate level. Federal engagement in U.S. education has been continuing to these days, including measures in the 1960s with the Elementary and Secondary Education Act (ESEA) and the Higher Education Act of 1965. Similarly, agencies like the National Science Foundation, National Aeronautics and Space Administration and National Institutes of Health have contributed substantially in funding pre-college programs, undergraduate, graduate, and postdoctoral studies in STEM fields (National Academy of Sciences, 1995). For example, the National Institutes of Health established its roles and control in supporting academic research over most health-related research, including biomedical research, which has been given greater attention and funding by the federal government (National Academy of Sciences, 1995) in the late 1950s in light of new scientific understanding of disease in the anticipation of medical breakthroughs.

From the perspective of Butz et al. (2004), the NDEA was the most comprehensive approach to meeting STEM education issue, which would set a precedent for federal involvement in American education and institute a STEM education policy to counteract the fact that the Soviet Union's educational system was becoming more competitive in mathematics and science. The American people had expectations about education to teach technological and literacy skills to move the American economy ahead and assure its security. The NDEA would help "to strengthen the national defense and to encourage and assist in the expansion and improvement of educational programs to meet 
critical national needs," (Public Law 85-864, p. 1581). However, realizing that federal funding of basic research represented 10 per cent of the total federal government appropriations in 1964 compared to military and space program development and technology (Killian, 1964), "the large increase of military ${ }^{3}$ and space research...may have created an imbalance in the allocation of [the United States] research talent leading to a shortchanging of research in many parts of the private sector" (U.S. Congress. JEC, 1964). At the same time, the increased pressure placed on federal budget with science compromised the growth of the pool of future scientists and engineers to be recruited (Atkinson, 1990). Just as Bush (1945) had estimated the deficit of science and technology students to 150,000 baccalaureates, fewer PhDs in science were also accounted for, supported by a cumulative shortfall estimated at 16,000 between 1941 and 1955

(Atkinson, 1990). Reingold (1979) asserts that at the exception of those 15 years after the World War II, the number in PhD's was low a few years before the Great Depression as well. The immigration of scientists from Europe that had begun before the war continued into the Cold War era, addressing the increased demand of scientists for defense research. In the 1960s, baby-boomers spurred college enrollments even though fewer than 5,000 Ph.D.'s were graduating each year (Atkinson, 1990). These relatively low numbers would be compensated for at some point in time, like in 1973, when about 6,000 scientists and engineers immigrated to the United States (Reingold, 1979). Atkinson (1990) sees that the shortage of the supply of scientists and engineers could also have been affected by an uncompensated decline due to fewer college graduates being ready to meet demand on

\footnotetext{
${ }^{3}$ Teitelbaum (2014a) explains that science and technology became increasingly important for national security - military superiority depended on technological advancement.
} 
time despite the peak that occurred in 1981 with 4.3 million college students of the 22year-old cohort as identified in Figure 4.

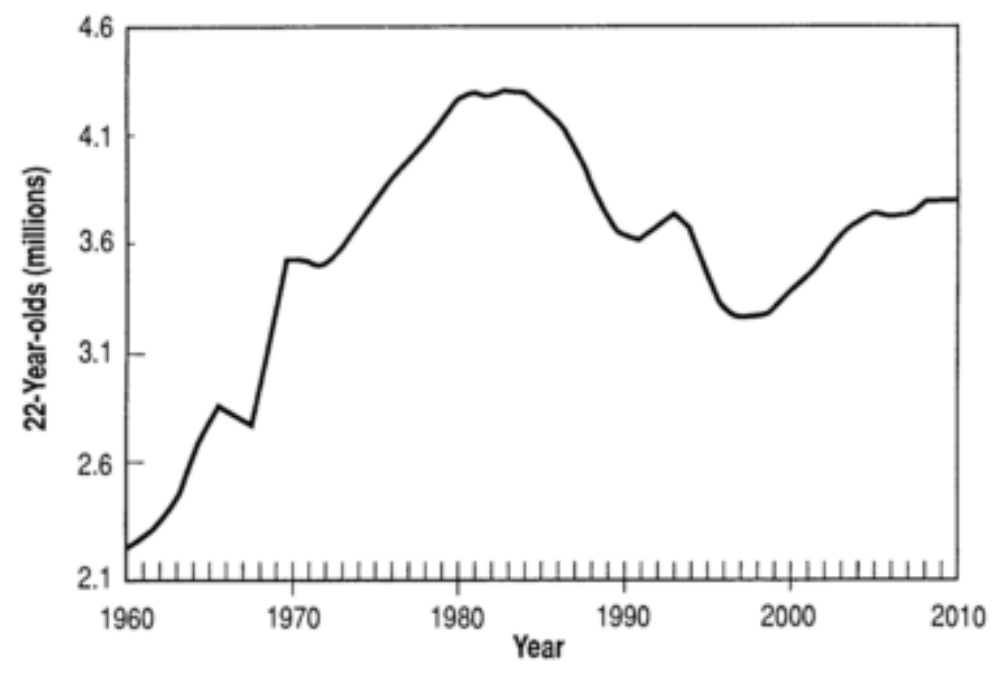

Figure 4. Millions of 22-year-olds in the U.S. population. Adapted from "Supply and demand for scientists and engineers: A national crisis in the making," by R. C. Atkinson, 1990, Science, 248, p. 427.

Source. Bureau of Census, 1980 census

Nonetheless, it still does not exclude the fact that in the early 1960s "the science education community [had become] more and more interested in the strategic role of scientific knowledge in society" (DeBoer, 2000, p. 585). Concerns were raised about the effectiveness of the educational system and how to address it in face of rapid scientific and technological changes in order to prevent the shortage of technically trained personnel. While Apollo 11 in 1969 marked a huge leap in the history of science and discovery in America, it also inspired many people to pursue careers in science (Hechinger Report, 2011). It makes one ponder if that new mode of thinking positioned science as a 'bargaining chip' for nations to sustain their production of human capital 
across the competitive landscape that operates on different principles. The consumption of rapidly 'transformative currencies' such as technology, for example, is a major principle that many societies in the world population have become dependent on for personal and business use, daily.

Anti-science idiosyncrasies of two presidencies. In light of the role of the military that affected academic science and university researchers, who worked under military-sponsored projects during World War II (Sapolsky, 1979; Xie and Killewald, 2012), the optimism associated with science and technology in early twentieth century was damaged after realization of the destructive potential scientific development had had on society on the onset of World War II (DeBoer, 2000). In the late 1960s, the Vietnam War created anti-war movements in the United States, holding science and engineering or scientists rather responsible for war casualties, but also draining the American economy. Both Presidents Lyndon Johnson and Richard Nixon cut university research budgets because of their dislikes of university faculty, who opposed the war (Shapley, 1973). Reingold (1979) refers to the anti-science idiosyncrasies of Lyndon Johnson and Richard Nixon at the time, when science was not represented as a symbol of the nation "despite $\$ 32$ billion for research and development in 1974, [with] more than a half million persons [involved in the process and] despite $\$ 4$ billion for basic research" (p. 19).

Nonetheless, science served both purposes; the cultural uplift and a service role of American universities. The University of Illinois as a land-grant school for agriculture and mechanical arts and University of Chicago are two examples of this ideal with "theory and practice, culture and service, the elite and the masses" (Reingold, 1979, p. 17). Despite these efforts in promoting an environment to distinguish basic research from 
the national tendency to blend theory and practice, U.S. scientists were still not at ease in society. By 1960, McGrath (2002) alludes to how American scientists were largely invisible to the public, perhaps due to 1) the apolitical attitude of the science advisory committees observed by President Eisenhower (Killian, 1964) and 2) the peculiarities of Johnson and Nixon toward science.

The changing landscape of science (and the world). Looking at the United States from the perspective of a "research-reliant society" and in the domain of 'innovation industry', Killian (1964) argued that science in the United States was "full of growing" (p. 12) and pure science was still lacking while science and engineering held in U.S. universities were unmatched globally. Between 1950 and 1970, the American economy saw an unprecedented rate of growth with a flourishing research university system, linking education with research in graduate schools. The American university was able to distinguish itself with a large number of Nobel Prizes awarded to Americans. All things considered, the federal government played an important role, with support accounting for 54.6 percent of research performed in U.S. colleges and universities as opposed to the industry support accounting for 7.7 percent in 1953 (Atkinson \& Blanpied, 2008). However, since the World War II, financial expenditures for research of modern science have increased so much that universities have been faced with a dilemma for not being able to afford such expenses. As a result, support from private foundations or federal agencies such as the National Science Foundation and the Atomic Energy Commission, for example, have become increasingly sought after. Although "the federal government had an incentive to support basic research as a public good" in the 1940s (Atkinson, 2008, p. 35), these large sums of money may have attracted more attention 
from the general public in recent years, particularly with the false perception the public may have about higher education (Griswold, 2006). Along with the increased number of scientists in many areas and competitive pressures in academic life per se, scientists have become more dependent on reputation as they try to build a prestige to assure further assistance for their research, financially and from assistance of postdoctoral fellows. The nature of scientific work has changed and universities are more engaged in active research of high-quality compared to industry and government laboratories (Reif, 1965). At the same time, advances in basic research have increasingly been leading to rapid technological developments coupled with patenting and publication of results within a narrow timeframe. These practices have weighed even more in highly developed disciplines, for example, in physics, reflecting the expansion of science through rapidly changing 'fashionable areas' of scientific activities (Reif, 1965). Between 1940 and 1960, the annual research and development growth rate of nearly 20 per cent indicated in Machlup (1962) continued despite limited funding and personnel. While the U.S. industry had hardly any competitors until the mid-1960s, this prominent position would soon be faced with an increased competition from Europe and Japan (Atkinson \& Blanpied, 2008). Associated with the relatively low federal government support allotted to higher education, the percentage of students comparison and distribution in science and technology versus humanities, arts and law in the United States was substantially below the mean of sixteen advanced countries, including West Germany and Australia, for example, with more students studying science or engineering (Harbinson \& Myers, 1964). Despite national needs, Killian (1964) concluded that too few students were electing science and technology. 
Is American science and technology in decline? In the late 1950s, questions about the goals that science education should play and the effectiveness of the educational system in the United States were raised. From the five reports the Rockefeller Brothers Fund issued in June 1958, one focused on the state of American education. The report on education raised the question about effectiveness of the educational system in light of rapid scientific and technological changes people were facing and social concerns scientific literacy continued to raise (DeBoer, 2000). Scientific literacy had already gained more momentum in the 1970s and early 1980s relative to the increasing societal benefits it was offering (DeBoer, 2000). Adams (2010) notes that the expansion of U.S. universities after World War II tapered off after 1980, when science and engineering seemed to have converged. It was in the 1980s that Reagan, Thatcher, and Kohl believed that free-market and private enterprise could engender greater economic and social prosperity (Makwana, 2006). As the Reagan administration had instituted the transfer of federal student aid programs to the states, William Bennett drew attention away from student aid to focus on academic standards, making the statement that higher education needed reform more than new money. The NCEE (1983) report, A Nation at Risk was published soon after.

Policies that surround STEM education are more prominently discussed at the federal level and can be traced back to 1957 with the Sputnik I launch that became a focal point for criticism of American education, pitched as a crisis in education, particularly about math and science education. Nonetheless, failures in the American school system were spotlighted by A Nation at Risk. The school system was blamed for inadequate training of teachers in mathematics and science and poor academic performance of 
students, high school standardized average scores were lower than when Sputnik I was launched, for example. All these reasons led to the weakening of educational foundations in the United States in face of global competitiveness for a nation's “once unchallenged preeminence in commerce, industry, science, and technological innovation ... [ that had been] overtaken by competitors throughout the world" (NCEE, 1983, para 1). Despite this political maneuvering, concerns shifted to the nation's competitiveness and quality of workforce, but also limited the feasibility of student aid (Stampen and Layzell, 1997). However, while the educational researcher Paul Hurd echoes what the NCEE (1983) report placed on deficiencies of the school system in "raising a new generation of Americans that is scientifically and technologically illiterate" (p. 4), John Slaughter, a former Director of the National Science Foundation, warns that there is "a growing chasm between a small scientific and technological elite and a citizenry ill-informed, ..., on issues with a science component" (p. 4) that are fundamentally critical and must be addressed.

In 1985, the American Association for the Advancement of Science created Project 2061 - a long-term research and initiative for all Americans to become literate in science, mathematics, and technology. Although these efforts led to reform initiative with "national standards and inquiry-based approach instruction", Anthony P. Carnevale notes that results were not conclusive (Sarachan, 2013, para 21) even though the need for more inquiry learning in undergraduate STEM education, for example, had already been investigated by some universities in the late 1970s. Breiner, Johnson, Harkness, and Koehler (2012) note that even though changes could have happened in the educational system, they often failed to concretize. 
From the mid-1990s to the early 2000s, significant changes in science and engineering have occurred, with the rapid transformation of the high-tech industry, including the dot-com and telecom booms (Teitelbaum, 2003; Teitelbaum, 2014a). During that time, universities were faced with considering alternative sources of funding to remain competitive with private universities, including tuition plans (Adams, 2010). Nonetheless, corporations and lobbyists argued on a supply-demand political agenda despite the fact that shortages had at least existed since the 1990s, if not since the 1950s at different rates in different STEM-related fields of study. How could these issues be acknowledged just as Vannevar Bush viewed the program for science in 1945 in that these issues warrant immediate attention and leadership despite the lack of consensus that may exist across the educational model?

\section{Australia}

The history of science in Australia has been greatly influenced by the presence of German scientists in Australia and the foundational expertise and scientific leadership they brought with them in the mid-nineteenth century. Home (1995) attributes the flow of German scientists to have been "in response to a vision of science inspired by the writings of Alexander von Humboldt" (p. 19), that goes beyond the economic value scientists bring to another culture. Despite these influences, the idea of the university in Australia was still in need to be defined. Just as the Rockefeller Foundation had been involved in science and research in the United States, it extended its activities and support to Australia in fieldwork discoveries. In 1930, the Australian Council for Educational Research was established, funded by the Carnegie Corporation. The source of those provisions from American private foundations were crucial, particularly when 
"there was no external support for research in the Australian University - until 1936 when the Commonwealth provided pitiful annual sum of $£ 30,000$ for scientists" (Mcintyre, 2009, p. 361).

The call for more trained personnel. World War II had a profound effect on Australian higher education. The Commonwealth had become concerned of an immediate shortage of trained personnel as too few doctors, dentists, engineers and other specialists were trained by universities (Australian War Memorial, 1977a). It did not take long, that "on 29th October 1942, [provisions] for financial aid to all students admitted to the quotas in the Faculties of Medicine, Dentistry, Engineering, Science, Veterinary Science and Agriculture, [were adopted] (Australian War Memorial, 1977a, p. 38). Shortly before the end of the war, labor shortages of skilled technicians, for example, in the rubber industry, timber-cutting or manufacturing of agricultural machinery still remained a concern. In a sense, the need for a skilled workforce transpired through the Commonwealth Reconstruction Training Scheme (CRTS) just as it did in the United States with the GI Bill. Introduced in March 1944, the CRTS offered individuals, who had served in Australia's armed services during World War II educational and vocational training (NAA, 2015). Under the CRTS, "25,000 ex-servicemen and women [were able] to undertake university studies" (Mcintyre, 2009, p. 361). In light of labor shortages, the federal government's response lent itself to the creation of the Australian National University as a research institute in 1946. Nonetheless, the Australian university remained dependent on government support, including the Commonwealth in the funding of highly localized programs and fields of study. The Australian university lacked autonomy and the programs of study it offered were not sufficiently diverse as they were 
in the United States. Despite these constraints, under the legislation the Commonwealth Scientific and Industrial Research (CSIR) was established in 1926 to recognize scientific discoveries in Australia. The CSIR was renamed CSIRO in 1949. The latter is an active government agency organizer in national education STEM programs, orchestrated by the Office of the Chief Scientist and the Australian Science Teachers Association (ASTA). The CSIRO is one of other government agencies besides universities and some colleges of advanced education among which applied research initiatives are distributed. It is important to remember that in 1970, the Australian Research Council had funded only A $\$ 4$ million towards the Australian's system of research (Mcintyre, 2009). With this in mind, Dawkins had the intention to maintain the reputation of Australia in being a nation that conducts high-quality basic research. In post-World War II years, reforms and expansion were going to be the hallmarks of the Australian higher education. Post-war economic prospects in Australia called for the resumption of a large-scale immigration (Australian War Memorial, 1977b; Mcintyre, 2009), which have rendered Australia as a more culturally diverse nation since then.

The 1960s to the mid-1980s. Within a few years, and as a result of the Committee on the Future of Tertiary Education appointed in 1961, the Australian higher education system of universities and degree-granting colleges of advanced education (CAE) would be differentiated by the function of colleges and universities, hence be transformed as the binary system, which lasted until 1988. While colleges would include vocational and teaching-oriented functions; universities would include academic and research-oriented functions. Comparatively to the United States and the Federal Republic of Germany, the proportion of Australian labor force holding at least a first degree in 
1981 was similar to the Federal Republic of Germany in 1980 at 8 percent. In the United States, that proportion of labor force was 19 per cent in 1981 (Dawkins, 1987).

The Australian higher education kept expanding; nine other universities would be created by the mid-1970s, in addition to the ten in the early 1960s. However, the Commonwealth Tertiary Education Commission (CTEC) (1986 as cited in Mcintyre, 2009) observes that funding for universities provided by the Commonwealth government between 1975 and 1985 was stagnant even though the number of students increased by 15.5 percent (or 175,000 ) in 1985. Australia's participation rates for young students in all forms of education and training had been historically among the lowest of OECD countries until the early 1980s (Dawkins, 1987). The CTEC reported that an estimated 11.0 percent of 18-24 year olds were enrolled in higher education in 1986. Looking back at 1942 when shortages of specialists were critical, shortages were attributed mainly to the cost of a university education for able students. Thirty years later, in 1974, the Witham Labor government would establish new policies, in part by abolishing student fees and making the Commonwealth government responsible for nearly all funding of higher education.

The late 1980s. Despite these changes, universities were not prepared to face new demand and by 1988, John Dawkins as the Minister for Employment, Education and Training reformed higher education and streamlined its operations. King and James (2013) see that the current character of Australian higher education reflects very much the reforms that took place under Dawkins. In 1985, expenditures on higher education research and development accounted for more than $\$ 731$ million (Dawkins, 1987). More research and development and innovation-related policies and strategies have occurred 
since and reports like Transforming Australia's Higher Education System have had direct implications on STEM discipline education.

The Dawkins Revolution was not well received from academia. From the political actions led by Dawkins, student fees were restored in 1989 and just as enrollments increased, government funding did not. As a result, students were left with deferred, income-contingent loans (Mcintyre, 2009). Under legislation, the Higher Education Funding Act had been passed in 1988, enabling grants of financial assistance to higher education institutions. Nonetheless, the act served as the statutory basis for the Higher Education Contribution Scheme (HECS) that the Hawke labor government introduced in 1989 to have students responsible for part of their university education through the taxation system. As Dawkins had announced that increasing student enrollments was essential to increase Australia's competitiveness internationally, private financing would reduce the cost to government of financing higher education. Lastly, Dawkins had also wanted to increase university-industry partnerships to become more prominent in a national innovation policy.

The turn of the twenty-first century. After the more systemic restructuring of Australian higher education and new forms of financing students in their university education, "the Bradley Review proposed an architecture for growth in undergraduate education as a major step towards creating a more responsive tertiary sector" (King and James, 2013, p. 13). In essence, the intention of the 2008 Review of Australian Higher Education, also known as the Bradley Review had been to incentivize universities for increasing enrollments under the premise of uncapped university places in light of little interest shown in moving across Australia for higher education (King \& James, 2013). 
The report has been reviewed by different authors, including the University of Melbourne in July 2008 and Bradley, Noonan, Nugent, and Scales (2008), who wrote the final report. Mcintyre (2009) observes that the Australian university did not have strong links with the industry. Dawkins had planned to solidify those relationships, by building stronger ties with businesses just as Australia sought to imitate the success of the American University (Mcintyre, 2009).

Stability in the 'rules of the game'. The call for stability is announced in the 2008 Review of Australian Higher Education. The wording espouses how the adaptability of American high education has enabled stable approaches to economic and political change over time. In the review by the University of Melbourne in July 2008, the "American higher education [is described as to have] adapted more quickly and easily to changing demographic, economic and political change" (p. 26). Australia has followed the United States with avid attention (Mcintyre, 2009), in that it sees in part, how the United States has an advantage with data collection and analysis to benefit students, the education sector and government (University of Melbourne, 2008). Although Australia has done extremely well with its international education marketization, that market has nonetheless being sluggish since 2009 . Australia has been faced with a rapidly growing number of universities and research science enterprise in East Asia. Marginson (2013) sees "the Australian government seems unable to generate the kind of extended vision" to support these new developments (p. 7). Since the 1980s, the Australian higher education system has gone through major reforms, which may have prevented adaptability to changing circumstances. There is hope nonetheless for Australia to set long-term plans, in that "the Chief Scientist, Professor Ian Chubb is working hard to put science and 
technology policy on the political agenda" (Marginson, 2013, p. 8).

\section{Germany}

Higher education in Germany has a long and foundational history, in that it distinguishes itself with the Humboldtisches Bildungsideal (or Humboldtian educational ideal) created by Wilhelm von Humboldt (1767-1835) in the early nineteenth century. Humboldt founded the University of Berlin in 1810. In the United States, the Humboldtian ideal shaped the research universities. In the late nineteenth century, Hinsdale (1898) had noted that Germany had "exerted upon [America] the most protracted, the deepest, and the most salutary educational influence” (p. 61).

Under the Nazi regime between 1933 and 1945, the Reich’s Ministry of Science, Education, and Popular Education exercised strict control over German universities (Lingens, 1998). During those times, between 120 and 150 world-class German scientists migrated to the United States (Reingold, 1981), inevitably leading German science to a dramatic decline. In the first five years, between 1933 and 1938 the number of students had dropped by almost 54 percent, from 121, 000 to 56,000 students (Lingens, 1998). Those migrations led to strengthening American science in supplying scientific talent and expertise.

The years following World War II. After World War II ended, the idea to 'democratize' universities in Germany was a high priority. At the same time, attitudes towards the noble humanistic educational ideal of the Humboldtian model were soon going to change as the need to align curricula to the acquisition of professional skills was increasing. As the shortage of engineers had raised vivid discussions in the early 1950s, the Cold War would bring those big ideas for reform the German university to a halt. In 
whole, the rebuilding years of the 1950s happened under the reminiscence of proud traditional times for the German university. As the German education system moved from elite to mass education in the early 1960s, a new type of universities of applied science (Fachhochschulen) permitted to attain an engineering education more quickly. Also, more students were graduating in engineering as the duration of engineering studies had been shortened to four years. In sum, Fachhochschulen provided a more attractive curriculum, more strongly oriented to meeting requirements and needs of professional occupations to industry demand. Schramm and Fraunholz (2012) state that participation in the field of engineering increased by only 55 percent between 1960 and 1971 as opposed to 217 percent for humanities and social sciences (Figure 5).
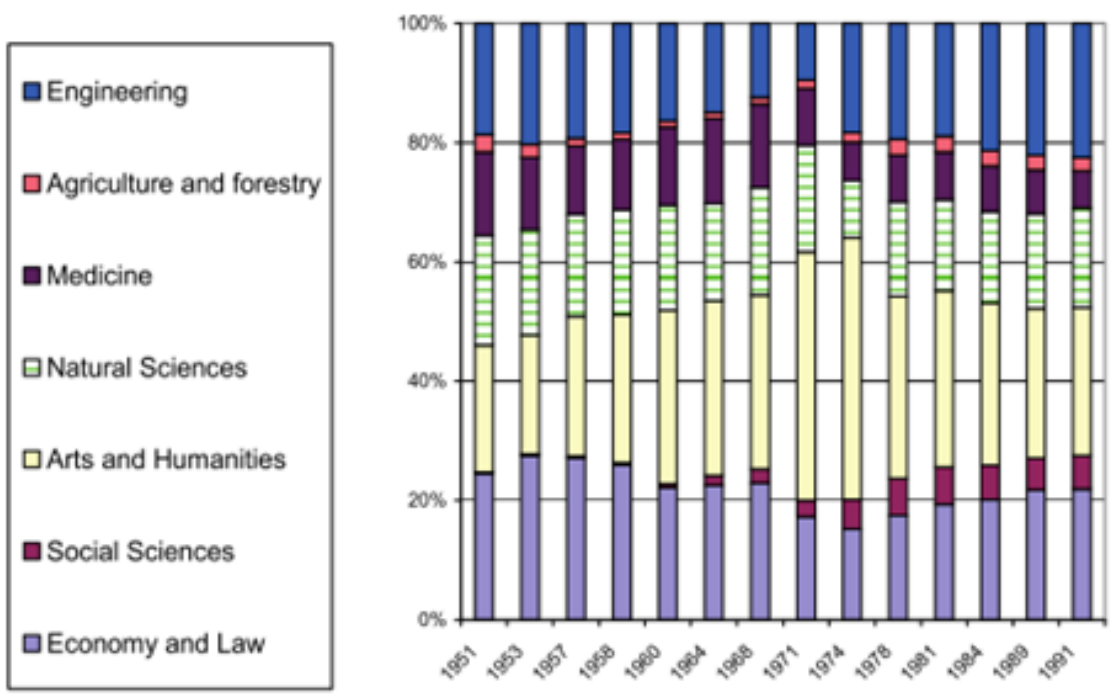

Figure 5. Fields of study at West German universities and technical colleges, 1951$1991{ }^{*}$. Adapted from "Between the Ivory Tower and the Industrial Laboratory: Universities in the West German Innovation System, 1945-1990,” by M. Schramm and U. Fraunholz, 2012, Historical Social Research, 37, p. 258.

* Statistisches Jahrbuch für die Bundesrepublik Deutschland, various years 
By the late 1960s, the increased desire to attend higher education and the number of West German students increased rapidly with the expansion of higher education (Kehm, 1999). Essentially, the number of higher education graduates increased even more after the reunification with the German Democratic Republic (GDR) in October 1990 (Kehm, 1999, Table 1). Nonetheless, soon after the enactment of the Federal Framework Act for Higher Education in 1976, which purpose was to establish a more uniform legal framework for higher education (Lingens, 2012; Kehm, 1999), admission restrictions began to be discussed. In 1977, the Federal Ministry of science and education rejected the provision as such action would be against the Constitution (Lingens, 2012). By the 1980s, able German students sought to study in the United States or other countries, known for their high-quality postsecondary education (Fallon, 2012). Although the public sector had been the main employer, graduates started to merge to the private sector as the need for highly qualified professionals was on the rise in the industry, for example. Graduates from Fachhochschulen, which accounted for about one third of the total student population in the mid-1990s, were prime candidates for the industry as students held skills in engineering, for example, to meet "the ever-increasing complexity of industry" (Lingens, 1998, p. 48). 
Table 1

Numbers of Higher Education Graduates in the Federal Republic of Germany: 19601996

\begin{tabular}{|c|c|c|c|c|c|c|c|c|c|}
\hline & 1960 & 1965 & 1970 & 1975 & 1980 & 1985 & 1990 & $1993^{37}$ & $1996^{b)}$ \\
\hline \multicolumn{10}{|c|}{ Graduates (in thousands) } \\
\hline Of universities & 27.9 & 40.5 & 47.3 & 70.7 & 70.9 & 78.3 & 86.7 & 91.7 & 139.1 \\
\hline Of Fachhochschulen & 11.3 & 15.3 & 22.0 & 30.6 & 33.3 & 46.2 & 53.6 & 57.5 & 75.3 \\
\hline Total & 39.2 & 55.8 & 69.3 & 101.3 & 104.2 & 124.5 & 140.3 & 149.2 & 214.4 \\
\hline \multicolumn{10}{|c|}{ Graduates in percentages of the corresponding age group ${ }^{e)}$} \\
\hline Of universities & 3.4 & 4.3 & 7.2 & 9.6 & 8.9 & 7.8 & 7.6 & 8.0 & $n$ \\
\hline Of Fachhochschulen & 1.4 & 1.6 & 3.3 & 4.1 & 4.2 & 4.6 & 4.7 & 5.0 & $\cdot$ \\
\hline Total & 4.8 & 5.9 & 10.5 & 13.7 & 13.1 & 12.4 & 12.3 & 13.0 & - \\
\hline
\end{tabular}

Note. Adapted from "Higher education in Germany: Developments, problems, and perspectives,” by B. M. Kehm, 1999, CEPES Monographs on Higher Education, p. 45. Sources. Wissenschaftsrat, Zur Lage der Hochschulen Anfang der $80^{\mathrm{er}}$ Jahre. Textteil (Cologne, 1983); Wissenschaftsrat, Empfehlungen des Wissenschaftsrates zu den Perspektiven der Hochschulen in den $90^{\mathrm{er}}$ Jahren (Cologne, 1988); Wissenschaftsrat Eckdaten und Kennzalen zur Lage der Hochschulen. Stand 1996 (Cologne, 1996); Statistisches Bundesamt, Bildung und Kultur. Fachserie 11, Reihe 4.2; Prüfungen an Hochschulen 1996 (Wiesbaden, 1996).

The decision to invest in higher education. At the turn of the twenty-first century, the German's university system was in need of restructuring to sustain its academic and economic future. In 2004, the federal minister for higher education and research, Minister Edelgard Bulmahn expressed that federal investments in higher 
education were a must. The idea was to elevate a selected number of German institutions to an elite status (Fallon, 2012). As a result of a prompt undertake, $\$ 2.6$ billion shared by the federal government ( 75 percent $)$ and the states (25 percent) were appropriated within 18 months, towards the Excellence Initiative (WR/Wissenschaftsrat, n.d. as cited in Fallon, 2012). Although the intent had been limited to focus on a few 'elite' institutions initially, the university sector was more broadly impacted from it since the program would encompass the strengthening of research and reforming of doctoral education (Fallon, 2012).

The production of scientific and scholarly talents. More generally, since the 1990s, STEM policy has very much been on the European Commission's agenda (Marginson et al., 2013, p. 55; Marginson, 2015). Nonetheless, the needs for Germany to compete for top scientific and scholarly talents on the global stage have led to significant investments to increase the contribution of universities in human capital formation and research innovation (Fallon, 2012). The role played by MINT is crucial, particularly for a nation, where engineering has a large presence. The work of Germany in basic and applied research is displayed by reputable institutes such as the Max Planck and the Fraunhofer Society, respectively.

Besides Germany's strengths, it is also, just as Australia is, looking at the American's system of higher education and research. Comparatively, expenditures in tertiary education for Germany accounted for 1.1 percent of the GDP between 1995 and 2005. During the same time period, expenditures increased from 2.3 percent to 2.8 percent for the United States. Latest figures indicated a slight increase $(0.2 \%)$ for Germany and a decrease for the United States (-0.2\%) (NSF, 2014a). 


\section{Summary}

As science in the United States emerged as a profession and higher education began to employ a greater number of scientists in the early years of the twentieth century, science education was also becoming more important. Progressively, industrial and government research laboratories began to expand rapidly, which also led to greater numbers of baccalaureate degrees. As the World War II conflict was unraveling, the United States soon realized how important science, engineering and technology were to be successful in the military conflict. At the same time, funding played a vital part in articulating research and development while shifting the need for technically trained personnel and faculty to wartime activities. Although many German scientists had migrated to the United States in the 1930s, the need for more human resources after World War II was fundamentally crucial to expand American science. While concerns were to establish a position in the world of research and science, the National Science Foundation Act of 1950 was instrumental toward establishing a national policy to promote basic research and education in the sciences.

Prospects about science and engineering workforce were not limited to the United States. Both Australia and Germany were facing similar issues, addressing their needs and wants either by means of a large-scale immigration or rebuilding from the destruction of the war in Europe. It was not long before the Cold War had a profound effect on Germany, slowing down the higher education reform and leading to critical times in the United States, when it began to question its technical superiority after the launch of Sputnik I. As a result, federal appropriations for science and engineering education and technology in the United States were greatly increased in light of critical needs for STEM 
workers. Despite concerns about the hegemonic position of the United States in promoting scientific research and fulfilling its obligations to the public, the nature of scientific work has changed over time and so has the work of universities' research in 'fashionable areas' (Reif, 1965). Coupled with scientific and technological transformations in the last decades, the political discourse based on supply and demand for high-skilled scientists and engineers has presented fundamental challenges for higher education about funding and the means to remain competitive globally despite the lack of consensus that may exist across the educational model. While Australia and Germany may not qualify their shortages in STEM workers or MINT, for Germany, the notion that shortages exit is a valid cause for concerns in light of an ageing population and demographics that has changed over recent decades. 


\section{CHAPTER IV \\ CRITICAL REVIEW OF THE STEM SHORTAGE DISCOURSE \\ IN THE UNITED STATES \\ What is Meant by STEM in the Educational Context?}

\section{Understanding STEM}

While Bybee (2010) recalls how education in the United States was facing national and international challenges in the 1950s, leading to a major curriculum reform, he also advocates to make STEM literacy an educational policy to advance STEM education in a broader sense in that the acquisition of new knowledge develops a capacity beyond STEM disciplines to shape one's intellectual, social and cultural world. The notion of a general agreement extends to a more fundamental issue in that STEM education needs to be better understood amongst professionals (Brown, Brown, Reardon, \& Merrill, 2011). In promoting STEM, Brown et al. (2011) see many benefits in how technology education has attempted to integrate the 'other' letters of the acronym. With this in mind, students can experience real-world situations and build the connections across STEM fields that are needed in an ever-changing workforce environment. This could resonate as an operational definition of STEM.

The need to better define what STEM education means and how the definition carries out with the other disciplines like science and technology remains nonetheless essential to more clearly address how STEM education is implemented. Conant (1947) 
argued for the need of "a widespread understanding of science" (p. 3), which in his opinion could best be understood by laymen like public servants, teachers, businessmen, and others. Sanders (2009) maintains that STEM remains ambiguous and that its meaning can easily be misinterpreted when people in the field of education refer to it, as STEM.

The demand for STEM degrees is "a proxy for the demand for underlying competencies" (Carnevale et al., 2011, p. 9) that shape the values of STEM education and influence how cognitive human capital is developed (knowledge, skills and abilities KSA) in the United States. While cognitive competencies contribute largely to building knowledge, answering what STEM is does not end here. There is a non-cognitive facet to it as well, in that learners can explore STEM from an investigative standpoint to build the valued interest to achieve their goals for a successful career, independently in STEM fields. Nonetheless, the fact that "there is not a clear vision for STEM education even amongst those who believe it is important" (Brown et al., 2011, p. 8) could inevitably impede its implementation along with the valued collaboration between peers across STEM disciplines about curriculum matters and integrated planning, for example, that STEM often requires.

\section{Defining STEM}

While Chomsky (2014) sees education as a means that involves "acquir[ing] the capacity to inquire, to create, to innovate, to challenge," (para 14), the four letters of the STEM acronym are used interchangeably by different audiences, which can make the conceptualization of STEM more difficult (Breiner et al., 2012) than it probably had been expected.

In the early 1990s, SMET for science, mathematics, engineering, and technology 
was the acronym used by the NSF. However, STEM was branded in 2001, when Judith A. Ramaley, a former director of the NSF's education and human resources division first used the acronym to refer to science, technology, engineering, and mathematics (Teaching Institute for Excellence in STEM, 2015). Nonetheless, it makes one ponder the question what STEM is and how it is defined.

The NSF defines the term 'STEM' more broadly while it funds research in the socalled core sciences such as mathematics and physical sciences for example and engineering, but also social and behavioral sciences as psychology, economics, sociology, and political science (Breiner et al., 2012; Gonzalez \& Kuenzi, 2012). By contrast, other federal agencies define STEM more narrowly such as Department of Homeland Security (DHS), U.S. Immigration and Customs Enforcement (ICE), with a focus on mathematics, chemistry, physics, computer and information sciences, and engineering, excluding social sciences.

From a data perspective about occupations in the United States and under the BLS 2010 Standard Occupational Classification, STEM occupations are divided in two primary domains, including two sub-domains each, 1) The science, engineering, mathematics, and information technology domain includes two sub-domains such as life and physical science, engineering, mathematics, and information technology occupations and social science occupations and 2) The science- and engineering- related domain includes two sub-domains, architecture occupations and health occupations (BLS, 2012; 2013). A more granular examination of the BLS definition of STEM occupations shows mathematical science occupations; architects, surveyors and cartographers; STEM-related postsecondary teachers; physical science technicians; STEM-related sales; STEM-related 
management; drafters, engineering technicians and mapping technicians; engineers; computer occupations (BLS, 2014, Figure 6).

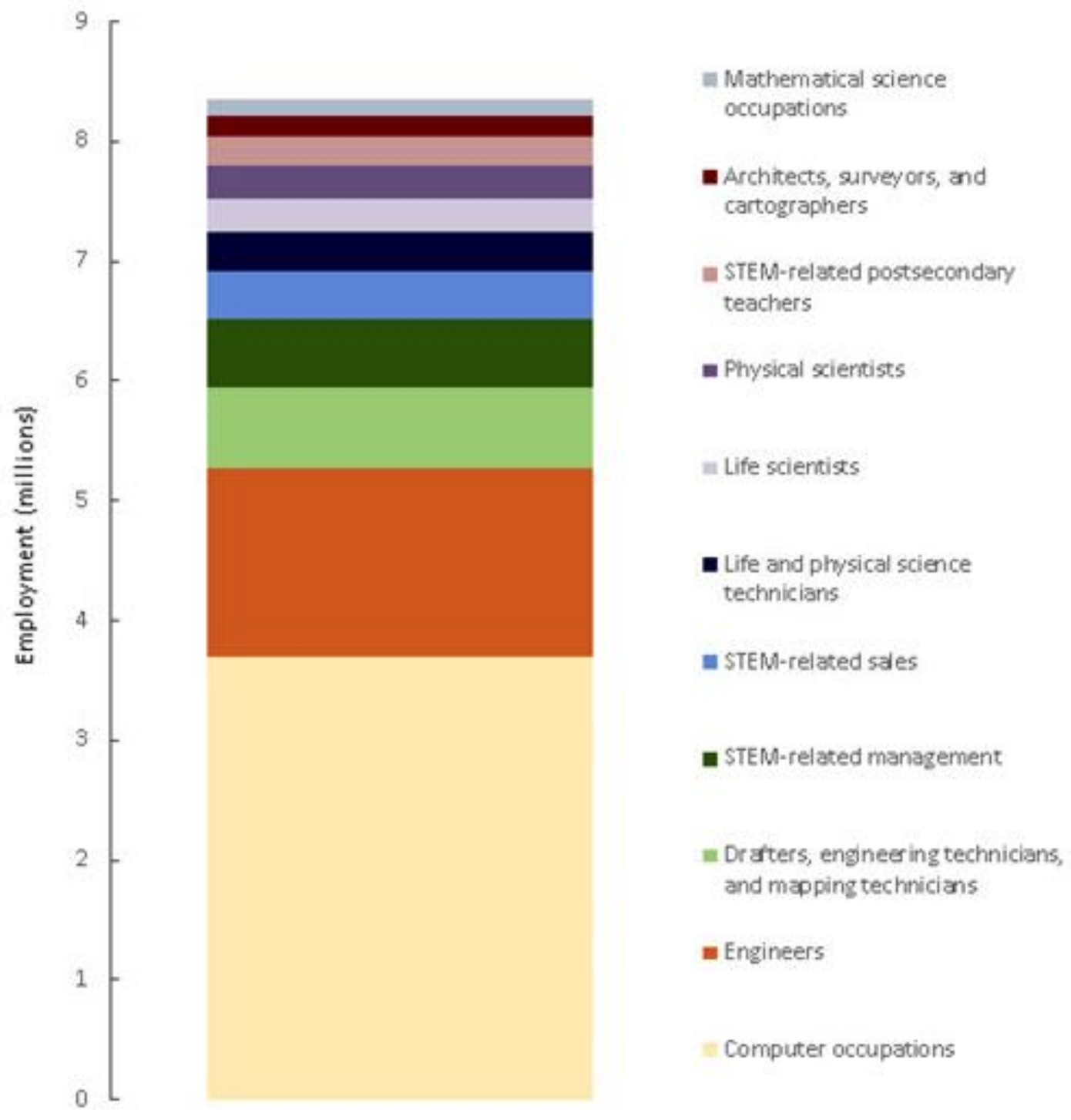

Figure 6. STEM employment by type of STEM occupation, May 2014

Note. STEM occupations are defined here to include computer and mathematical, architecture and engineering, and life and physical science occupations, managerial and postsecondary teaching occupations related to these functional areas, and sales occupations requiring scientific or technical knowledge at the postsecondary level. 
Adapted from "Occupational Employment Statistics. Employment by type of STEM occupation,” by U.S. Department of Labor, Bureau of Labor Statistics, 2014.

Upon request from the Office of Management and Budget (OMB) in July 2011, the final recommendations issued by the Standard Occupational Classification Policy Committee (SOCPC) to define STEM occupations were approved in April 2012. As "the discussion and analyses quickly get confounded since there is no commonly agreed upon definition of STEM" (BLS, 2012, para 1), these recommendations are to improve data comparability across organizations and statistical agencies that use those data for policymaking decisions about STEM workforce (BLS, 2012). Although the publication of the revised SOC codes is scheduled for 2018, Landivar (2013) reported on the first SOCPC recommendations, identifying STEM across three separate categories, STEM, STEM-related and non-STEM occupations (Table 2).

Defining STEM remains a challenge and even though it is commonly used, "there is no consensus on how it is defined" (NSF, 2015, p. 1) 4 $^{4}$ For example, the STEM workgroup formed under the SOCPC (2012) includes the NSF as one of many representatives; at the same time the NSF defines STEM under slightly different field of degree categories, under a broader scheme. The lack of consensus and standardization in defining STEM extends to whether some occupations are represented, for healthcare practitioners, engineering managers or social scientists. Those occupations are included in the BLS definition, however machinists are not. Interestingly, the Center on Education

\footnotetext{
${ }^{4}$ It might be possible to draw reasonable boundaries in defining STEM; it nonetheless depends on, "what's your purpose" H. Salzman (personal communication, September 29, 2015) affirms.
} 
and the Workforce at Georgetown University includes workers at the sub-baccalaureate level, who are often not part of STEM discussions and definitions (Carnevale et al., 2011).

Table 2

Classification of STEM, STEM-Related, and Non-STEM Occupations

\begin{tabular}{|c|c|c|}
\hline High-level occupation aggregation & Occupation group & STEM occupation classification \\
\hline \multirow[t]{5}{*}{ Management, business, science, and arts } & ivanagement & $\begin{array}{l}\text { Non-STEM (exc. computer and informa- } \\
\text { tion systems managers, architectural and } \\
\text { engineering managers, and natural science } \\
\text { managers) }\end{array}$ \\
\hline & Business and financial operations & Non-STEM \\
\hline & $\begin{array}{l}\text { Computer, math, engineering, and } \\
\text { science }\end{array}$ & $\begin{array}{l}\text { STEM (exc. architects; incl. computer and } \\
\text { information systems managers, architectural } \\
\text { and engineering managers, natural science } \\
\text { managers, and sales engineers) }\end{array}$ \\
\hline & $\begin{array}{l}\text { Education, legal, community service, } \\
\text { arts, and media }\end{array}$ & Non-STEM \\
\hline & Healthcare practitioners and technicians & STEM-related (incl. architects) \\
\hline Service & $\begin{array}{l}\text { Healthcare support } \\
\text { Protective service } \\
\text { Food preparation and serving } \\
\text { Building and grounds cleaning } \\
\text { Personal care and service }\end{array}$ & $\begin{array}{l}\text { Non-STEM } \\
\text { Non-STEM } \\
\text { Non-STEM } \\
\text { Non-STEM } \\
\text { Non-STEM }\end{array}$ \\
\hline Sales and office & $\begin{array}{l}\text { Sales and related } \\
\text { Office and administrative support }\end{array}$ & $\begin{array}{l}\text { Non-STEM (exc. sales engineers) } \\
\text { Non-STEM }\end{array}$ \\
\hline Natural resources, construction, and maintenance & $\begin{array}{l}\text { Farming, fishing, and forestry } \\
\text { Construction and extraction } \\
\text { Installation, maintenance, and repair }\end{array}$ & $\begin{array}{l}\text { Non-STEM } \\
\text { Non-STEM } \\
\text { Non-STEM }\end{array}$ \\
\hline Production, transportation, and material moving & $\begin{array}{l}\text { Production } \\
\text { Transportation } \\
\text { Material moving }\end{array}$ & $\begin{array}{l}\text { Non-STEM } \\
\text { Non-STEM } \\
\text { Non-STEM }\end{array}$ \\
\hline
\end{tabular}

Note. The full list of Census Bureau occupations and occupation specific used in the report by Landivar (2013) is available at http://www.census.gov/people/io/methodology/. Adapted from "Disparities in STEM employment by sex, race, and Hispanic origin," by L. C. Landivar, 2013, American Community Survey Reports, ACS-24, p. 3.

With these definitions in mind, Angier (2010) speaks about the easily misconstrued interpretation of STEM education. At the same time, some analysts argue that field-specific definitions can be too static and that definitions of STEM should focus on "an assemblage of practices and processes that transcend disciplinary lines and from 
which knowledge and learning of a particular kind emerge" (Moon \& Rundell Singer, 2012, para 3). To that effect, STEM could mean "an integrated curricular approach to studying grand challenges of our era" (Bybee, 2010, p. 31). Despite all these definitions, the definition of STEM is somewhat amorphous (Bettinger, 2010). While opinions about how STEM should be defined differ, defining it may simply depend on the purpose for which a definition is sought out and how it impacts or benefits "the national health, prosperity, and welfare" (P.L. 81-507, p. 1).

\section{The Ambiguity with Labeling STEM}

While Bybee (2010) seeks to advance an understanding for STEM education, he sees it "as a generic label for any event, policy, program, ... that involves one or several of the STEM disciplines" (p. 30), for example, science or mathematics and not so much as technology or engineering. There is a sense that STEM operates under a common operational concept, which is lacking (Breiner et al., 2012). While asking what science is, Conant (1947) alludes to social scientists and yet acknowledges that "the failure to agree on a satisfactory definition of science is in part responsible for some of the confusion in the verbal conflict about the study of man" (p. 27). This ambiguity associated with the STEM acronym raises the question whether this lack of clarity prevents the United States to adequately address education and workforce issues in STEM, where major stakeholders involved in discussions are legislators, administrators, teachers, parents, and more. With this in mind, it is not clear how the teaching of each of the four concepts separate from one another still represents STEM education.

While Breiner at al. (2012) sought to address the conceptualization of STEM education and partnerships, they run a qualitative study to reinforce the idea that the 
STEM acronym meant enough and was not leading to confusion ${ }^{5}$. More precisely, from the 222 responses collected from STEM education faculty in the College of Education and Criminal Justice and Human Services at the University of Cincinnati, Breiner et al., (2012) gathered three themes, 1) A null relationship to STEM, 2) Personal reasons, and 3) Societal issues in addition to the authors asking the question, what is STEM? Findings revealed that 72.5 percent of respondents knew what STEM stood for, yet only 57 percent of that group had used the acronym. Breiner et al. (2012) revealed the lack of cohesiveness across the acronym, which inevitably constitutes "a challenge in changing the paradigm from compartmentalizing academic disciplines" (p. 9). Those findings are echoed by Dr. Elizabeth Stage, director of the Lawrence Hall of Science at the University of California, Berkeley, who thinks that it takes away what the fields have in common like problem solving, critical and analytical thinking for example to 'silo out' the different disciplines (Angier, 2010).

Schibuk (2008) points out that a multidisciplinary approach to STEM education would boost STEM curricular innovation - an alternative that had not been discussed by educators and education researchers until the 1970s. Three decades later, new perspectives presented by Moon and Rundell Singer (2012) indicate an understanding that interdisciplinary collaboration across core concepts and practices is essential to fundamentally build up on STEM learning and teaching processes in undergraduate science education, for example, including how STEM knowledge is learned and conceptualized even though there is no consensus for agreeing on the right approach.

\footnotetext{
${ }^{5}$ Although STEM policies are also critical to P12, this policy analysis does not concentrate on this level of education.
} 
However, the question remains in determining what STEM is and how it aligns with education and workforce. Besides, depending on how STEM is defined and how science education could remove the narrow interpretation of science attributed in STEM in concepts and objectives remains a matter of interpretation as understanding STEM is central to the federal policy conversation (Gonzalez \& Kuenzi, 2012). The fundamental confusion raises questions whether STEM may be a form of currency to serve a particular audience in space and time.

Looking at STEM education from the perspective of federal STEM education measures such as the America COMPETES Reauthorization Act of 2010 (P.L. 111-358) signed into law in 2011, which established a broader approach to STEM education at the federal level under the coordinated efforts of the National Science and Technology Council (NSTC), the term STEM means "the academic and professional disciplines of science, technology, engineering, and mathematics" (Section 2). This definition remains too vague and can easily lead to confusion as to what each of the terms does include or is interpreted as. The spelling of the acronym may well be known by several agencies, organizations and even policymakers, its definition remains nebulous and ambiguous (Moon \& Rundell Singer, 2012). The American physicist and astronaut, Sally Ride, who is one of the founders of Change the Equation acknowledges that the acronym "is not very helpful when talking to the public" (para 8), which may become more evident when it is directed to education (Angier, 2010). At the same time, Moon and Rundell Singer (2012) see that the phrase 'STEM education' tends to focus more on the K-12 science education framework, which in itself represents the underpinnings that provide the fundamental knowledge to many Americans in that science, engineering and technology 
permeate nearly every facet of modern life (NRC, 2012). This level of confusion aligns with critics' viewpoint in that, why not simply use science education, just as it is referred to in most of the twentieth century literature? The misleading interpretation of STEM education according to Sanders (2009) resonates more like when new things seem to emerge, the 'business as usual' in a sense. By contrast, "STEM without education is a reference to the fields in which scientists, engineers, and mathematicians toil" (Sanders, 2009, p. 20).

\section{The Need to Establish a Clear Vision}

While STEM is critical for the United States, it is likely to expand with innovation, playing a strong role in the development of sustainable means to meeting societal and individual needs in education, transportation, environmental protection, healthcare, for example, as demographic changes occur. Bybee (2010) sees that what policymakers make of STEM does not always filter down in STEM educational programs. Science- and technology- based innovation can only happen with an educated workforce in STEM, where the learning of skills remains an ongoing process triggered by rapid market changes (Atkinson \& Mayo, 2010). Somehow, the philosophical approach that the "university and the university-scientist must play [a vital role] in maintaining an effective relationship between government and science" (Killian, 1964, p. 33) constitutes a guarantor to generate knowledge-seeking and the impetus to feed our growing dependence on research with the means that invigorate innovation.

While STEM education might not have produced the results that policymakers had expected, solutions seemed to have been more about "addressing the shortage of qualified science and mathematics teachers, a problem the No Child Left Behind Act 
(2001) ha[d] targeted" (Sanders, 2009, p. 22). Somehow, historical perspectives bleed in within different contextual circumstances. They transpire through federal STEM education measures, for example, the America COMPETES Act of 2007 (P.L. 110-69) and America COMPETES Reauthorization Act of 2010 (P.L. 111-358). These acts have set a focus on technology and engineering to meet twenty-first century needs, both playing a fundamental role in the welfare of American people in light of global competitiveness (Sanders, 2009). The America COMPETES Act of 2007 included several recommendations that were incorporated into law from the Rising Above the Gathering Storm report, circulated as a draft in October 2005 by the National Research Council (NRC) ${ }^{6}$. However, the "authorizations" [under the two-key U.S. legislative funding process] can only enable the expenditures specified, but do not provide the needed funds" (Teitelbaum, 2014a, p. 19), which ended up having direct consequences in ensuring that the ambitious public policies set forth by the committee be plausible in the long-term even though "most [empirical studies that were conducted after the publication of the final hard copy] have not been able to find credible evidence in support of the report's concerns about insufficiency in the numbers or quality of scientists and engineers being produced by U.S. higher education" (Teitelbaum, 2014a, p. 21). Despite these facts, the committee draws a daunting outlook for America to compete for quality jobs, thus leading to the publication by the National Academies Press in 2010 with the sinister

\footnotetext{
${ }^{6}$ The National Academic of Sciences had been co-opted. This critical report had been written in a very short timetable, which meant that it was not based on empirical evidence and careful analyses; the report was known to be flawed (H. Salzman, personal communication, September 29, 2015; R. Hira, personal communication, October 6, 2015; Teitelbaum, 2014a).
} 
feel given by the subtitle, "Rapidly Approaching Category 5" (NAS, 2010).

In the 2011 State of the Union, President Obama emphasized on how "this is our generation's Sputnik moment" (The White house, 2011) in that the American leadership in research, education and innovation can ensure the nation's competitiveness and security. Although engineering and technology were included when the National Science Foundation and other government agencies began to prepare national standards for science education, economics has also become part of what STEM education entails, particularly in face of an increasing industry responsiveness to government needs in developing "the link between a well-rounded science education and tomorrow's techie workforce" (Angier, 2010, para 15). As STEM education gets more attention for funding its future as an integrated model will likely depend on how relevant it aligns with the curriculum, including the education of applied science skills at post-secondary educational levels. Along those lines, the National Science Foundation recently funded a program seeking to enhance STEM education at Iowa State University and Des Moines public schools with a $\$ 4.5$ million research grant. Similarly, the University of Pittsburgh was awarded a \$2.6 million NSF grant in 2010 to investigate integrative learning combining mathematics, engineering and science.

\section{Summary}

STEM education is fundamentally important in sustaining societal and individual needs as the United States has become more dependent on STEM workers. In light of a rapidly changing global marketplace, the learning of STEM skills remains an ongoing process that must align with the curriculum and the increasing cost of education. Although understanding what STEM means, who it includes and what disciplines count 
as STEM, may be a matter of interpretation. It remains nonetheless essential to understand it in order to adequately address education and workforce issues in STEM, where the major stakeholders involved in discussions are legislators, administrators and university leaders, corporations supported by industry and lobbyists, and researchers.

\section{Major Tenets (Grounding) of the Discourse}

\section{How is the STEM Shortage Discourse Framed?}

Current beliefs of STEM education in the United States are founded on the economic principles of supply and demand, articulated across a political framework. Besides differences in opinion about STEM education programs in generating a capacity in human capital, the influence of a global marketplace associated with rapid technological development and the import of high-skilled scientists and engineers is fundamentally different today. More specifically, governmental entities, including legislators, university leaders, corporations supported by industry and lobbyists and researchers do not seem to share the same opinion about what STEM education means and what it can do and how it translates into the American workforce supply and demand. On the basis of those economic principles, issues of funding and immigration are discussed within the political framework onto which market indicators are added to help articulate the beliefs that increasing enrollment in STEM education programs in higher education could be necessary.

While it is believed that a strong supply in STEM workforce can help the nation to maintain its competitive edge, the discourse is to increase enrollments in STEM education programs to remedy the STEM labor shortage. One example is the field of computer science, where proponents of a STEM shortage like Microsoft or Intel 
Corporations argue that a shortage of college graduates would have a dramatic effect on occupational demands. In order to remedy this problem, the U.S. pipeline for education and training of STEM workers needs to be supported in order to ensure there are sufficient graduates in computer science. More precisely, graduates in computer science include the sub-bachelor level, which is underfunded, yet is projected to account for 66 percent of job openings by 2020. Conversely, the rhetoric of a STEM shortage that frames the need for increasing enrollment in STEM education programs has another side. Not all researchers and pundits agree that there are too few STEM graduates in the United States (Hagedorn \& Purnamasari, 2012). Policy reports on labor market shortages are very much reflecting individual employers' accounts of the hiring problems of qualified skilled workers in STEM fields (Lowell \& Salzman, 2007). However, Salzman (2013) questions that if there were a shortage of STEM talent, "where are the market indicators (namely wage increases) that signal students there is an opportunity to pursue a career in this industry that is better than their alternatives?" (p. 64). What transpires from those observations is that the difficulty in finding workers with sufficient experience and specific technical skills may be more the cause for complaints on behalf of employers ${ }^{7}$. Justifiably, Anft (2013) thinks that Americans are not told the truth about the real problem, considering that: 1) most of the claims come from employers of STEM workers, lobbyists and trade associations in support of industry, 2) \$3.1 billion in fiscal 2010 of federal money was appropriated for STEM programs in higher education (U.S. GAO, 2012), 3) international students bring in high tuition revenues and 4) STEM programs are

\footnotetext{
${ }^{7}$ The discourse is very much divided across the aisle. Much emphasis is placed on information technology-related fields as revealed by my conversations with interviewees.
} 
prestigious for academic education. Along similar lines, Anft (2013) adds that 20 percent of American scientists in the field of biochemistry and molecular biology, for example, are considering leaving the United States.

The American tradition could be one of hard-core pragmatism (Anft, 2013) global competitors are nonetheless not going to wait while business leaders and politicians remain concerned about the issue just they have been since World War II, the Sputnik I launch, the competition with Japan and Europe. Undeniably, the politics of shortage might arise from four primary perspectives, such as: 1) the level of competitiveness that the National Science Foundation tried to addressed in the 1980 s by predicting 'looming shortfalls' in STEM, yet to be scrutinized with embarrassment by members of Congress in the early 1990s (Teitelbaum, 2003), 2) corporations that employ high-skilled scientists and engineers and negotiate wages, 3) immigration lawyers who earn a living from these negotiations, facilitating the import of skilled foreign workers, and 4) university administrators who depend on enrollments and tuition, while being faced with increasing challenges in assuring that the fundamental missions of universities of higher education are met, including producing graduates in STEM fields. Teitelbaum (2003) sees that these perspectives could align with how "government science-funding agencies may find wages problematic insofar as they result in increased costs for research" (p. 19).

Economic principles. Teitelbaum (2014a, 2014b) recalls a few time periods since World War II, each lasting about 10 to 15 years when workforce shortages in science and engineering had been claimed to be critical. These shortages were argued on the basis of economic principles of supply and demand. From 1945 to the late 1980s, these motivations arose from 'existential' concerns of the Cold War. From the mid-1990s to the 
early 2000s, significant changes in science and engineering occurred, marked by the high-tech industry and information technology booms (Teitelbaum, 2003; Teitelbaum, 2014a). The consensus seems to be that "the STEM workforce crisis is an inadequate supply of domestic talent" (Hira, 2010, p. 950); a discourse that is supported by proponents from large corporations, university leaders and highly ranked government officials are clearly expressing the need to increase STEM supply.

The lack of supply. The rhetoric of a workforce shortage in the United States seems to be a repeat (Cohen, Kisker, \& Brawer, 2013), echoing broader fears of the past as emerging powerful markets have raised challenging concerns in science and technology innovation. However, focusing too much on repeated historical cyclical events can mislead public opinion (Salzman, 2013; Teitelbaum, 2014a, 2014b). At the same time, the changing nature of the labor market and rapid technological developments that have emerged from globalization and the introduction of other markets, like China and India are other contributing factors. All things considered, the question about the need for more new degrees and certificates is raised (Cohen et al., 2013). Coincidently, employers are being faced with a limited supply of high-skilled STEM workers while universities are claiming decreasing enrollments (Rochester Institute of Technology, 2007). In fact, claims abound, including the Obama administration, which called for five million more graduates from community colleges in 2011 (Marcus, 2011) or the Lumina Foundation stating that a gap of 23 million of two- and four-year college degrees by 2025 could cause an economic decline. However, it raises the question whether the number of degree holders, warrant these claims when "full-time employment declined by 5.7 million from November 2007 to November 2011" (Cohen et al., 2013). 
In reporting on wage trends -a key measure of labor demand-Camarota and Zeigler (2014) state that "over the entire period of 2000 to 2012, real hourly wages (adjusted for inflation) grew on average just 0.65 percent annually for those with only a bachelor's degree and 0.71 percent for all STEM workers" (p. 12; Figure 7; Figure 8). In a sense, low wages have become more prevalent recently and the number of temporary workers had already reached 2.94 million by October 2014 (U.S. Department of Labor, 2014).

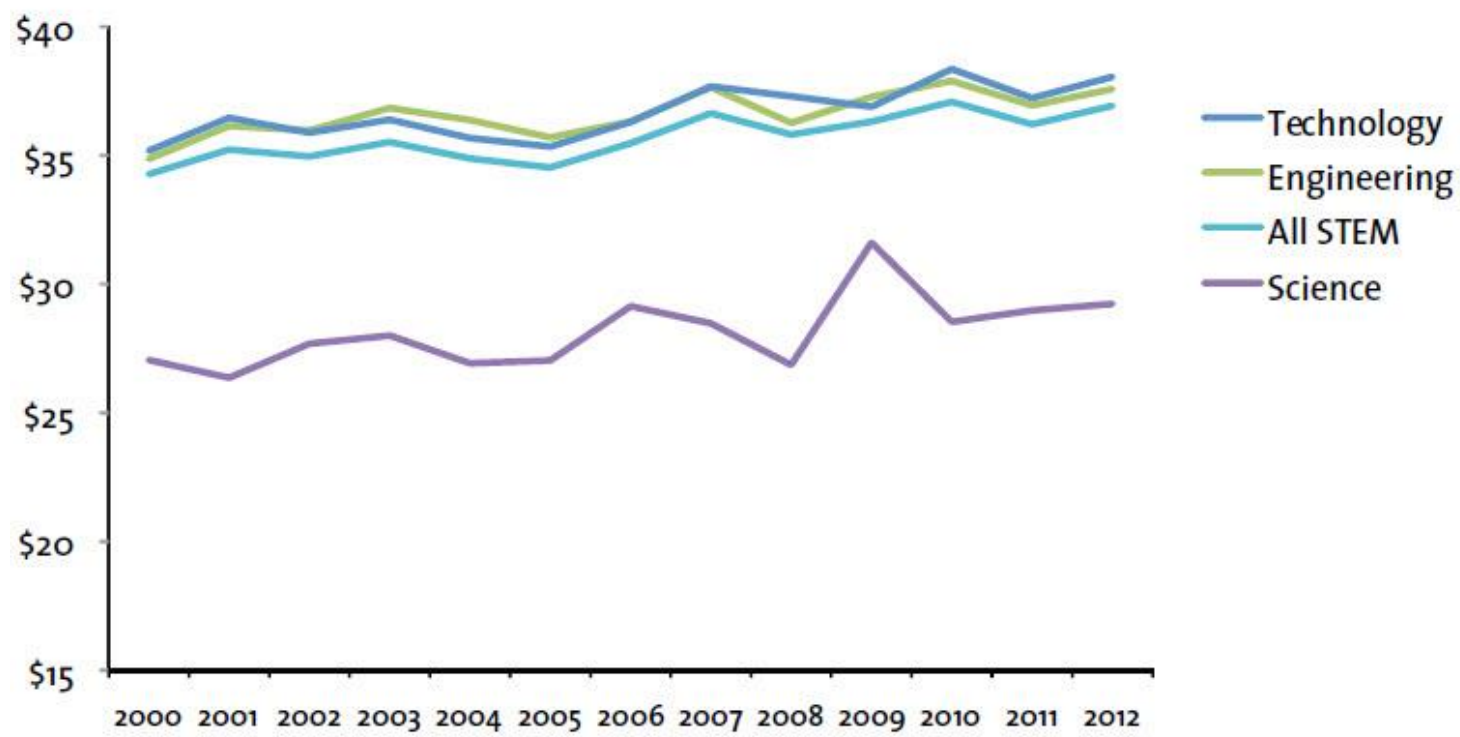

Figure 7. Average hourly wages for STEM workers with only a bachelor's degree in 2012 Dollars. Adapted from "Is there a STEM worker shortage? A look at employment and wages in science, technology, engineering, and math,” by S. A. Camarota and K. Zeigler, 2014, Center for Immigration Studies, p. 13.

Source. Public-use files of the 2000 to 2012 Current Population Surveys. Each year averages 12 months of data. Analysis confined to STEM workers with at least a bachelor's degree age below age 65. Pareto-imputed mean values for top-coded weekly 
wages are from the "State of Working America", 12th edition, Economic Policy Institute, p. 467. Pareto-imputed means for 2012 were provided by EPI separately. Figures for math tend to be more volatile because of small sample size.

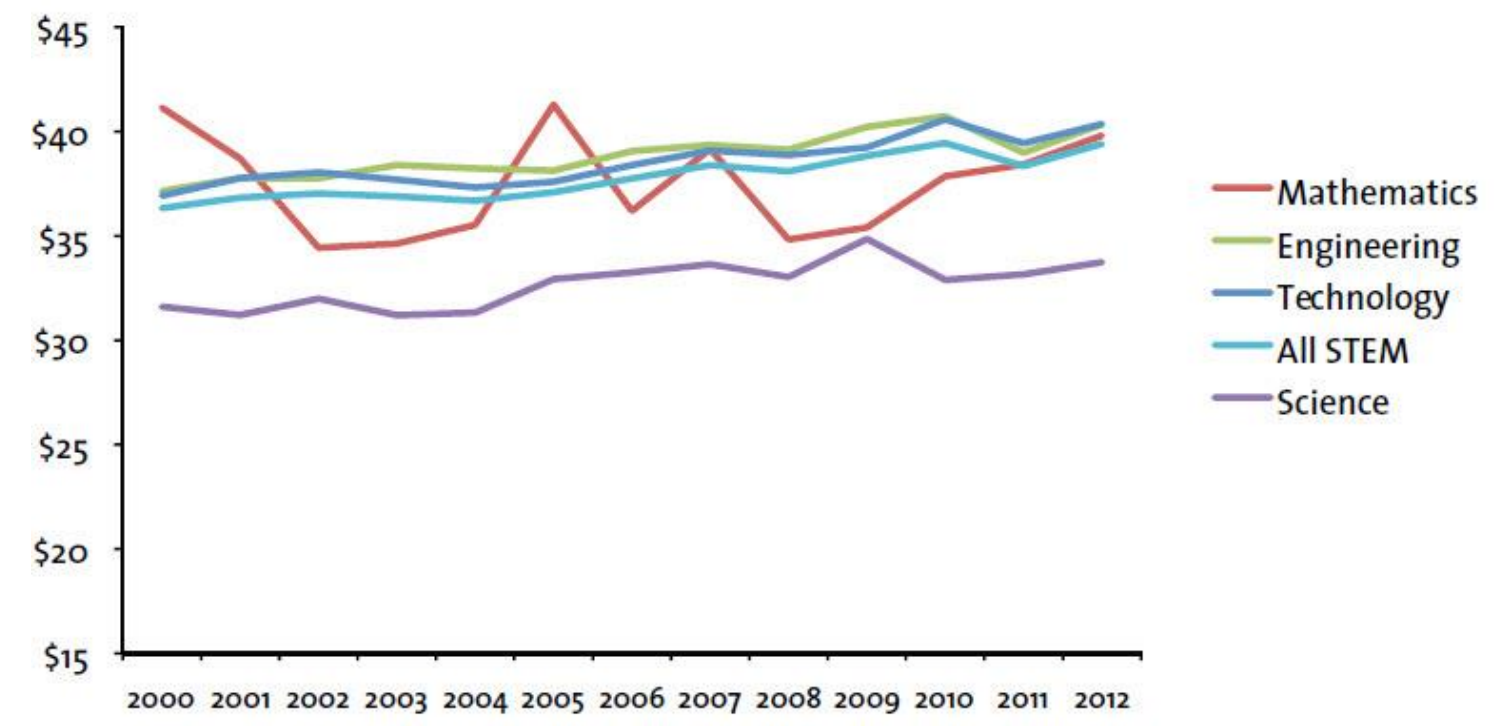

Figure 8. Average hourly wages for STEM workers with only a bachelor's degree or higher in 2012 dollars. Adapted from "Is there a STEM worker shortage? A look at employment and wages in science, technology, engineering, and math," by S. A. Camarota and K. Zeigler, 2014, Center for Immigration Studies, p. 13.

Source. Public-use files of the 2000 to 2012 Current Population Surveys. Each year averages 12 months of data. Analysis confined to STEM workers with at least a bachelor's degree age below age 65. Pareto-imputed mean values for top-coded weekly wages are from the "State of Working America", 12th edition, Economic Policy Institute, p. 467. Pareto-imputed means for 2012 were provided by EPI separately. Figures for math tend to be more volatile because of small sample size.

If the United States depends on education for prosperity and innovation, how valid are those claims while jobs are exported? Justifiably, proponents who make those 
claims "can easily [trigger] self-fulfilling prophecies" (Teitelbaum, 2003, p. 53) and create the adverse effect on American students, who wish to become science and engineering professionals. Most certainly, some see the rhetoric being a political game, making claims for lower wages and yet corporations, including Microsoft Corporation advocate for more federal funding of STEM education and more visas for foreign workers (Anft, 2013). David Hart, director of the Center for Science and Technology Policy at George Mason University supports the fact that even an engineer needs broader knowledge beyond science and technology for a nation to sustain its economic driving force (Anft, 2013). Again, defining STEM can be a matter of interpretation (Gonzalez \& Kuenzi, 2012), yet it is critical to understand it in the context of higher education as it generates a stock of human capital (Alexander, 2000). The product of STEM workforce system that derives from STEM education can be described as an interconnected system of variables -a heterogeneous system- characterized as "a multiple labor markets, demarcated by occupation, level of degree, geographic location, industry-specific knowledge, and years of experience" (Hira, 2010, p. 951).

However, most policymakers and industry leaders concur that the United States is facing a crisis in high-skilled talents (Salzman, 2013). Although STEM may represent only about 5 percent of the nation's workforce, it nonetheless plays a critical role in improving quality of living, national security and societal meaningfulness (Hira, 2010). More importantly, it is also when economics can shape science under the effects of a global economy on science and engineering workforce as Freeman (2006a) asserts in that these occupations contribute greatly to solidifying the leading edge of economic competitiveness of a nation (Teitelbaum, 2014a, 2014b). Occupations in STEM fields 
represent different levels of education and training. The supply of STEM workers is not limited to people with STEM degrees. Camarota and Zeigler (2014) state that "nearly one-third of the nation's STEM workers do not have an undergraduate STEM degree" (p. 1). These occupations include professionals such as blue-collar or nonprofessionals that might also require high-level STEM skills to perform their work such as manufacturing. These high-skilled STEM or STEM-related workers have been and continue to be an important workforce from an economic and innovative standpoint. What happens to individuals who are earning good wages in STEM jobs but who may not have an education as formal as what public policies are overemphasizing? Rothwell (2013) argues that vocational degrees in science and technology are not being assessed comparatively to PhD training in science and K-12. With this in mind, several observations are worth making in that, 1) most innovators and entrepreneurs may not hold a $\mathrm{PhD}$ and 2) tradespeople and technicians hold important roles in the implementation of new ideas (Toner, Turpin, Woolley, \& Lloyd, 2011), being the underpinnings in the pragmatics of innovative endeavors and global competitiveness. Interestingly, the secondary-technical sector is strong in Germany. In the United States, technicians contribute greatly in many important sectors of the economy, including technicians in cyber security. Denning and Gordon (2015) see those types of jobs to be critical on many level as they can ensure the operability and security of the information infrastructure that many Americans depend on. There is a downside to these types of jobs nonetheless as wages may be lower than for designer jobs or as employees can easily be displaced due to automation or offshoring.

It makes one ponder the question how the $\$ 260$ million government and private 
industry initiative, Educate to Innovate, launched by the Obama Administration in 2009 could help alleviate these feelings of job insecurity when employees are losing their jobs to automation or outsourcing as the intent had been "to move American students from the middle to the top of the pack in science and math achievement over the next decade" (The White House, 2013a) to meet the national need for a skilled workforce in science and technology in conjunction with corporate and public investments. The importance of knowing whether there is too little STEM workforce in the United States is not only for the nation to maintain its hegemony in the global competitive landscape, it is also to ensure a continuum in educating a citizenry to a well-qualified and diverse STEM workforce to boost innovative thinking and promote education and learning opportunities across the nation, including the underrepresented populations (OSTP, 2013).

However, Professor Nicholas Vonortas at George Washington University sees a disconnect between STEM education and what it is intended to do to meet the increasing needs of high-skilled workers (Charette, 2012). Besides computing technicians whose talent may be undervalued, in the October 2014 interview by Sonari Glinton on National Public Radio, one of the commentators states that too much emphasis may be given to college education instead of vocational skills directly applicable to manufacturing. Denning and Gordon (2015) see that while universities are not providing training for technicians jobs, which would require programming or the like, students could go to the local community college to acquire that knowledge. However, community colleges may not have the capacity to meet those needs. It was not until the 1960 s that vocationalism gained a certain appeal as students wanted to have more choice in pursuing their education (Cohen \& Brawer, 2008). In reality, the prestige of academic programs stems 
from false distinctions between so-called thinking occupations and so-called vocational occupations.

The lack of demand. Arguably, opinions differ. STEM workers agree that this is a lack of demand. Shierholz, Sabadish and Finio (2013) observe that unemployment and underemployment rates of young college graduates under age 25 , represented through the labor market prospects of the Class of 2013, not distinctive of STEM, have increased since 2007 (Figure 9).

In determining whether it is a lack of supply or demand, Hira (2010) shares anecdotal opinions in that STEM workers see the real STEM crisis being a lack of demand instead. Similarly, Shierholz (2014) concludes that the job market is weak due to a demand lacking for goods and services; however it is not a true representation of the labor force, particularly since the beginning of the Great Recession of 2007-2009. 


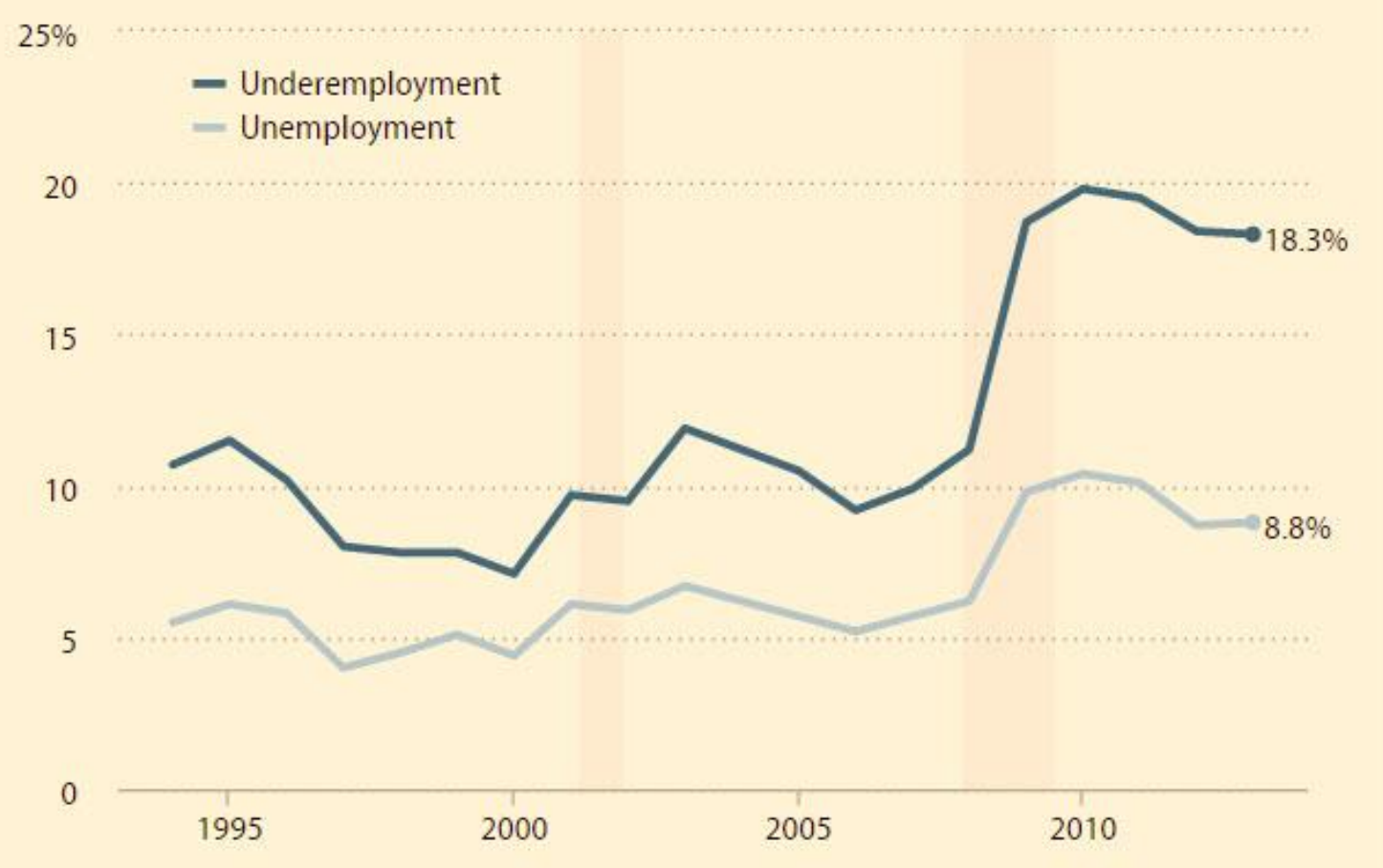

Figure 9. Unemployment and underemployment of young college graduates, 1994-2013*. Adapted from "The class of 2013: Young graduates still face dim job prospects," by H. Shierholz, N. Sabadish, and N. Finio, 2013, EPI Briefing Paper 360, p. 12.

* Latest 12-month average: March 2012-February 2013

Note. Underemployment data are only available beginning in 1994. Data are for college graduates age 21-24, who do not have an advanced degree and are not enrolled in further schooling. Shaded areas denote recessions. Authors' analysis of Bureau of Labor Statistics' Current population Survey microdata.

Shierholz (2014) asserts that the push for more education and training to remedy the cyclical phenomena will not generate demand and solve the unemployment crisis. While differences between the number of unemployed workers and job openings by industry for July 2012-June 2013 remain critical as indicated in Figure 10, the lack of 
demand can also be examined from the perspective of skills mismatch, which has a direct effect on the labor market, in that it weakens the aggregate demand (Shierholz, 2014).

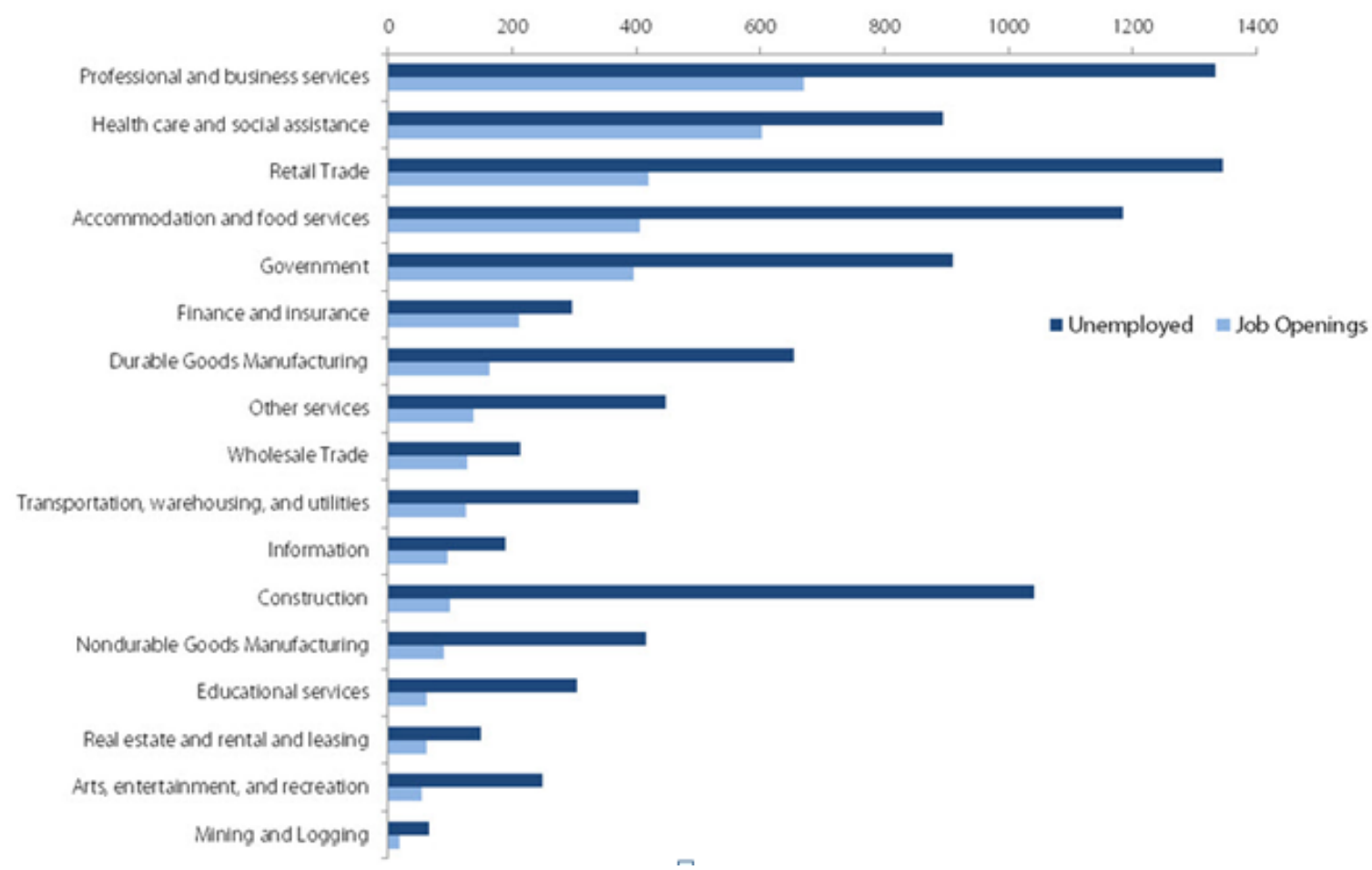

Figure 10. Unemployed and job openings, by industry (in thousands). Adapted from "Is there really a shortage of skilled workers?” by H. Shierholz, 2014, Economic Policy Institute.

Note. Due to the fact that the data are not seasonally adjusted, these are 12-month average, July 2012-June 2013. Author's analysis of Bureau of Labor Statistics' Current population Survey microdata.

Lazear and Spletzer (2012) note that the variation of unemployment rates over recent years, including the times of the recession was not due to structural changes. Although, the issue of supply could be labeled as a structural cause, it will nonetheless reflect changes in demographics or other conditions at some point in time, which can 
persist over time. By contrast, demand tends to be inherently cyclical. Whether a phenomenon is cyclical or structural, it can easily lead to misinterpretation when the public does not necessarily understand that demand is not strong because workers do not have the right skill-set to meet that demand. The right skill set can be technical; "soft skills", for example, work ethic and communication are also part of perceived skill gaps (Cappelli, 2015). With that in mind, the public hears anecdotally that employers cannot fill positions with skilled workers. Again, it remains a matter of interpretation, depending on who reports on those data. Unfortunately, the argument brought forth by politicians in that education and training are the answer to remedy the lack of skills is not scrutinized by the public, which in itself fuels the political discourse that STEM shortages are undermining the industry's capacity to prosper and to create jobs. At the same time, it is important to recognize that the labor force is not always able to change skills on time in light of rapidly changing economic and technological progress.

In the same NPR interview by Sonari Glinton in October 2014, Dan Adams, who is one the owners of MTI in South Bend, Indiana talks about the skills gap MTI Company is facing. MTI manufactures engine components for jet engines, but people like Dan Adams state that they cannot fill positions with high skilled workers in machining. Although there could be a number of reasons for not being able to find workers with the right skills, what are the root causes for this skill gap? While employment in the U.S. manufacturing sector slowed down in the 1940s and 1950s after industrialization had expanded, high-knowledge engineering jobs, closely tied to the manufacturing sector declined between 2000 and 2010 as well (Rothwell, 2013). However, what happens with MTI Company and other manufacturing enterprises when demand for high skilled 
workers cannot be filled? While there is demand in specialized sectors of the U.S. industry, do manufacturing jobs go begging because manufacturing is seen by students and their parents as a poorly paying industry that doesn't have a healthy long-term future? Professor Vonortas from George Washington University would say that the issue is not about the lack of students and because there is a lack of hard evidence, graduating more students is not the answer to sustain U.S. manufacturing (Charette, 2012). Based on these observations, increasing STEM education will not necessarily solve the employment problem (Shierholz, 2014).

\section{Markets indicators}

The picture of STEM workforce shortages. Defining the insufficiency of STEM workforce is a matter of interpretation and remains very much dependent upon agreeing on a common analytical framework. Not only the STEM workforce may not be uniform across the regions, it may also depend on the type of industry and how the adequacy of science and engineering workforce is viewed from policymakers and industry leaders. At the same time, an increasing number of STEM graduates have elected to work in nonSTEM career fields because of greater prospects and earnings. The diversion into nonSTEM fields, yet not unique to STEM indicates a persistence of 56 percent immediately after graduation and 46 percent 10 years later based on data from the Baccalaureate and Beyond Longitudinal Study (B\&B) survey, NCES, 1993/2003 (Carnevale et al., 2011).

Other data from the U.S. department of Education NCES regarding degree attainment and persistence in STEM fields indicated that students entering a STEM field during their first year of enrollment switched out of engineering and engineering technologies (23 percent); computer and information sciences (20 percent); and mathematics (32 percent) 
(Chen \& Weko, 2009) ${ }^{8}$. That said, the Business Higher Education Forum (2011) reported slightly different percentages based on these data such as 35 percent in computer and information sciences and 31 percent in engineering and engineering technologies. These data raise different concerns in that they not only relate to the interest and persistence in STEM fields, they indicate how the United States could address the capacity for STEM personnel. First, a sufficient number of STEM literate workers could help drive innovation. Second, a sufficient number of STEM specialists and teachers could help to remedy the departure of workers into retirements. Third, building a capacity in STEM personnel could align with the increasing shift of a demographic distribution in women and underrepresented minorities.

Teitelbaum (2003) sees several reasons that can deter U.S. students from pursuing a career in science such as post-doctoral work, tenure promotion, family life and attaining an independent scientific experience much later in life. Besides financial aid and more extraneous cost of studies in science curricula, for example, in the field of biochemistry, Teitelbaum (2003) speaks of 'opportunity costs' or the long years when a student foregoes earnings compared to non-STEM fields to which more students seem to rally to. Another critical area of study is biomedical research. Although, it is a prominent field of science and most heavily financed, it is the least attractive career prospect along with relatively low demand and wages (Teitelbaum, 2014b). While these limitations take away the attractiveness to science and engineering fields to draw in talents, students from

\footnotetext{
8 "This group includes students who had obtained one or more degrees only in non-STEM fields and were last enrolled in a non-STEM field as of 2001, or those who had not yet attained a degree and were enrolled in a non-STEM field in 2001" (Chen \& Weko, 2009, p. 12, Table 6)
} 
China and India, for example, are actively recruited and subsidized as graduate students in science $\mathrm{PhD}$ programs.

Wages are lagging behind. In times of a weak labor market caused by a skill mismatch, it is likely that overly qualified workers are hired at a much lower wage than their academic worth. Based on data analysis from the Current Population Survey, Shierholz (2014) retrieved no indication of a wage increase indicating a shortage of STEM supply ${ }^{9}$. Similarly, Hira (2010) notes that STEM salary growth has not been competitive compared to other occupations. With a salary growth of approximately 6 percent between 1995 and 2005, there is no strong indication of an unbalanced supply and demand at the aggregate level, therefore not supporting that STEM workers are persistently in short supply (Shierholz, 2014). Because salary trends are not identical from one STEM field to another, it is essential to break down data for analysis, which can support the need of more targeted policies (Hira, 2010). Despite the rhetoric of STEM shortages in computer-related and mathematical occupations, for example, Costa (2012) indicates that wages increased by $\$ 1.97$ between 2000 and 2011 ( $\$ 39.24$ in 2012 dollars) for workers with at least a bachelor's degree or in other words to an average wage increase of less than half a percent per year (Figure 11). Looking back to the early years of the twentieth century, Goldin and Katz (2007) note that the narrowing in wage distribution based on the education level had been the most substantial from the late 1910s to the early 1950s. Technology has triggered the transformation of the supply and demand relationship by increasing demand for skilled and educated workers. It has also

\footnotetext{
${ }^{9}$ Heidi Shierholz is the Chief Economist to the U.S. Secretary of Labor Thomas Perez.
} 
determined who received "the fruits of growth" (Goldin \& Katz, 2007, p. 5).

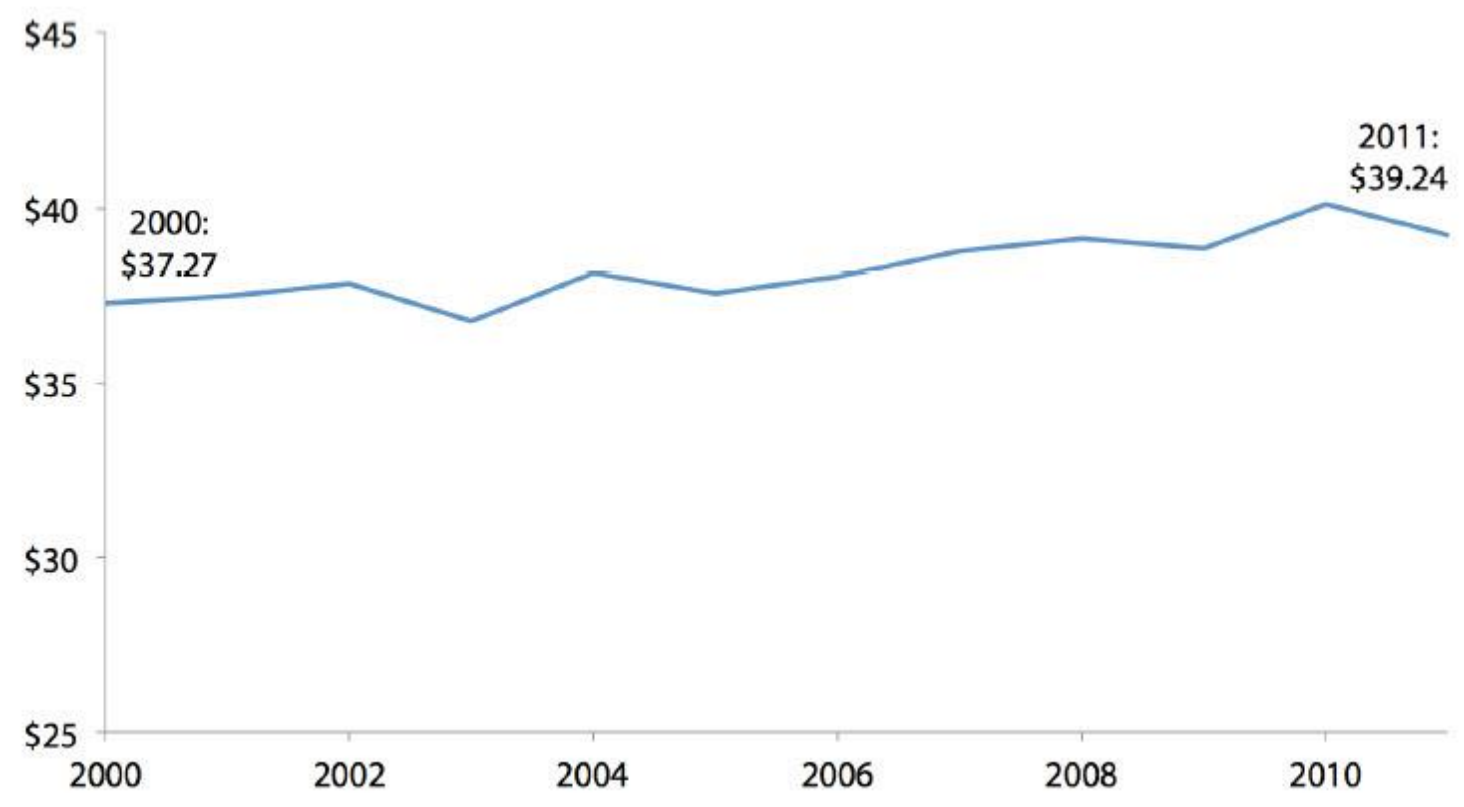

Figure 11. Average hourly wage in computer and mathematical occupations, workers with at least a bachelor's degree, 2000-2011 (2012 dollars). Adapted from "STEM labor shortage? Microsoft report distorts reality about computing occupations," by D. Costa, 2012, Education Policy Institute, p. 8.

Source. EPI analysis of Current Population Survey basic monthly microdata.

Since 1980, for individuals without a college degree, the trend has created a scenario where wages have been either very high or very low. This job polarization has created winners and losers from the perspective of economic return to education. At the same time, technological changes have made the job market more vulnerable, molding two STEM economies made of 1) professionals, who are "keeping American businesses on the cutting edge of technological development and deployment" (Rothwell, 2013, p. 3) and bridging the corporate sector and higher education and 2) tradespeople and technicians (Toner et al., 2011), who are nonetheless important to American scientific 
and technological innovative endeavors and global competitiveness. In sum, STEM careers can present risk and uncertainty in their employment, including how so many STEM occupations can be outsourced or offshored.

Unemployment rates are lower than expected. While Costa (2013) reports on comments by Microsoft Corporation on the minimal requirement of a bachelor's degree in computer science, he points out at flaws like the misleading use of the BLS Occupation Outlook discussed in Teitelbaum (2003), who sees that proponents of a scientific shortage manipulate data to support what they believe in that there are too few college graduates. However, they also intend to claim "the unemployment rate during periods of full employment for the entire national economy, not for engineers, scientists, or collegeeducated workers in computer occupations" (Costa, 2012, p. 5).

While large corporations lay off thousands of workers throughout 2012, the number of H-1B visas reached almost 130,000, supporting those employers' claims of an existing STEM shortage (U.S. State Department, 2012). Camarota and Zeigler (2014) refer to similar numbers of new immigrants with STEM degrees, who have settled in the United States annually even though STEM employment has only grown on an average of 84,000 jobs per year since 2000. Based on these data, Costa (2012) argues that the full unemployment rate of all workers in computer and mathematical occupations has been close to 2 percent since 2000 (Figure 12), as opposed to the 4 percent Microsoft has claimed about college-educated workers. Interestingly, statistical data could be influenced by the diversity of educational backgrounds that workers in computer-related occupations have, ranging from graduate degrees, undergraduate and certifications (U.S. GAO, 1998). Nonetheless, it is still important to account for the distribution on the level 
of education those workers have, which may not disqualified them to perform a computer-related job without holding a degree in computer science. As the lack of data is at the core of the rhetoric that there are too few STEM graduates in computer-related occupations, for example, evidence of data does not always match the political discourse.

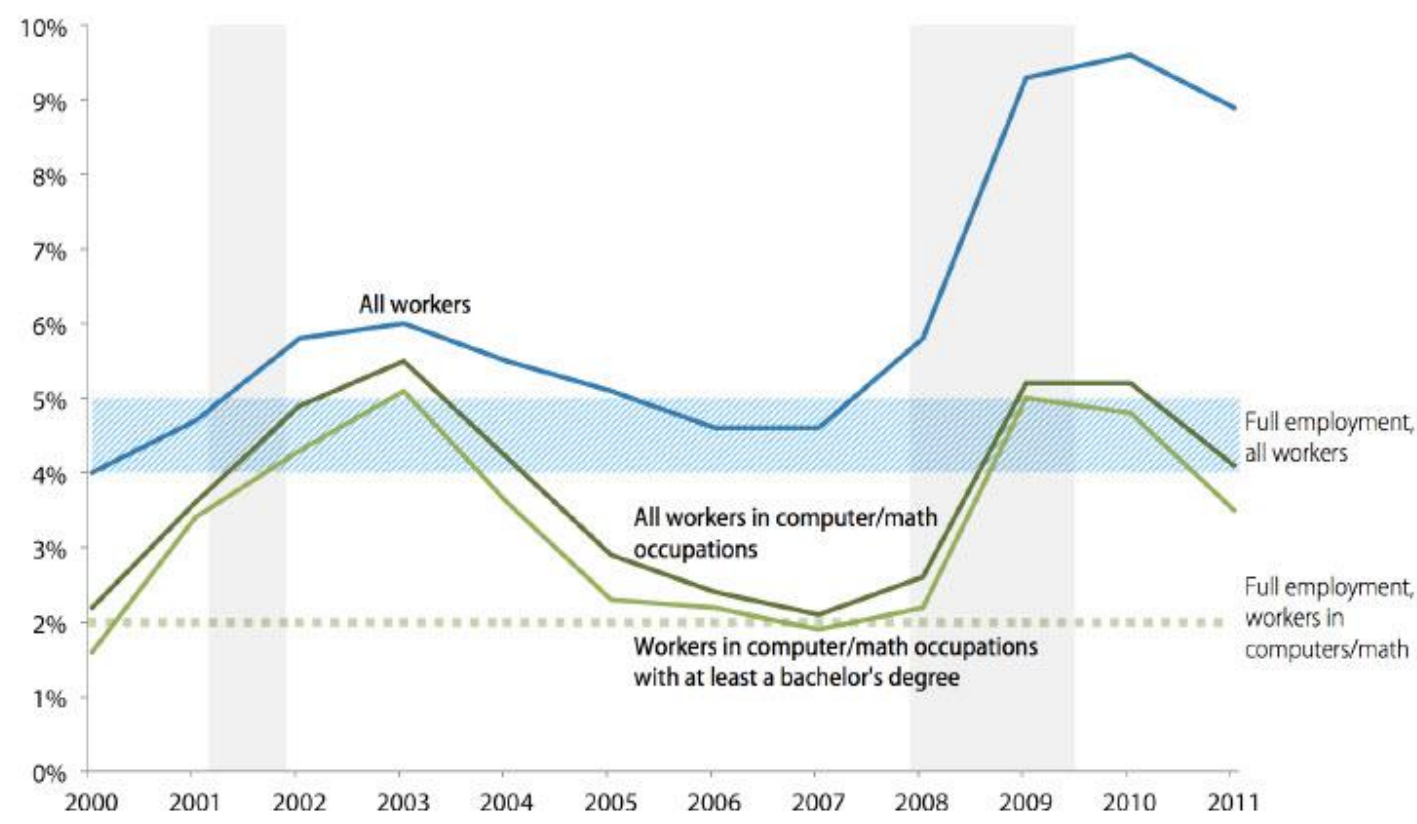

Figure 12. Unemployment rates of all workers and workers in computer and mathematical occupations, 2000-2011 (relative to unemployment rates at full employment). Adapted from "STEM labor shortage? Microsoft report distorts reality about computing occupations," by D. Costa, 2012, Education Policy Institute, p. 6. Note. Top horizontal shaded bar shows that the unemployment rate of all workers at cyclical peak (full employment) ranges from 4 percent to 5 percent. Bottom horizontal dotted line shows that the unemployment rate for workers in computer and mathematical occupations at cyclical peak is around 2 percent. Vertical shaded bars denote recessions. Source. Current Population Survey (CPS) public data series, unpublished Bureau of 
Labor Statistics analysis of CPS basic monthly microdata, and EPI analysis of CPS basic monthly microdata

As Camarota and Zeigler (2014) seek to inform employers and Congress in reconciling their wants about current employment and wage data, Costa (2012) concludes that the unemployment rate of 3.4 percent of college-educated workers in computerrelated occupations in 2011 still does not support the belief that there were too few STEM graduates. Actually, there may be too many experienced STEM workers. Looking at STEM education from a political lens and how the nature of the STEM labor market is changing, particularly when employers are leaning more toward 'on-demand' employment, it can only fuel the argument for H-1B visa skilled foreign-born workers (Atkinson et al., 2010). Coincidently, the Information Technology Association of America (ITAA) did exactly so with the third report in 2000, fueling political support to expand H-1B visas at 195,000 per year (Teitelbaum, 2003).

The changing demographics. Reflecting on Lazear and Spletzer (2012), the changing demographics of women and underrepresented minorities, including Blacks and Hispanics in higher education will inadvertently affect the supply of STEM collegeeducated workers in the United States. Besides improving undergraduate STEM education and aligning graduate education to today's workforce, better serving groups historically underrepresented in STEM fields is also one of the major investment areas of the America COMPETES Reauthorization Act of 2010.

Looking at the distribution of STEM workers by gender, men represent the majority of science and engineering graduates with approximately 61 percent compared to 39 percent for women, based on listed fields of bachelor's degrees (U.S. Census 
Bureau, 2013). However, the gender representation as workers in STEM occupation reveals a greater gap, accounting for 76 percent for men and 24 percent for women, respectively (Landivar, 2013, Figure 13).

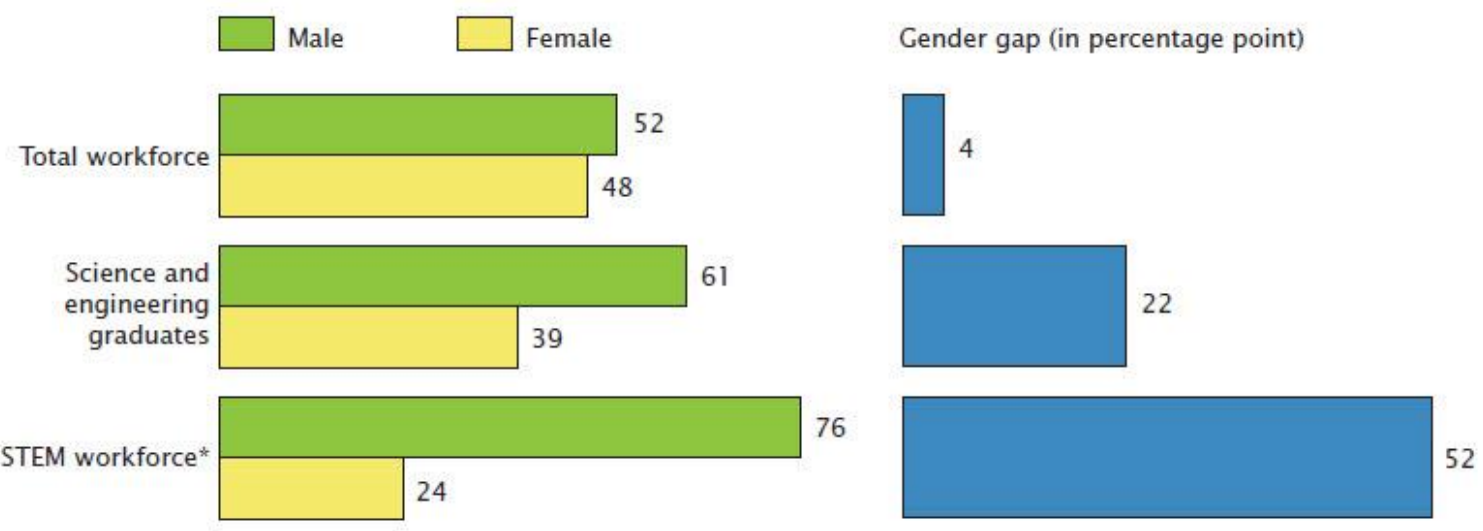

Figure 13. Share of total employment, science and engineering degrees, and STEM employment by sex. Adapted from "Disparities in STEM employment by sex, race, and Hispanic origin," by L. C. Landivar, 2013, American Community Survey Reports, ACS24 , p. 24.

Note. In percent. Data based on sample. For information on confidentiality protection, sampling error, non-sampling error, and definitions, see www.census.gov/acs/www/). ${ }^{*}$ With a science or engineering bachelor's degree.

Source. U.S. Census Bureau, 2011 American Community Survey.

More recently, Liana Christin Landivar reiterated in a news release the relatively low unemployment for STEM graduates, pointing out that they may not all work in a STEM field (U.S. Census Bureau, 2014). While the proportion of women's employment in STEM occupations has been consistently increasing since 1970 at the exception of computer-related occupations, they remain underrepresented (Landivar, 2013, Figure 14). 


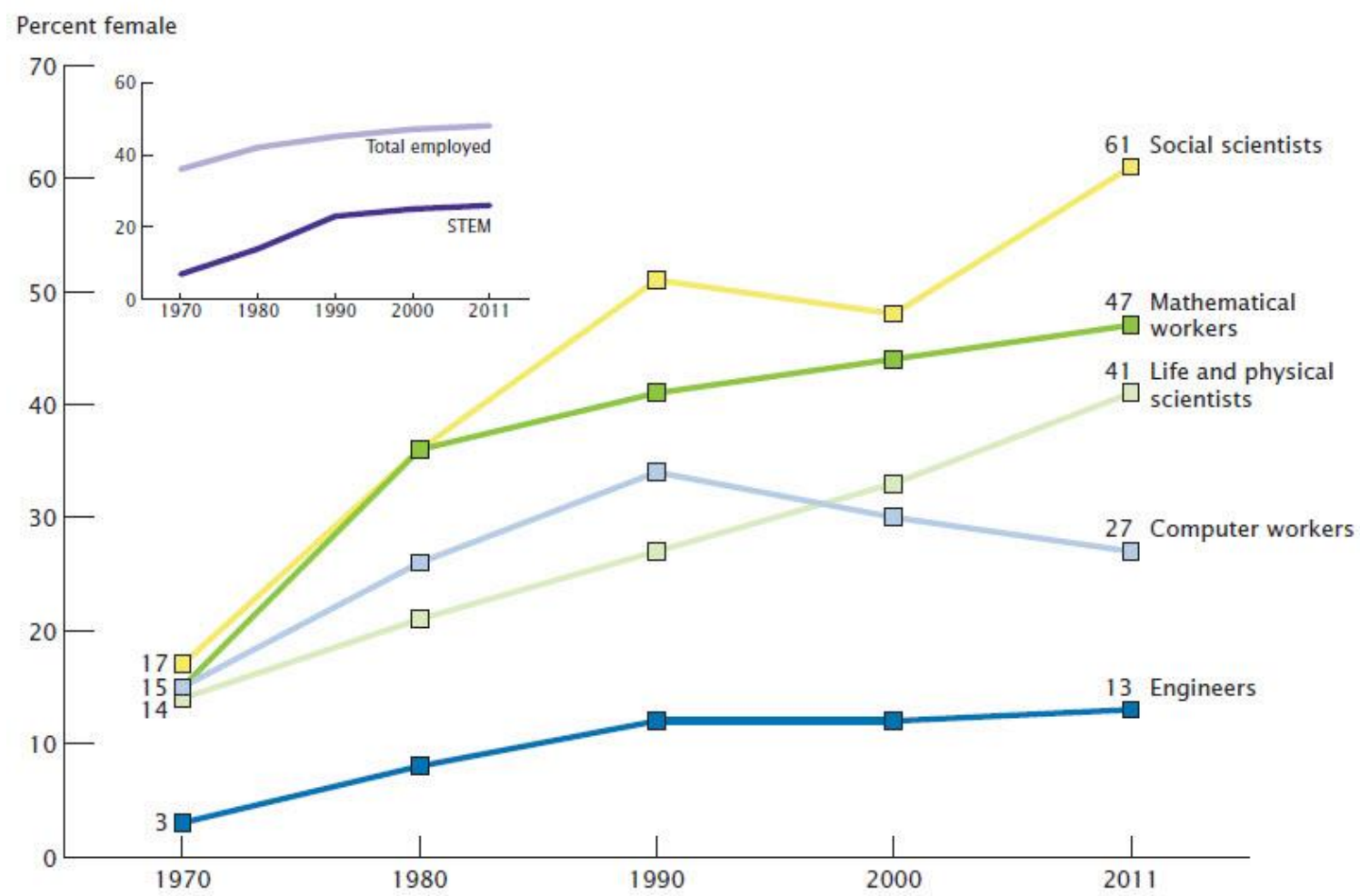

Figure 14. Women's employment in STEM occupations: 1970 to 2011. Adapted from "Disparities in STEM employment by sex, race, and Hispanic origin," by L. C. Landivar, 2013, American Community Survey Reports, ACS-24, p. 6.

Note. Data based on sample. For information on condentiality protection, sampling error, nonsampling error, and definitions, see www.census.gov/acs/www/

Source. U.S. Census Bureau, 1970, 1980, 1990, and 2000 decennial censuses and 2011 American Community Survey.

The distribution of STEM workers can also examined by race and ethnicity, where the Asian population has increased and the White population has decreased in the last two decades (NSF, 2014b). However, Black and Hispanic populations have not changed very much with the exception of Hispanics, whose representation has increased by a mere 2.3 percent since 1993 (NSF, 2014b). In short, Blacks and Hispanics accounted 
for nearly 10 percent of science and engineering occupations in 2010 (NSF, 2014b, Table $3)$.

Table 3

Distribution of Workers in S\&E Occupations, by Race and Ethnicity: 1993-2010 (Percent)

\begin{tabular}{|c|c|c|c|c|c|c|c|c|}
\hline Race and ethnicity & 1993 & 1995 & 1997 & 1999 & 2003 & 2006 & 2008 & 2010 \\
\hline American Indian or Alaska Native ............. & 0.2 & 0.3 & 0.3 & 0.3 & 0.3 & 0.4 & 0.3 & 0.2 \\
\hline Asian.................................................. & 9.1 & 9.6 & 10.4 & 11.0 & 14.2 & 16.1 & 16.9 & 18.5 \\
\hline 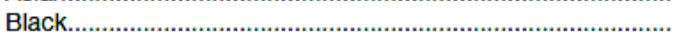 & 3.6 & 3.4 & 3.4 & 3.4 & 4.3 & 3.9 & 3.9 & 4.6 \\
\hline Hispanic. & 2.9 & 2.8 & 3.1 & 3.4 & 4.4 & 4.6 & 4.9 & 5.2 \\
\hline Native Hawailan or Other Pacific Islander .................................. & NA & NA & NA & NA & 0.3 & 0.5 & 0.4 & 0.2 \\
\hline White & 84.1 & 83.9 & 82.9 & 81.8 & 75.2 & 73.2 & 71.8 & 69.9 \\
\hline More than one race & NA & NA & NA & NA & 1.4 & 1.4 & 1.7 & 1.4 \\
\hline
\end{tabular}

Note 1: Adapted from "Science and engineering indicators. Science and engineering labor force," by National Science Foundation, 2014, p. 3-48.

Note 2. Before 2003, respondents could not classify themselves in more than one racial and ethnic category. Before 2003, Asian included Native Hawaiian and Other Pacific Islander. Hispanic may be any race. American Indian or Alaska Native, Asian, black or African American, Native Hawaiian or Other Pacific Islander, white, and more than one race refer to individuals who are not of Hispanic origin.

Source: National Science Foundation (2014b, p. 3-48, Table 3-23), National Center for Science and Engineering Statistics, Scientists and Engineers Statistical Data System (SESTAT) (1993-2010), http://sestat.nsf.gov

Compared to Whites, Blacks and Hispanics account for about 6.5 percent of the STEM workforce, while Whites make nearly 71 percent (Landivar, 2013, Figure 15). Despite these large disparities in numbers, the share of women and underrepresented minorities in STEM workforce may likely continue. As the supply side appears to be the most popular, Teitelbaum (2003) notes there are other factors that come into play such as 
retirement and with those demographics changes, part-time appointments have created a greater number of highly educated job applicants, including newly minted PhDs.

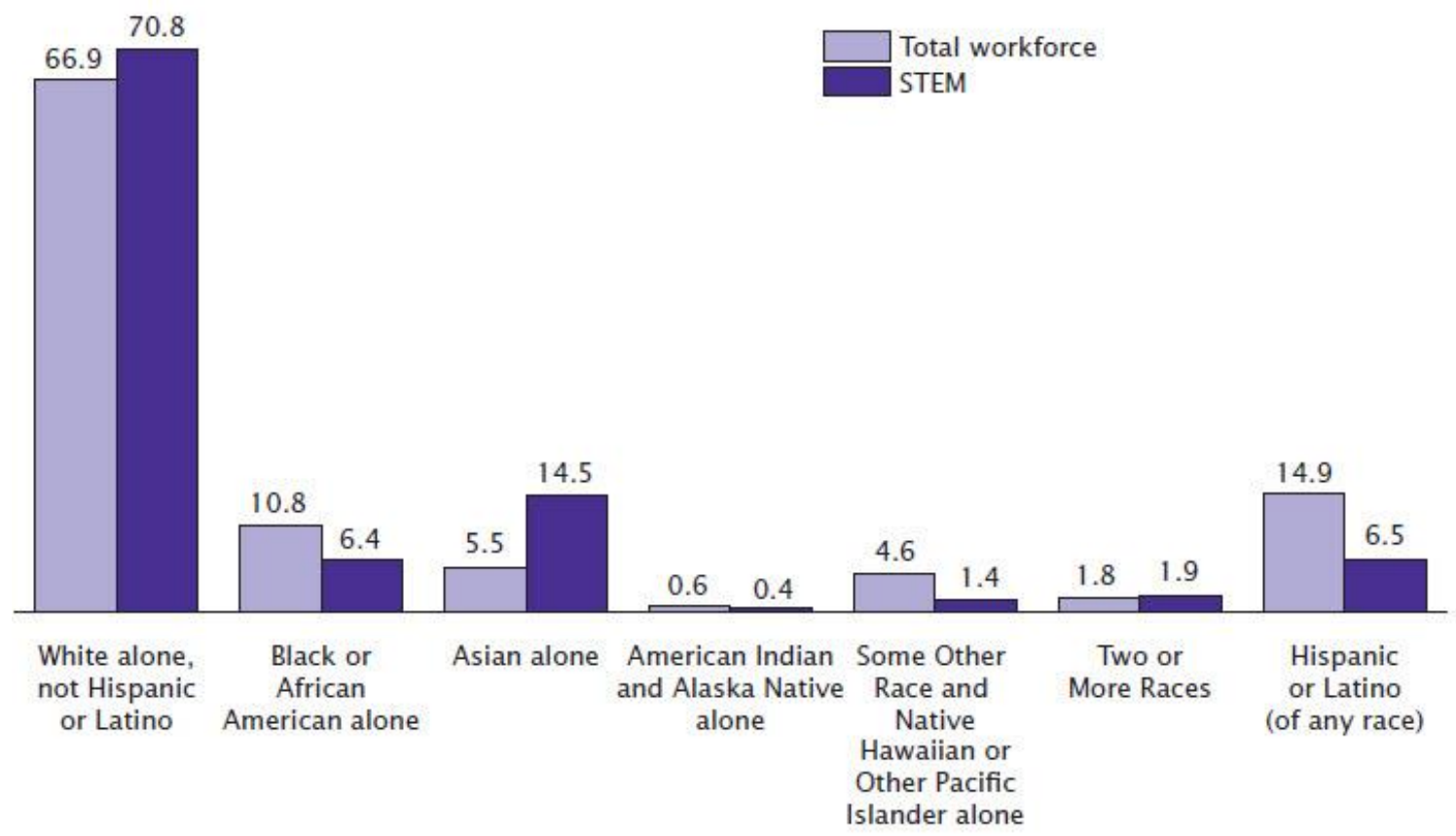

Figure 15. Racial and ethnic representation in the STEM workforce. Adapted from

"Disparities in STEM employment by sex, race, and Hispanic origin," by L. C. Landivar, 2013, American Community Survey Reports, ACS-24, p. 16.

Note. Native Hawaiian or Other Pacic Islander alone was combined with Some Other Race because of a small number of sample observations. In percent. Data based on sample. For information on condentiality protection, sampling error, nonsampling error, and definitions, see www.census.gov/acs/www/

Source: U.S. Census Bureau, 2011 American Community Survey.

\section{Political Framework}

Federal government STEM programs. While federal agencies have obligated large amount of funds for STEM programs, Galama and Hosek (2003) see the status of 
science and engineering infrastructure, education and workforce is not being sustained. In the area of research, Hira (2010) argues for greater federal research funding for basic research similar to what the National Academy of Sciences (2007) proposed by increasing federal investment in long-term basic research by 10 percent per year over the next seven years, particularly to the Department of Defense (DOD) and to disciplines like physical sciences, engineering, mathematics, and information sciences, and eventually including life sciences and the social sciences. In promoting basic research, the creation of new knowledge presents new opportunities that can also lead to innovative products and industries that would absorb new graduates (Hira, 2010). Other policy levers can also provide new expectations for learning opportunities and scholarships in STEM degrees just the NDEA was meant to do by "strengthen[ing] the national defense and to encourage and assist in the expansion and improvement of educational programs to meet critical national needs," (Public Law 85-864, p. 1581).

As the goals of federal, state and local government policies are to boost STEM education through many channels like community colleges, universities, for example, funding allocations are not necessarily done on an even distribution of STEM jobs across levels of education. Training toward Bachelor's degree or higher degrees received \$1.94 billion, or 45 percent of $\$ 4.3$ billion allocated to STEM education per year (Rothwell, 2013) for fiscal year 2010. By contrast, the sub-bachelor's level degree for STEM education or training received only 22 percent of total federal funding in fiscal year 2012. Rothwell (2013) responds avidly to the lower proportion of federal money allocated to the sub-bachelor's level, which in itself represents half of STEM jobs that do not require a Bachelor's degree as identified in the NSTC analysis. While an increase in funding 
would create a greater university enrollment capacity to eventually stimulate STEM labor demand, not all STEM occupations require undergraduate degrees or higher. For example, in the state of Oregon, only 23 percent of green jobs require a Bachelor's or advanced degree (Oregon Employment Department, 2012, p. 10). Along those lines, Rothwell and Ruiz (2013) observe that about 25 percent of H-1B visa requests for STEM occupations are commonly staffed by people with only an Associate's degree. At the same time, the cost of education in STEM programs at colleges and universities, as shown in Figure 16, tends to often be the most expensive (American Institutes for Research, 2013) with the exception of a few applied and liberal arts fields. 


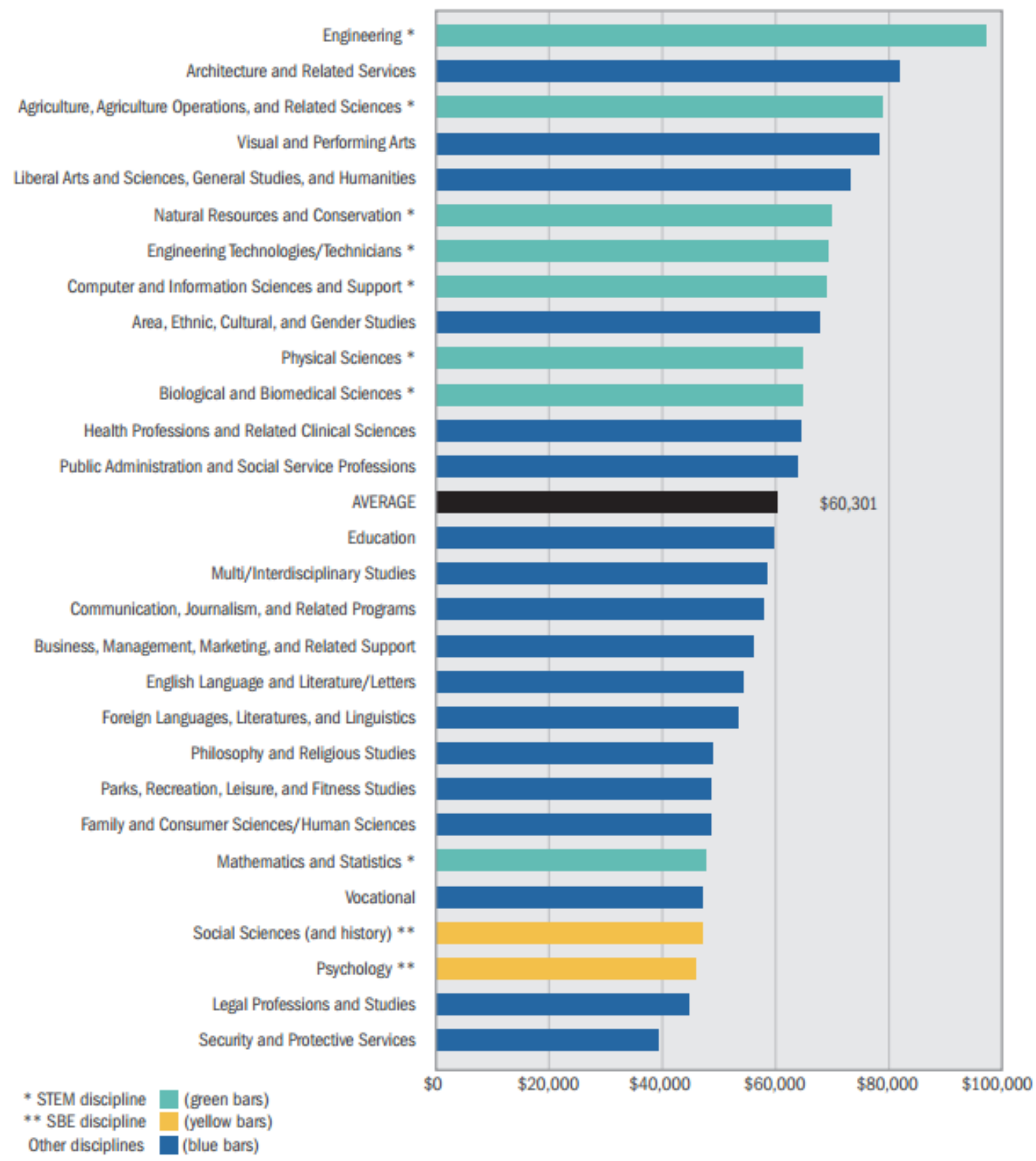

Figure 16. Full attribution cost—education and related spending per undergraduate completion at public four-year institutions, by discipline, 2009. Adapted from "How much does it cost institutions to produce STEM degrees?," by American Institutes for Research, Center for STEM education \& innovation, 2013, p. 2. 
This raises the question how the differential tuition practice since the 1980s is likely to be sustainable based on the argument to alleviate the cost of production associated with STEM-related majors. Jaschik (2013) sees that it tends to be more directed to programs like engineering and nursing. The realization that the U.S. economy can be strengthened to the extent that federal government funding provides for the development of a strong and educated workforce able to compete with other nations is essential, however it will be harder to assert of those needs when reliable and consistent data are lacking in order to clearly identify and quantify STEM jobs.

The immigration of STEM workers. Hira (2010) notes that legislators are focusing persistently on the lack of supply while immigration policies need to allow for more foreign workers. Just as Salzman (2013) referred to the entanglement between the labor policy and the immigration policy, he also speaks of the 'push' and 'pull' drivers of immigration, but in a slightly different way Hira (2010) does, who points out at "the burgeoning opportunities for STEM workers in India and China” (p. 957), which could greatly affect the flow of STEM workers that the United States has been increasingly depending on to drive its economic strength in absorbing and creating new technologies. Galama and Hosek (2008) state that the proportion of non-U.S. citizens with a bachelor's degree and above nearly doubled between 1994 and 2006, reaching almost a 13-percent share of the science and engineering workforce (Figure 17). 


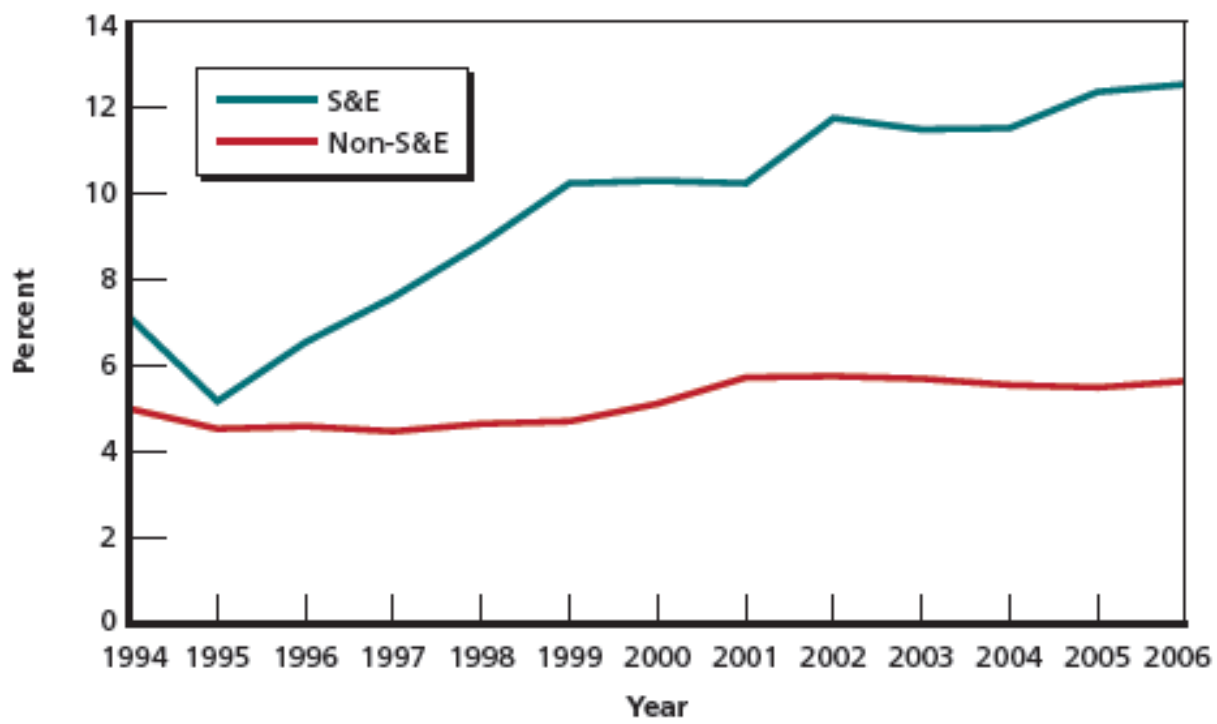

Figure 17. Percentage of non-U.S. citizens (bachelor's degree or higher). Adapted from "U.S. competitiveness in science and engineering," by T. Galama and J. Hosek, 2008, RAND Corporation, MG674-3.20, p. 101.

Source: RAND analysis of Current Population Survey data

At the same time, the cost of post-secondary education in the United States is "nearly double the amount per student — than the average of other industrialized countries" (Galama \& Hosek, 2003, p. 2). It is nonetheless unclear whether it could indicate potential weaknesses in the fundamentals of science and technology education and workforce in the United States. However, it raises the question whether other industrialized countries have to meet all assessment and accountability requirements that increase the cost of education. In the U.S. education system, student support and remedial education, for example, are other factors that drive the cost of education up.

At the same time, Costa (2013) sees that Microsoft Corporation has gone forward to suggesting having a greater number of temporary and permanent STEM workers in the 
United States because of too few college graduates and with the understanding that only employees with a bachelor's degree in computer science qualify for work in computerrelated occupations. In 2012, there were 5.3 million STEM workers (Figure 18), including both immigrants and U.S. natives - a one-million increase in 12 years (Camarota \& Zeigler, 2014).

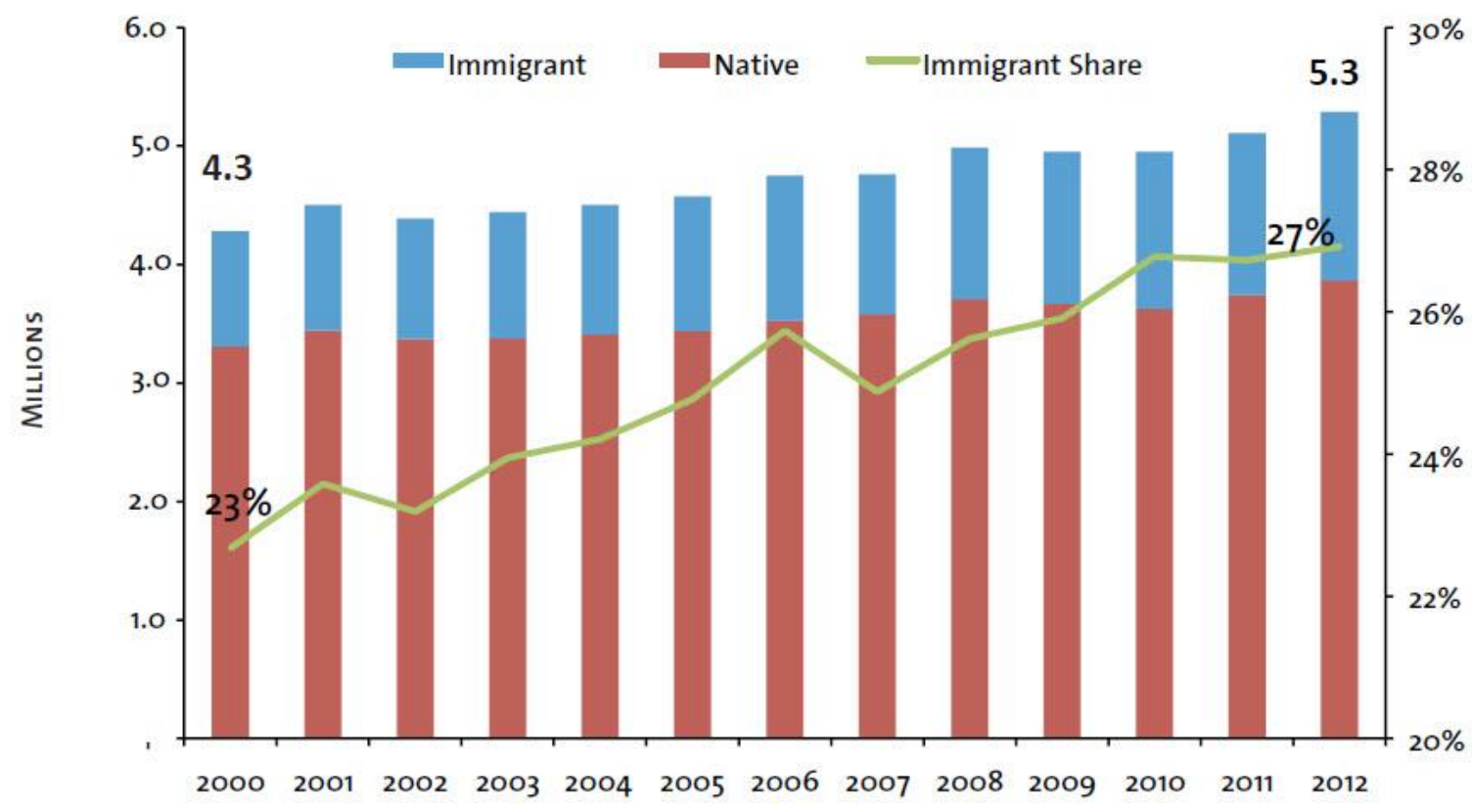

Figure 18. Growth in STEM employment 2000 to 2012. Adapted from "Is there a STEM worker shortage? A look at employment and wages in science, technology, engineering, and math," by S. A. Camarota and K. Zeigler, 2014, Center for Immigration Studies, p.4. Source. Public-use files of the 2000-2012 American Community Surveys. STEM employment is confined to those with a bachelor's degree or higher employed in a STEM field.

Data were reported by the U.S. State Department (2012), which Costa (2012) has seen as the supporting argument that proponents of STEM shortage like Microsoft is using. Still, the total STEM employment growth has only accounted to 53.6 percent 
$(84,000)$ each year since 2000 and yet the number of new immigrants with STEM degrees admitted each year (129,000 on average a year between 2007 and mid-2012) has been exceeding that percentage ${ }^{10}$ according to the American Community Survey (ACS) while U.S.-born STEM graduates account to 115,000 a year (Camarota \& Zeigler, 2014). Therefore, while it seems apparent that "most new immigrants with STEM degrees are not finding STEM jobs" (Camarota \& Zeigler, 2014, p. 5), it is nonetheless surprising when looking at the share of degree holders working in and out of their fields as indicated in Table 4 that "the share of immigrant engineers holding an engineering job is actually lower than natives - 23 vs. 34 percent" (Camarota \& Zeigler, 2014, p. 9) despite beliefs.

\footnotetext{
${ }^{10}$ That said, it makes one ponder the question "why this particular market [today] requires extraordinary measures and why there would be a shortage while all the usual indicators point out that's just to get cheap labor" (H. Salzman, personal communication, September 29, 2015)
} 
Table 4

Share of Degree Holders Working in and out of their Fields

\begin{tabular}{lrrrrr}
\hline \multicolumn{5}{c}{ Natives } \\
\hline & \multicolumn{7}{c}{} & & \\
\cline { 2 - 6 } & & & & & \\
Degree & & & & & \\
& Technology & Math & Engineering & Science & Any STEM Job \\
Technology & $50 \%$ & $1 \%$ & $3 \%$ & $0 \%$ & $54 \%$ \\
Math & $16 \%$ & $2 \%$ & $3 \%$ & $2 \%$ & $22 \%$ \\
Engineering & $9 \%$ & $0 \%$ & $34 \%$ & $1 \%$ & $45 \%$ \\
Science & $3 \%$ & $0 \%$ & $2 \%$ & $10 \%$ & $16 \%$ \\
STEM Degree & $13 \%$ & $0 \%$ & $14 \%$ & $5 \%$ & $33 \%$
\end{tabular}

\begin{tabular}{lrrrrr}
\multicolumn{6}{c}{ Immigrants } \\
\hline \multicolumn{7}{c}{ Occupations } \\
\cline { 2 - 6 } Degree & Technology & Math & Engineering & Science & Any STEM Job \\
Technology & $55 \%$ & $1 \%$ & $4 \%$ & $1 \%$ & $61 \%$ \\
Math & $22 \%$ & $2 \%$ & $3 \%$ & $2 \%$ & $30 \%$ \\
Engineering & $22 \%$ & $0 \%$ & $23 \%$ & $2 \%$ & $48 \%$ \\
Science & $6 \%$ & $0 \%$ & $2 \%$ & $16 \%$ & $24 \%$ \\
STEM Degree & $24 \%$ & $0 \%$ & $13 \%$ & $6 \%$ & $43 \%$
\end{tabular}

\begin{tabular}{lrrrrr}
\multicolumn{7}{c}{ Natives and Immigrants } \\
\hline \multicolumn{7}{c}{ Occupations } \\
\cline { 2 - 6 } Degree & Technology & Math & Engineering & Science & Any STEM Job \\
Technology & $52 \%$ & $1 \%$ & $3 \%$ & $1 \%$ & $56 \%$ \\
Math & $17 \%$ & $2 \%$ & $3 \%$ & $2 \%$ & $24 \%$ \\
Engineering & $14 \%$ & $0 \%$ & $31 \%$ & $2 \%$ & $46 \%$ \\
Science & $4 \%$ & $0 \%$ & $2 \%$ & $11 \%$ & $18 \%$ \\
STEM Degree & $16 \%$ & $0 \%$ & $14 \%$ & $5 \%$ & $35 \%$ \\
& & & & & \\
\end{tabular}

Note. Adapted from "Is there a STEM worker shortage? A look at employment and wages in science, technology, engineering, and math," by S. A. Camarota and K. Zeigler, 
2014, Center for Immigration Studies, p.8.

Source: Public-use files of the 2012 American Community Survey. Analysis confined to those with a bachelor's degree or higher.

The power of lobbying. While lobbyists advocate for more graduates, Camarota and Zeigler (2014) point out that "it would be a mistake to think that the supply of STEM workers is limited only to those who have a STEM degree" (p. 10), considering that the proportion of those working in STEM occupations without STEM degrees is 85 percent native-born and 31 percent of all STEM workers do not hold an undergraduate degree in STEM (Figure 19).

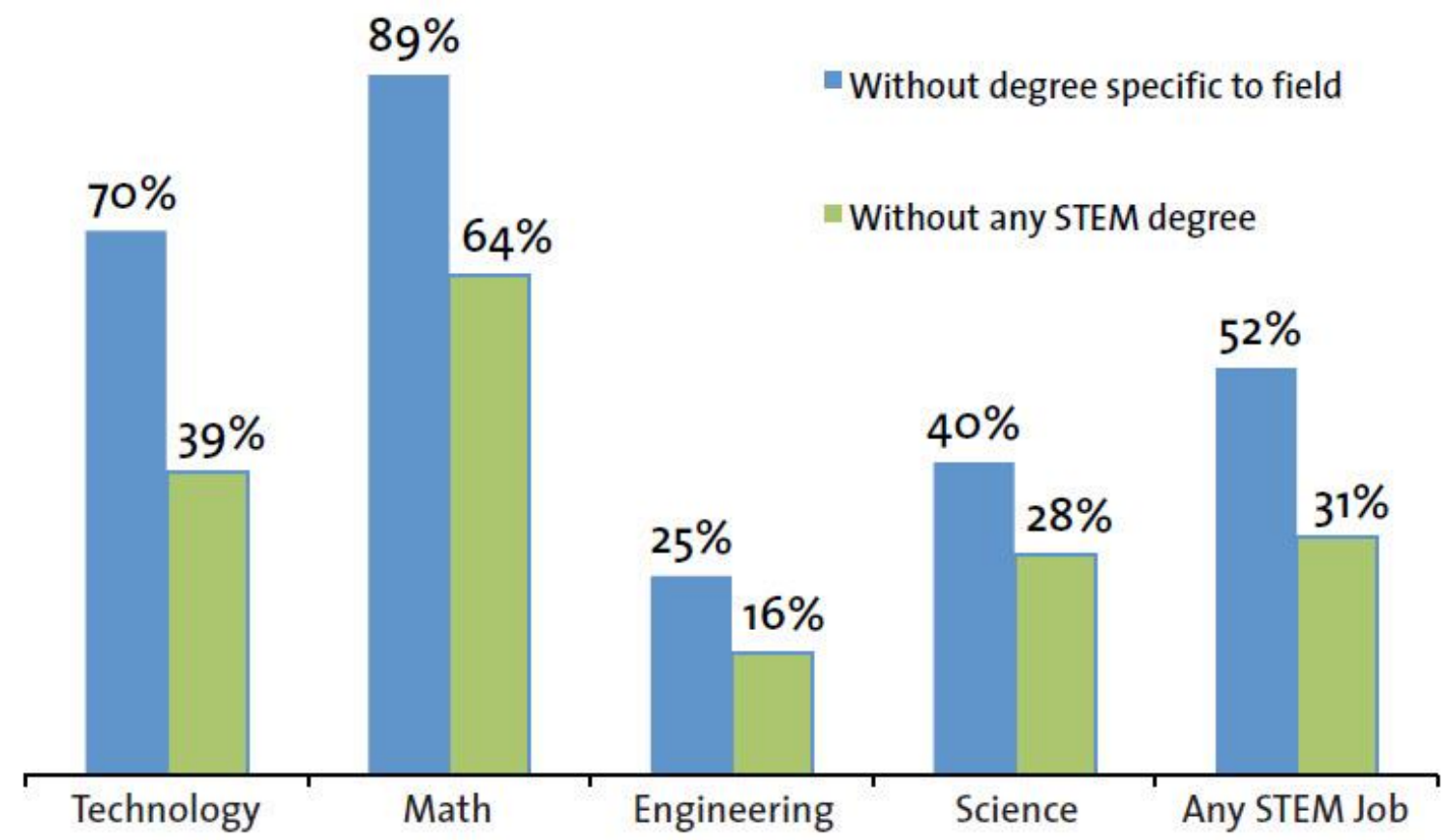

Figure 19. STEM jobs distribution and the question of degree specificity by native and immigrant. Adapted from "Is there a STEM worker shortage? A look at employment and wages in science, technology, engineering, and math," by S. A. Camarota and K. Zeigler, 2014, Center for Immigration Studies, p.10. 
Source: Public-use files of the 2012 American Community Survey. Analysis confined to those with a bachelor's degree or higher.

With this in mind, Microsoft (2012) has had an easy fix by having Congress allocate 20,000 visas a year to match the alleged shortage of STEM skills and at the same time have employers contribute financially to the development of the American STEM pipeline to obtain new visas and green cards in return. Subsequently, the federal government could raise $\$ 5$ billion over ten years should employers charge $\$ 10,000$ for each new STEM H-1B visa and \$15,000 for each new STEM green card (Microsoft, 2012), while alluding to a philanthropic-style distribution of funds to states where STEM education is not as well supported.

In a sense, shortage of STEM workforce is not a new phenomenon and the push by CEOs in lobbying Congress for importing guest workers is still happening. Kuenzi (2008) had already noted how federal STEM education programs tend to incentivize careers in STEM fields at the graduate and postdoctoral levels. The report by National Academy of Sciences (2007) includes a similar language directed toward H-1B workers with the preferential immigration quality that a "doctoral-level education and science and engineering skills would substantially raise an applicant's chances and priority in obtaining U.S. citizenship" (p. 9). Nonetheless, fewer U.S. citizens or permanent residents earned STEM doctoral degrees between 1998 and 2005, just over 13 percent (AIR, 2013), while the underrepresented populations increased slightly by only 15 percent (National Science Foundation, 2008). These data present another mean to fuel the need for $\mathrm{H}-1 \mathrm{~B}$ visa skilled foreign-born scientists and engineers. 
There is a lack of evidence despite current beliefs. Despite decades of federal investments in STEM education, the inadequate evaluation processes of these investments presents an obstacle to collect data to adequately assess long-term student outcomes; the lack of coordination among STEM program and agencies is one additional barrier to evaluate the effectiveness of intended STEM education programs (U.S. Department of Education, 2007). Carnevale et al. (2011) state that, "What is really at stake in the current debate over the existence of quantifiable STEM shortages is an important question regarding a national strategy for sustaining economic innovation in the United States" (p.7).

While STEM contributes greatly to the nation's economic growth, national security and the like (Kelly, Butz, Carroll, Adamson, \& Bloom, 2004), Teitelbaum (2014a, 2014b) reiterates the lack of evidence to support the current belief that there are too few Bachelor's degrees or higher in science and engineering. However, the need for these levels of education is not absolute (Rothwell, 2013). Science and engineering shortages are not clearly justified particularly under the assumption that higher education produces too many science and engineering graduates and that real wages have remained flat. However, this is not the case for petroleum engineering, for example, for which wages have grown, reaching 14.9 percent between 2008-2012 (Camarota \& Zeigler, 2014; Salzman, 2013; Sargeant, 2014) after declining in the 1980s and 1990s (Lynn, Salzman, \& Kuehn, 2011). Just as Teitelbaum (2014a, 2014b) argues, these cyclical periods in history cannot necessarily be reliable indicators to determine labor markets in science and engineering that fluctuate over time across industries. Information technology is a very good example of those fluctuating fields that may be affected by 
offshoring, the import of temporary guest workers or rapid technological changes. However, Carnevale, Cheah, and Strohl (2012) make a point by differentiating "unemployment [rates] between people who invent computer technology as opposed to people who use computer technology" (p. 4), which could help explain higher unemployment for recent college graduates in engineering ( 7.0 percent), computer science and mathematics (7.8 percent) and information systems (11.7 percent). Nonetheless, Teitelbaum (2003) is critical of the claims brought forth by the proponents of shortage in the public sphere, who undermine the analytical rigor that scientists and engineers value as professionals. Understandably so, the reference to the 2003 RAND study noted in Teitelbaum (2003) not only indicates the obsolescence of data referring back to 1999 or 2000 despite the significant changes during the information technology boom of the 1990s, it also discredits the rhetoric of labor shortages, which again needs to account for the heterogeneous nature of STEM made of multiple labor markets and the like. Still, researchers do not find evidence that supports the current belief of a STEM labor market shortage, including proving skills mismatches based on unemployment with data, but again it is important to differentiate the current belief with empirical evidence (Salzman, 2013; Shierholz, 2014; Teitelbaum, 2014a, 2014b). Also, the lack of evidence extends to how federal funding expenditures for research and development are divulged, which could help indicate whether practices and activities in STEM education are efficient and whether a lag in the performance of science and engineering in the United States exists (Kuenzi, 2010; Galama \& Hosek, 2003). Just as the issue of STEM labor shortages dates back nearly 70 years, Killian (1964) was himself calling for more information about manpower utilization so to "[separate our analyses of skills and talents 
from] decisions based on hunches, intuition, or fragmentary data" (p. 24).

The U.S. innovative leadership. Lowell and Salzman (2007) assert that the workforce shortage in the United States may be an impediment for the country to sustain its innovation and technological expertise in the global economy. Between 1950 and 2007, the science and engineering workforce has sustained an average annual growth rate of $6.2 \%$ due largely to increased degree production, fewer retirements and an influx of immigrant science and engineering workers (NSF, 2010). More recent figures show that between 1960 and 2011, the number of workers in science and engineering occupations grew at an average annual rate of 3.3 percent (NSF, 2014b). At the same time, the science and engineering workforce remains nearly the same to approximately 5 million, but it could also be well over 19 million depending on how science and engineering is defined or STEM is in other circles. With that in mind, Hagedorn \& Pursanamari (2012) posit that "most of the reports and statistics are too broad of a picture" (p. 147) to clearly determine whether there is a shortage of STEM. This opinion is further supported by Lowell and Salzman (2007) who do not see a weak science and engineering labor market supply. Although their analysis reflects aggregate numbers, Lowell and Salzman (2007) note that shortages could exist in some specific occupations or industries. This is exactly what Carnevale et al. (2011) argue, that "the rapid growth of STEM occupations as a group masks marked differences in growth among particular STEM occupations" (p. 19), reiterating the adequacy of science and engineering graduates. However, it makes one wonder how an adequate representation of science and engineering graduates could impact the capacity for the U.S. to innovate within a global market.

Essentially, the U.S. innovative leadership in science and technology should not 
be taken for granted, which would align with the need to increase enrollments in STEM education programs, for example, to boost the supply of STEM workers. However, the belief that there is a need to increase enrollment in STEM education is a bit more complicated to explain, particularly when Atkinson et al. (2010) describe it as a means to incentivize innovative policies that could pay for themselves. Based on the argument that the American Competitiveness and Workforce Improvement Act (ACWIA) would enforce a fee based on the number of $\mathrm{H}-1 \mathrm{~B}$ visa holders per American company, it represents a means to an end in that it would generate a revenue stream of $\$ 73$ million based on the current annual cap of $65,000 \mathrm{H}-1 \mathrm{~B}$ visas in the United States. Although the number of STEM doctoral degrees has declined by 13 percent between 1998 and 2005 (Poirier, Tanenbaum, Storey, Kirshstein, \& Rodriguez, 2009), Atkinson et al. (2010) do not seem confident the United States could meet its high skilled STEM needs, therefore they advocate for the provision of highly-skilled foreign graduates, who could help boost the American innovation and competiveness. Although the report by NAS (2007) indicates a strong sense of national pride, it nonetheless asserts that the United States needs to not be complacent and resume its commitments to education, research and innovation policies.

\section{Summary}

Scientists and researchers are at the core of the knowledge economy. The beliefs that the United States can sustain its competitive edge within the global marketplace have raised many challenges for higher education as the current political discourse is to produce more STEM workers. However, it is wonder if graduating more STEM workers would stimulate labor demand and solve the unemployment crisis (Shierholz, 2014). 
Although this phenomenon is not new -it dates back to the Cold War- the push by corporations supported by industry and lobbyists, for example, seems to focus mainly on the mythic supply side and may not necessarily account for the time to train up-to-date skilled workers to match industry demand in light of rapid economic and technological developments. Besides the heterogeneous nature of STEM fields, it seems that the shortterm solution is to import guest workers and at the same time boost enrollments in STEM education programs to remedy the STEM labor shortage in the United States, discounting any future repercussion on new graduates. These claims could also produce an adverse effect and deter people away from being inspired to becoming scientists. It forces us to ask how this approach could help sustain higher education in generating human capital and the American economic innovation in meeting the long-term needs for high-skilled STEM workers. Although, many scientists in the history of the United States have been foreign-born (Reingold, 1979), there is nonetheless a lack of evidence today supporting a political discourse that a STEM shortage exists and that the United States must import more H-1B workers despite decades of federal investments in STEM education.

\section{Conclusion}

The rhetoric of STEM workforce shortages in the United States has a direct impact on scientific and technological innovation and education. Reflecting on Teitelbaum (2014a, 2014b), who demonstrates how workforce shortages in science and engineering had been claimed to be critical, intermittently since World War II, the discourse based on economic principles of supply and demand remains true despite the fact that the focus tends to be more on the production of supply, fueled from educational systems. As federal investments in STEM programs and initiatives aim to expand a 
STEM talent pool in the United States, it remains to see whether STEM education is well connected with the demand of a high-skilled STEM workforce in different sectors of the American economy. Historically speaking, Australia has not had as strong of ties with industry compared to the United States and Germany has been known for its Fachhochschulen, which are more closely integrated with professional occupations and the needs of industry. Although fewer investments are allocated to higher education systems and research initiative in Australia and Germany compared to the United States, "the ultimate test of the success of STEM [or MINT] policies is whether or not the education and training systems produce enough skilled people to meet future overall labour force needs" (Dobson, 2015, p. 10). In sum, the issues at stake are whether sufficient information about future vacancies is made available to best assess demand and the adequacy of the supply.

More recent reports have demonstrated that the U.S. is falling behind and losing its edge in science and technology, yet it forces us to ask what it means and if the rhetoric reflects the real situation. At the same time, the situation of science and technology in Australia and Germany and how those two countries can serve as a frame of reference to best identify what the discourse is about once placed in the global setting may help provide some perspectives about the situation in the United States. As Killian (1964) had made the point that from the perspective of "a research-reliant society", the interrelation between science and government remains important, and just as governmental funding contributed to the NDEA to better science, mathematics and technology educational programs, it remains essential that the United States has a clear vision for STEM education and a cohesive and consistent understanding of what STEM 
means when articulated in a federal policy discourse. 


\section{CHAPTER V}

\section{CRITICAL REVIEW OF THE STEM SHORTAGE DISCOURSE}

\section{IN AUSTRALIA AND GERMANY}

This chapter includes the major elements that place both Australia and Germany as frames of reference in the study. The terms of reference provide a general understanding of the rhetoric of STEM (MINT or Mathematics, Information Technology, Natural Sciences, and Technology) shortages in both countries, and describe how the rhetoric (or narrative) about STEM (or MINT) in higher education come into play within the social and economic context of each country.

In light of the current rhetoric of shortages of STEM workers in the United States, a relatively similar situation exists in both Australia and Germany. The rhetoric that surrounds skills shortages in STEM or MINT fields in Australia and Germany, respectively, are seen as growing concerns, marked by the lack of adequate qualifications and the need for education to focus more on the sciences. In both instances, the innovative workforce and adaptive capacity generated by those areas of expertise are a priority to guarantee a future economic prosperity in the competitive global knowledge economy. 


\begin{abstract}
Australia

\section{Introduction}

The creation of the Australian National University as a research institute in 1946 had marked an important step in Australia's history as a contributor to the world's knowledge. Despite the weak support by the business sector investors in higher education and research, Australia ranks as the third largest exporter of higher education after the United States and the UK (Marginson, 2003). Beyond the commitment toward education and training, Australia seeks to position itself on the global stage to compete in the emerging economy and for that, it will need to be a leader in the formation of an Asian-
\end{abstract} Area Research Zone (Office of the Chief Scientist, 2014). Needless to say, Australia recognizes that government funding of science, mathematics and engineering education is a key priority for the nation's future (Office of the Chief Scientist, 2012a).

In the mid-1980s, the Australian government had begun to focus on microeconomic reforms, particularly by stimulating knowledge intensive exports. It is then that education, training and research regained policy interest. With the proximity of the South Asian market, Australia holds a significant advantage for business in that part of the world. However, the national drive to operate internationally necessitates a strong human capital in STEM skills. However, political debates and industry groups are expressing the difficulty to recruit qualified STEM labor. They have also engendered tensions in Australia around the immigrant labor force, when claims about STEM shortages may not always be substantiated empirically, or may not account for the development of graduates and their integration of new entrants into the STEM workforce. 


\section{Placing STEM in Context}

As indicated in the Office of the Chief Scientist (2013), the Australian

Government foresees a different Australia by 2025, where STEM would play a major role in addressing the nation's economic and social dimensions, at least. Australia wants to expand its capacity to increase knowledge and skills in the global economy. Marginson et al. (2013) argue that "Australia is relatively strong in participation in the sciences but weak in mathematics and engineering" (p. 17), with "a large workforce in health services and a small workforce in manufacturing and the engineering profession" (p. 30). With that said, Panizzon, Corrigan, Forgasz, and Hopkins (2015) reflect on how ambiguous the delineation of STEM is in Australia. At the same time, Benderly (2015) reflects on what Deborah Corrigan, associate professor at Monash University says about the definition of STEM and how flexible the definition can be adapted to serve one's political agenda.

In another instance, and while mathematics and basic sciences may be foundational knowledge to several STEM-based occupations, including health and other applied life sciences (Marginson et al., 2013), these occupations are part of the STEM definition. Although it would be important to agree on a definition of STEM in order to compare STEM skills shortages on a commonly understood framework. Panizzon et al. (2015) state that "the inclusion or exclusion of medicine and the health sciences in the field of STEM varies in Australia” (p. 72). The same would apply with non-university pathway STEM professions, such as vocational level qualifications (AiGroup, 2015; Panizzon et al., 2015). With respect to the definition of STEM proposed in Chapter IV on the United States, Healy, Mavromaras, and Zhu (2012) defines a 'STEM-qualified' person, one who holds a Bachelor Degree level or higher in one of the [following fields: 
natural and physical sciences, information technology, and engineering and related technologies]" (p. 2).

In 2010, a new Skills Occupation List (SOL) was developed by the Skills Australia, now known as the Australian Workforce and Productivity Agency (AWPA), located in the Department of Industry. The SOL was created for the Commonwealth government's Department of Immigration and Citizenship General Skilled Migration Programme. Although the SOL is supposed to identify skills confined to occupations that are in a short supply nationwide, occupations like accountants and IT professionals are still on the list despite being in oversupply (Birrell \& Healy, 2014). Inconsistencies in the delineation of STEM occupations occur with the type of discipline, as they do with the type of education as well. Surprisingly, technology is not included in the secondary education sector, which includes mathematics, physics, biology, chemistry, geology and earth science (Panizzon et al., 2015). At the university sector, health professions (i.e., medicine and nursing), architecture, agriculture, and computing may be added to the list in the secondary sector (Panizzon et al., 2015).

While it is important to point out how common those inconsistencies are, including the degree level in reports from the United States, they hinder the reliability and substantiation of statistical reports to appreciate and compare what is happening about STEM shortages. Panizzon et al. (2015) assert that "unless the specific areas of need are clearly communicated to the populace and stakeholders, the government and industry rhetoric that there is a shortage across the board does little to address any 'real' gaps that very likely exist in the STEM workforce" (p. 73). With that said, Richardson (2007) sees that "it is in the interest of [unions and employers] to exaggerate the problem 
of shortage" (p. 27).

\section{Major Tenets}

How is the discourse framed? In essence, the STEM policy framework revolves around the economic principles of supply and demand. While new STEM graduates must increasingly compete with professional migrants sponsored by employers under the 457 visa program, Birrell (2015) sees that the problem is not so much about science and engineering as it is with IT. As Australia aims to be more competitive globally, including in hi-tech fields, the Coalition Government is not addressing the pressing needs to create high value-added companies in Australia, making it very difficult for the nation to compete with hi-tech giants on the global stage, given that Australia only has a very small corporate base (Birrell, 2015). Nonetheless, there are differences in opinion that are disputed by researchers, governmental entities, university leaders, and industry as to whether shortages in STEM workers exist, particularly as the immigration policy plays out an important role in providing a cheaper labor in IT, for example. With that said, the Department of Employment reported in 2014 that there was no shortage of IT professionals in Australia.

Professor Brian P Schmidt FAA, who was awarded the 2011 Nobel Prize in Physics jointly with Adam Riess and Saul Perlmutter, argues that Australia needs to grow a new sort of business landscape able to compete with hi-tech giants on the global stage (Birrell, 2015). In Rahn (2013), Professor Brian P Schmidt FAA says:

Part of Australia continuing to succeed in the rapidly evolving world of science and technology is looking beyond our borders to work cooperatively with colleagues overseas. Increasing our overseas linkages allows Australians to augment their knowledge and skills to help make Australia even more competitive on the world stage. (p. 12) 
This vision seems sensible, given that Australia still does not have a coherent national strategy to establish a constructive STEM framework (Braue, 2015; Marginson et al., 2013), which would help concretize the agenda set forth by the Office of the Chief Scientist. In April 2015, the federal government expressed that it has committed to do so (Monto, 2015). Arguably, STEM had already been firmly placed on the political agenda by Professor Ian Chubb, Australia's Chief Scientist, as reported in the Health of Australian Science (Office of the Chief Scientist, 2012a). More specifically, the chief scientist released his recommendations for a strategy in science and technology in September 2014. Nevertheless, funding of the Australia's national science agency, the CSIRO has been reduced by the Coalition in the past two years as well as its universityindustry program (Monto, 2015). While the CSIRO, that supports education and outreach programs, in part will be getting AUS $\$ 70$ million over ten years to support starts-ups (CSIRO, 2015), it may explain why the Coalition Government sees that "the best thing it can do for Australian enterprises is to reduce government intervention (as with red tape and restrictive environmental and labour market rules)" (Birrell, 2015, para 23). Despite the cuts in Australian scientific research, the Australian Academy of Science (2015) clearly states that it is a must to invest for more tertiary education and training in STEM in order to ensure Australia's economic and social prosperity.

In sum, "adopting technological innovation to develop high-value products and services for a global market" (Bell et al., p. 34) will be an essential step for Australia to take. The emergence of Asia as a global innovation hub has created the thrust for Australia's STEM economic policy agenda to lift the general quality of the supply of human capital (ACOLA, 2013a; Marginson et al., 2013) to respond more effectively to 
the large investment Asia is making on STEM training, particularly in the engineering and IT fields (Birrell, 2015).

\section{Economic concepts.}

Supply. In Marginson et al. (2013), the intent had been to produce possible lessons and ideas for STEM policy and strategy in Australia. The body of the work comprises a wealth of data derived from 23 specific reports. By and large, the consultants did not indicate conditions of a general shortage in the Australian STEM labor market. Although there are 'episodic' shortages, such as in engineering and computing (Marginson et al., 2013), there are no clear indications of the specific areas in need. The Australian Government, Department of Employment (2015) reports that "shortages of technicians and trades workers are more prevalent than those for professionals" (p. 1; Figure 20).

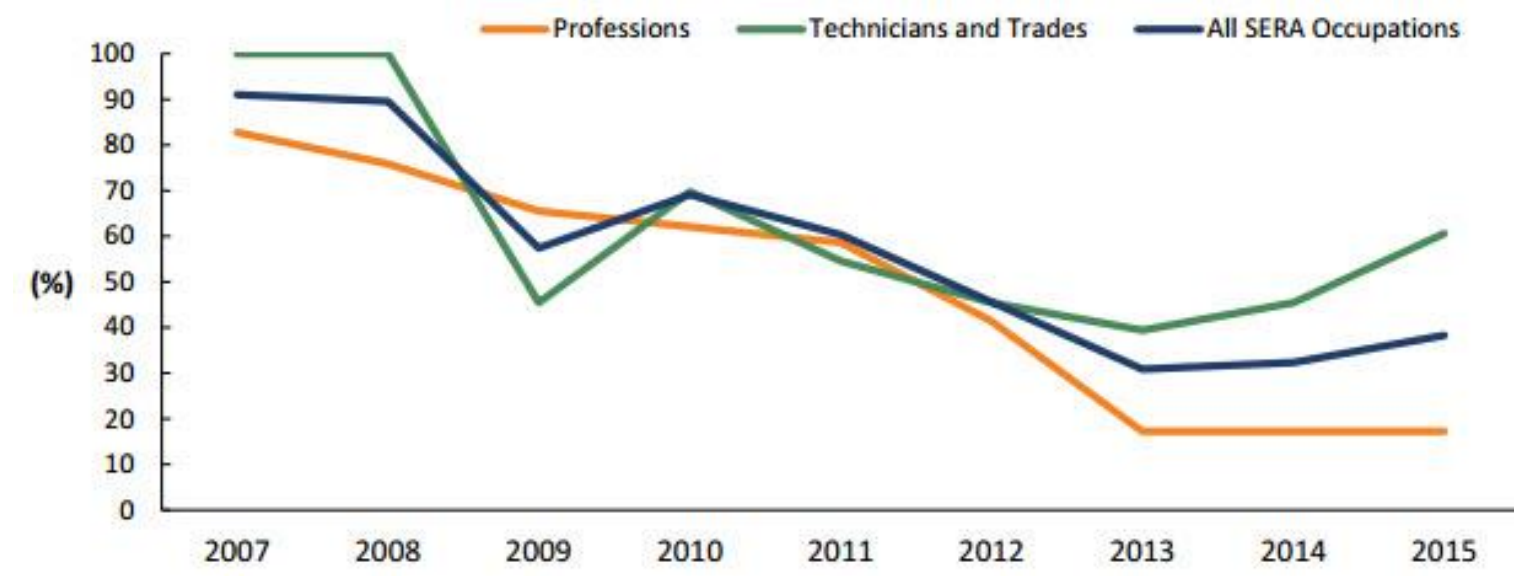

Figure 20. Proportions of assessed occupations in shortage, Australia, 2007 to 2015 (\%). Adapted from "Skills shortages -Statistical summary," by Australian Government, Department of Employment, 2015, p. 2. 
Source: Department of Employment, skill shortage research, based on a set of around 80 assessed occupations.

Along the same lines, Benderly (2015) reports on confusing data, when it can sometimes be difficult to account for changing conditions such as the representation of STEM subjects studied at a particular level. For example, studying a double major is not unusual; however, to clearly determine which degree is recorded can be problematic in survey data. Birrell (2015) states that "at [the] university level,...data [are] almost impossible to gather" (para 2). STEM skills can be used in a variety of occupational sectors. In 2010-2011, it was estimated that 2.1 million workers in Australia had STEM qualifications (Australian Bureau of Labor Statistics, 2014). More specifically, the number of STEM qualified individuals with Bachelor Degree or higher in Australia in 2011 was 651,000 . Of the total Australian workforce, people with STEM qualifications accounted for 18 per cent (Bell et al., 2014). By excluding health sciences from that group, it would lower the number of STEM qualified individuals by 20 percent.

In a sense, the situation is not any different for Australia as it is for the United States. The adaptability and transferability of STEM competencies to non-STEM is well known for several reasons, and for a relative part, economics (Marginson et al, 2013, Carnevale, et al., 2011). Another cause of skills shortages is attractiveness to STEM fields and how several factors can push new graduates away, particularly when professional migrants are hired in place of new entrants for a lower wage. In line with the inconsistencies Panizzon et al. (2015) are referring to and how these are portrayed across the political landscape, Bell et al. (2014) note that some of the difficulties, businesses have had to recruit Information Communications Technology (ICT) specialists may 
coincide with the drastic decline in domestic IT undergraduate enrolments since the peak in 2002 at 37,000 compared to the low of about 19,000 in 2008 . The decline has slightly recovered since 2008, yet the Department of Education (2015) for the first half year indicates a lower number ( 0.4 per cent) in commencing students in IT, compared to the 2014 first half year.

Demand. Most often, the rhetoric about STEM shortages revolves around the lack of supply rather than the lack of demand. For example, the need to lift the supply of human capital is a clear imperative (ACOLA, 2013). While the lack of demand can be assessed from the perspective of skills mismatch, the deployment and utilization of STEM graduates' human capital by industry is not readily apparent from the data (Marginson et al., 2013). Marginson et al. (2013) see that "the manner in which, and the extent to which, graduates' human capital is utilised at work, industry by industry, in the short- and long-term - remain largely a 'black box' for research" (p. 126). With that said, Australia would need to better collect information about "the uses of STEM knowledge and qualifications in Australian labour markets.... [and] description of the STEM-trained workforce in teaching than the census data provide" (Marginson et al., 2013, p. 133).

\section{Market indicators.}

Wages and unemployment rates. While the shortage of STEM skilled workers is raising concerns about the prosperity and competitiveness of Australia in an emerging global economy, STEM skills are in demand in several other sectors of the economy. Essentially, agreeing on a common definition of STEM must be taken into account in the reporting of data, whether to be inclusive or exclusive of certain occupations. In short, the drive to increase levels of education seems to be a response to meeting demand for 
STEM skills and expertise in fast growing occupations and emerging industries (Bell et al., 2014). Associated with STEM skilled workers, who choose non-STEM employment because of higher wages, other skills may certainly apply, known as 'soft skills' (Cappelli, 2015) or "general business skills" (Bell et al., 2014).

It is common currency that wages increases are an important measure of labor demand. Interestingly, the full-time mean weekly earnings in main jobs - and in this case Engineering, ICT and Science Technicians - exceeded (16.7 per cent), the national average, (15.9 per cent) between 2007 and 2011. However, ICT professionals showed a percentage change of only 9.2 per cent for the same period (Healy et al., 2012). Although Bell et al. (2014) note that these data may have suggested that there was no systemic shortage in those skill sets, the aggregation of data could affect results, highlighting the challenge of conflicting data. Coincidentally, this period tends to correspond to the drastic reduction in domestic students studying ICT (Bell, et al., 2014), but also corresponding to when the SOL was developed. Panizzon et al. (2013) confirm lower salary levels and vacancy rates for those professional occupations as well, except for mathematics. More recent data by the Australian Bureau of Statistics (2015) show that average weekly ordinary time earnings for full-time adults in information media and telecommunications were almost similar to earnings of professional, scientific and technical services. However, there are greater differences when comparing earnings between genders. Data show that earnings for males and females in information media and telecommunications vary from AUS $\$ 1,853$ to AUS $\$ 1.459$, respectively. Even more so, for professional, scientific and technical services, earnings vary from AUS \$1,939 to AUS \$1.465 (Australian Bureau of Statistics, 2015). 
Similar to the United States, Marginson et al. (2013) see how non-STEM employment could have some implications for Australia, in that the opportunities STEM competencies can offer and how they can be used are not limited to STEM occupations only. Within this process of diversion, STEM skills can extend to other fields, but it is to wonder how it will play out for Australia's STEM labor market, where declines in the participation in mathematics and science appear to already be a concern for the government and the industry. Putting two and two together, it could lead to imagining a shortage in the available workforce with STEM-related competencies, sometime (Marginson et al., 2013). The analysis by Li and Miller (2013) based on data from Graduate Destination Surveys from 1999 to 2009, completed by recent university graduates shows that "natural and physical science graduates ... earn[ed] about 5-6 per cent less than their peers who studied management and commerce" (p. 22).

In terms of unemployment rates, results from an analysis of 2011 data from the Australian Census indicated high employment rates (81 per cent) for STEM graduates or a relatively low unemployment rate (4 per cent) compared to graduates from most other disciplines (Marginson et al., 2013). Similar data were reported by Bell et al. (2014).

Demographics. This is a workforce issue of common concern in Australia, and the role of women in STEM workforce in Australia remains a problem. Their participation, along with under-represented populations and even seniors, could be a driver of innovation. The STEM-qualified population is much more male-dominated and even more so in engineering and related technologies (92 per cent) and information technology (75 per cent), while the representation of women is greater in non-STEM fields (60 per cent) (Australian Bureau of Statistics, 2014). At the tertiary level in 
Australia, men outnumber women in mathematics, statistics, sciences (particularly physics), engineering, manufacturing, construction and computing (Marginson et al, 2013, p. 136), while women are over-represented in health disciplines (almost 80 per cent) (Freeman, 2015).

\section{Political Framework}

Industry. When a shortage of skills is likely to hamper the quality of the workforce that companies depend on for productivity (Richardson, 2007), effectiveness of training in the workplace is critical to ensure that companies have a capable workforce. In light of a shortage of skilled labor, the SOL appears to purposefully meet the medium to long-term skill needs of the Australian economy (Australian Government, Department of Education and Training, 2016). While the industry can benefit from skilled migrants, employers are inevitably resistant to train since they can recruit highly employable skilled workers from abroad, particularly through the 457 Visa Program and not have to train graduates. However, what appears to be convenient for industries could be damaging to sustain Australia's STEM workforce. In light of the ICT work being relatively universal around the world and the added value it brings to the Australian economy, it is to wonder what would happen if the migrant labor were to decide to work elsewhere for greater opportunities. Besides, what happens to the domestic labor, including women and underrepresented populations, and where are the incentives for Australian students, including low socio-economic status students, to study STEM disciplines?

Lastly, under the Dawkins government, the plan had been to increase universityindustry partnerships to build stronger ties with businesses and to become more prominent in a national innovation policy. To that effect, Minister of Education 
Christopher Pyne announced the funding of 252 new research projects in July 2015 (AUS $\$ 86.9$ million) (Australian Government, Australian Research Council, 2015). It is a positive initiative since collaborative partnerships between businesses, universities and government in Australia has ranked low amongst OECD nations.

Immigration. While the rhetoric could sometime resemble a political game in the United States and when claims are made for lower wages and more visas for foreign workers (Anft, 2013), "there is an imperative for industry [in Australia] to demonstrate they cannot get workers locally before visas can be approved" (Benderly, 2015, para 6). In reality, the Australian Government has chosen to maximize the nation's growth potential by attracting more STEM graduates to the Australian labor market and not cap the number of 457 visas issued to IT professionals and managers, for example, (Birrell, 2015). Between 2013 and 2014, 8,482 visas were issued to primary applicants under the 457 program (Birrell, 2015).

Similar to the United States and Germany, offshoring companies for IT workers operate just the same in Australia. Global information technology consulting companies such as Cognizant, Tata and Infosys, for example, operate in those nations. Infosys partners with General Electric. Greythorn is another staffing agency that serves healthcare IT and big data industries. With that said, news reports question the reliance of ICT immigrant workers, who are serving as currencies, answering the short-term skills gap in the technology 'global game' and 'war for talent' (Aynsley, 2015, para 14).

Programs, participation and STEM in society. Similar to the United States with the COMPETES Act, for example, many other countries have at least one thing in common, the need to invest in more teachers of STEM education (Office of the Chief 
Scientist, 2012b). The same debate is true in Australia. However, the report by Marginson et al. (2013) indicates that the number of mathematics and science teachers trained each year is unknown; "What is clear is that supply is insufficient" (p. 17). More of the report indicates a dearth of data on the qualifications of teachers of STEM (Marginson et al., 2013). This phenomenon is concerning on several levels, because it hinders the identification and appreciation of the values and roles of education and training associated with the learning of (new) skills.

The participation of students in STEM fields is one other concern in Australia, and to make things more complicated, controversial data are being reported about enrollments in those fields. Panizzon et al. (2015) point out intriguing pieces of evidence that seem to indicate serious discrepancies between researchers' studies and government documents. Arguably, a shortage in STEM skilled workers could impede Australian employers' productivity and competitiveness. While there is the widespread belief that only talented students in STEM disciplines, like science and mathematics, are able to study those disciplines (Marginson et al., 2013), Panizzon et al. (2015) reflect on the reports that have been feeding the notion of "the impending demise of industry due to a 'STEM shortage' of graduates" (p. 71). Even though STEM is heterogeneous in its nature and its representation (Freeman, et al., 2015; Xue \& Larson, 2015) data on participation rates do not match. Government reports have led the public to believe on the continuing declines in enrollments in Year 12, however Panizzon et al. (2015) show that enrollments for Year 12 science students in Victoria have increased from 2010 to 2012 in all the sciences. Similarly, other data show that enrollments have not stalled, indicating a 10 per cent increase in engineering and related technology and a mere one per cent in natural 
and physical sciences between 2009 and 2013 (Birrell, 2015). Justifiably, these years correspond to "the abolition of domestic full-fee paying undergraduate places" (Parliament of Australia, 2014) by the Rudd-Gillard Labor Party government. Besides changes in higher education policy over time, Bell et al. (2014) see that more can be done to increase the domestic supply of ICT specialists, including women, not only about enrollments but also about the completion of ICT-related disciplines. In the 2013 PMSEIC report one major attribute of national strength in STEM is to provide an education in mathematics and science at all levels of the secondary sector (ACOLA, 2013b). However, Australia does not have compulsory focus on disciplinary content (Office of the Chief Scientist, 2013). To some extent, "Why complete a science subject if not required for university entrance" (Panizzon et al., 2015, p. 72)? To that effect, Minister of Education Christopher Pyne is trying to push a plan for making mathematics and science compulsory in Year 11 and 12 (Cook, 2015). This initiative would align with the broader engagement from the Australian government to raise scientific literacy (Marginson et al., 2013), which would require public debate to understand why STEM matters in order to undertake the challenges of the global knowledge economy ${ }^{11}$. Based on OECD (2013) statistics, Australia performs below the OECD average for tertiary new entrants in engineering, manufacturing and construction (9 per cent). In other STEMrelated fields of occupation, the distribution of new entrants is relatively the same, with sciences ( 12 per cent), physical sciences ( 2 per cent) and computing ( 4 per cent) (data on mathematics are not reported) (OECD, 2013).

\footnotetext{
${ }^{11}$ Although STEM policies are also critical to P12, this policy analysis does not concentrate on this level of education.
} 
Lack of cogent data. Based on the extensive report by Marginson et al. (2013), "Australia collect[s] information on the broad sectors where graduates by discipline are employed, the practical relationship between education and work, especially the deployment of skilled labour in the workplace" (p. 126). The notion that data cannot necessarily be substantiated seems contradictory to what the intention might be, to identify and communicate gaps in order to justifiably establish education policies. Dobson (2015) asserts that "it is extremely difficult to measure the long-term impact of any reform or group of reforms" (p. 4). Nonetheless, occupations are represented differently, for example, the category of natural and physical sciences is very broad while information technology is relatively focused.

Funding and higher education. Funding of higher education by the federal government in Australia has fluctuated over the years since 1951. While Australia is foreseeing the growing dependence on knowledge and innovation globally, the Australian Government has committed AUS \$54 million to mathematics, engineering and science in light of harnessing STEM in its advantage (Australian Government, 2012b). With that said, reflecting on the inconsistencies in defining STEM across educational sectors, Panizzon et al. (2015) note "that in 2011, the Australian government provided additional subsidies to the field of natural and physical sciences even though graduates had a high probability of over education" (p. 73). Aside from that, the Australian Government invested close to AUS \$9 billion in research and innovation in 2012-2013 through a suite of 79 programs across 14 portfolios (Parliament of Australia, 2014; Figure 21).

In the case of Australia, the neo-liberal agenda has had a greater influence on its higher education policy landscape, which has changed the academic culture making 
universities more vulnerable to corporatization to respond to their increasing role as an exporter of higher education (Pick, 2008). Australian higher education has been faced with recruitment challenges, in part due to the increased casualization of academics, associated with more difficult working conditions in response to global competition (Bradley et al., 2008; Freeman, 2013).

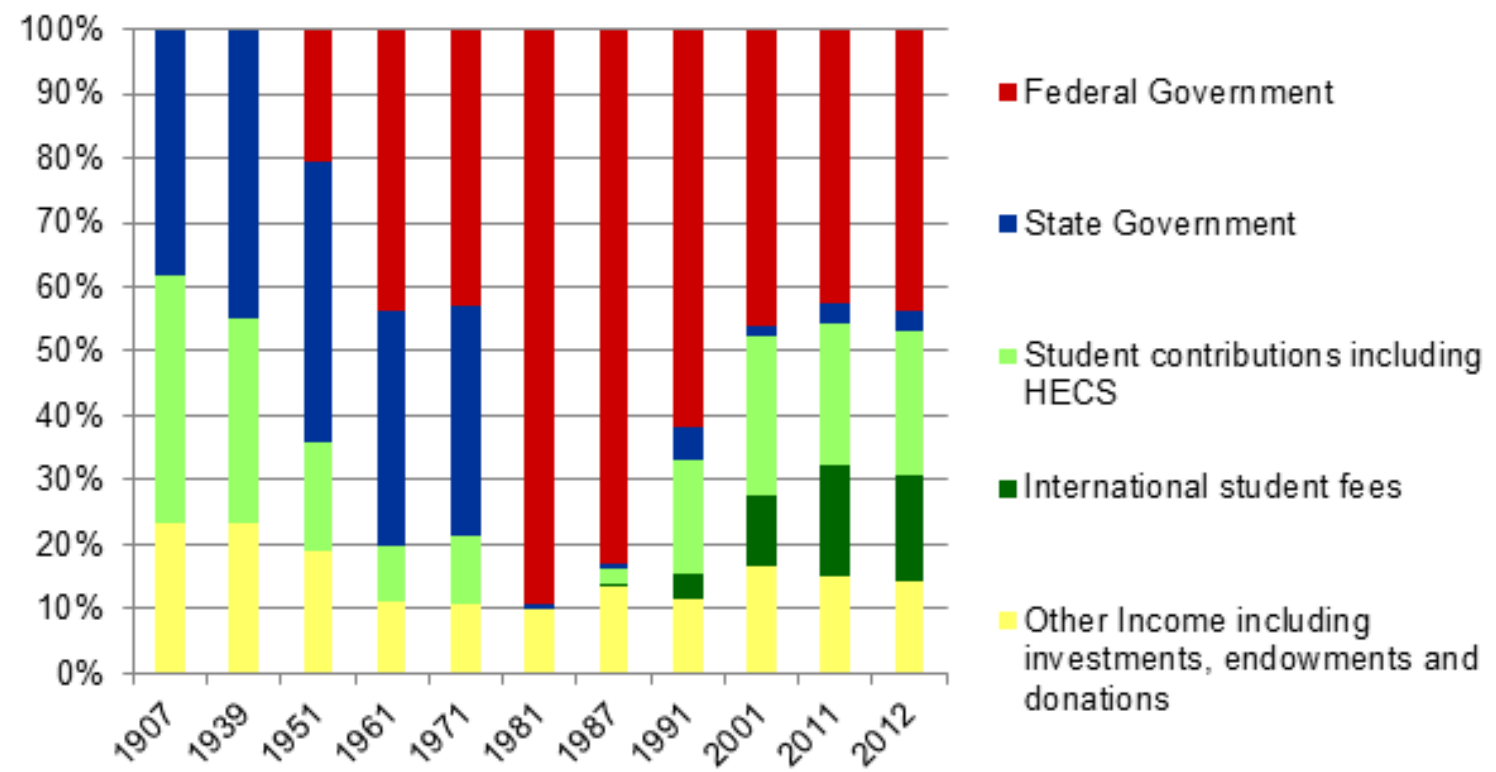

Figure 21. Higher education revenue by source, 1907-2012. Adapted from "Education and Employment Legislation Committee," by The Senate, Higher Education and Research Reform Amendment Bill 2014, 2014, Chapter 2.

A perspective in 'smoke and mirrors' down under. The rhetoric about STEM shortages in Australia exists just as it does in United States and Germany. The public may hear different viewpoints about how industry cannot fill positions; nonetheless Deborah Corrigan, associate professor at Monash University, tells in the Science journal that "much of it is to do with industry acting as consumers of graduates rather than investing in the education process for both the education system and their own workforce" 
(Benderly, 2015, para 5). Basically, the current 'smoke and mirrors' (Benderly, 2015;

Panizzon et al., 2015) may not be going away anytime soon without a common analytical framework that could help determine a clear definition and consistent data about STEM despite political and economic agendas.

\section{Summary}

Observations seem to indicate a lack of perspective in Australia at the moment that is taking away the drive for entrepreneurship, for example. Australia has an economic imperative in advancing STEM. The Australian educational system does not seem to match the imperatives set forth by the Australian Government about the role of STEM education as well as industry groups, such as the Australian Industry Group, which is strongly advocating for more graduates at all levels, guaranteed by an increased quality of STEM graduates to prevent the national economy from being held back (AiGroup, 2015).

In the final report by Marginson et al. (2013) about Securing Australia's Future, it is noted that "[Australia] lacks the national urgency found in the United States, East Asia and much of Western Europe, ...” (p. 12). It leads us to wonder about the strategies Australia is envisioning to address anticipated shortfalls that are temporarily answered by short-term visa programs. A commitment to advancing STEM will be needed in addition to making the necessary investments in education, training, research, and to "increase ... the share of human resources in science and technology" (Office of the Chief Scientist, 2013, p. 9). 


\section{Introduction}

\section{Germany}

The importance of science and technology in Germany has rallied professionals and politicians in the public discourse. In light of public debates that revolve essentially around labor shortages in MINT fields, the rhetoric has led to differences in opinion among researchers, organizations and political establishment. As several countries in Western Europe have directed their focus on STEM policy, it is critical for Germany as a nation with a strong industrial core that is internationally competitive. However, it has also been noted that "European policy-makers have so far been tardy to recognise the STEM skills shortage and its consequences, as well as to act on it" (Business Europe, 2011, p. 3).

\section{Placing MINT in Context}

While the rhetoric on skills shortages has so far been about STEM, the equivalent acronym in German is MINT. Initially, the question about defining MINT could be raised, whether it is strictly comparable to STEM contextually, when discussions and comparisons take place at the European level and more broadly at the international level. Under the European Commission (2015), the concept of STEM skills is defined as "skills expected to be held by people with a tertiary-education level degree in the subjects of science, technology, engineering and maths" (Key Term 'S'). While the definition seems relatively vague, it excludes graduates who obtained STEM qualifications through uppersecondary level vocational education and training (VET). All in all, executing a search about STEM in Germany seems to retrieve more results than searching for MINT.

Within the broader European context, the question of skills shortages in Germany 
is subject to public debate among labor market experts, the Institute for Employment Research (InstitutfürArbeitsmarkt- und Berufsforschung or IAB) researchers and the Association of German Engineers (VDI), for example. Besides agreeing on a definition of STEM or MINT skills, the issue could be examined with more depth looking at how those skills align to demand across diverse occupations, industries and the economic regions.

As identified in Bott, Helmrich, and Zika (2011), MINT occupations are grouped under (Major Occupational Field) MOF 8, "Technical-scientific occupations” (p. 9), identified from the 54 occupational fields developed by BIBB. MINT occupational fields include engineers, chemists, physicists, natural scientists, technicians, technical draftmen and draftwomen, allied occupations, surveying, specialized technicians, and core IT occupations. Despite the distinctive MOF, Gunther (2013) sees that there is no consensus about a definition. While the problem of skills shortages is already being debated, it remains a long-term issue that needs to be addressed.

\section{Major Tenets}

How is the discourse framed? The public and scientific debate on the shortage of skilled labor in Germany is ongoing. Often, skill shortages will tend to vary by region, occupation and industry. Neubecker (2014) presents a comprehensive perspective on the debate about the shortage of skilled workers in Germany. By and large, the narrative on shortages seems to revolve around a consensus of no general shortages vs controversies over shortages in specific disciplines in MINT occupations (Brenke, 2012b; Kalhenberg \& Spermann, 2012; Neubecker, 2014). With that said, the discourse on shortages also extends to the making of projections. However, projections tend to instill skepticism, 
similar to that of Teitelbaum (2003), who said that making "labor-market projections for scientists and engineers $[i s]$... notoriously difficult ..." (p. 46) as labor markets can vary a lot across occupational fields and can adapt to new market exploration at a particular time. From the perspective of measuring human capital, Brenke (2012a) points out two major sources that can inform on the employment of engineers - industry-related engineers - the Federal Employment Agency (Bundesagentur für Arbeit BA), which is an important source of data on job vacancies and the German Microcensus, which informs on German demography and the labor market. Besides these data sources, Bellmann and Hübler (2014) note that "most empirical evidence that we have or that we have to expect on skill shortage is provided by politicians, ministries, employer associations or unions" (p. 5).

While Brenke (2012b) sees that there is no shortage in sight, there are IAB researchers and the Association of German Engineers (Verein Deutscher Ingenieure VDI) claiming that there are indeed shortages in MINT fields. Just as Brenke (2012a; 2012b) had sought to examine the accuracy of the VDI's claims about the shortage of engineers in manufacturing, he stated that the reporting by the VDI in 2012, that there had been too few engineers, is an exaggeration. Associated with a study conducted by the VDI and the Cologne Institute for Economic Research (IW) in 2009, examining the German's industry demand for MINT skilled labor, the Federal Ministry of Economics and Technology (BMWi) (2010) reported that skill shortages of engineers alone accounted for "the loss of value added at 3.4 billion euros" (p. 8). Basically, Brenke (2012c) disagrees with those claims. At the same time, Bräuninger and Majowski (2012) state that there are other perspectives to the claims, including the issue of skills mismatch that exists between 
supply and demand as well as geographical location, which can be induced by too little mobility. Arguably, this is not a situation that is unique to Germany. To delve a bit more into the mobility of workers in Europe, Business Europe (2011) reported that "only around 2.4 [per cent] of Europeans [were] currently living in another member state" (p. 14). It raises the question as to how this lack of exchange or coordination across member states could affect the effectiveness of programs, thus the labor supply from one member state to another.

The Federal Government aims to have "a skilled staff primarily through training and continuing efforts in education" (Dobson, 2015, p. 29) in face of global competitiveness and to make Germany more attractive to foreign talent. More specifically, Germany has a national policy, supported by an association also known as "MINT" (Eurydice, 2011). MINT has several objectives, including to "pool industry and regional business initiatives towards promoting MINT under the name "creating a MINT future"” (Dobson, 2015, p. 59). Despite these objectives, Kalhenberg and Spermann (2012) see demographic changes to be critical for the nation's prosperity in order to ensure human capital resources to maintain or enhance the skills and competencies of the German labor force productivity. By and large, "a critical appraisal of the federal government's 2012 demography strategy must conclude that policymakers still lack clear guidelines" (Kalhenberg \& Spermann, 2012, p. 27).

While Germany exhibits a strong physical infrastructure with the manufacture of technology-intensive and innovative products (p. 92), it has weaknesses nonetheless. Based on a fourth international comparative survey about Germany's innovative capacity by the DIW Berlin, Belitz, Clemens, Schmidt-Ehmcke, Schneider, and Werwatz (2008) 
affirm that "Germany's greatest weakness lies in the area of education" (p. 89) and funding of the German educational system is lacking. Nevertheless, "the Federal Government [had] committed to investing an additional 12 billion euros in education and R\&D by $2013 . .$. calling on the Länder to continue to strive to spend 10 [per cent] of economic output on education and research" (BMWi, 2010, p. 17).

Economic concepts. Similar to the United States and Australia, the narrative of skills shortages tends to focus primarily on supply. Arguably, Osborne \& Dillon (2008) see that demand is rarely examined and that the future of STEM demand lacks evidence in order to adequately address education policy initiatives.

Supply. There may be a consensus that there exist no general shortages, however there are still points of contention in agreeing on definitions, methods, and models to adequately measure and assess shortages on a common analytical framework. While business associations, for example, claim a shortage of skilled people and a demand for engineers are unmet, Brenke (2012b) sees that there is no statistically sound method that exists today to get a truly accurate indication of supply and demand of workers.

Nonetheless, there are German critics, as noted in Neubecker (2014), who will disagree with Karl Brenke's work, not taking into account “engineers working in jobs not subject to social insurance" (p. 3), for example, yet it seems impossible to clearly state that a shortage in MINT (STEM) exists in the absence of dependable data. That said, it makes one ponder the question as to how reports can be published with supposedly accurate data of alleged shortages of skilled workers if no known scientific method can accurately detect the complexities of the labor market. Along the same lines, Bellmann and Hübler (2014) would add that "no theory can convincingly explain why some companies report 
skills shortage" (p. 11).

Nonetheless, sector-specific and regional bottlenecks have been reported, including difficulties to fill positions, including in some specific areas like high-tech, advanced manufacturing and medical specialists (Bellmann \& Hübler, 2014). Still, the focus of empirical studies tends to be on aggregate data for different occupations and industries (Bellmann \& Hübler, 2014; Constant \& Tien, 2011). For example, the IAB is collecting data on the aggregate national supply of labor (Constant \& Tien, 2011). Along those lines, Bellmann and Hübler (2014) report on results from an empirical investigation on skill shortages focusing on data from the IAB Establishment Panel Survey for the period 2007-2012. Bellmann and Hübler (2014) examined whether German establishments - excluding agriculture, forestry and fishing - were expecting problems to fill positions in the next two years with skilled workers that held university degrees and qualified workers with vocational training. The investigation revealed an "average number of years with skill shortage [to be] 0.643 with a standard deviation of 1.197 ” (Bellmann \& Hübler, 2014, p. 10). Bellmann and Hübler (2014) concluded that young firms in the service sector were more prone to skill shortages, in part due to competitive pressure and high wages.

As discussed about Australia and the United States, the issue of mobility of workers is also true in Germany. Germany does not appear to be a preferred destination for immigrants to settle in for a variety of reasons as opposed to the United States, Australia and other English-speaking nations. By and large, one major push and pull factor is the integration of non-EU nationals, which creates a critical barrier for Germany. Language is another limitation, where the preference will be given to English-speaking 
countries. Besides, migrants to Germany tend to experience lower wages; they are also facing excessive regulation, taxes and contributions (Bräuninger \& Majowski, 2011). Besides those issues, Germany is faced with a brain drain (Brenke, 2012b; Constant \& Tien, 2011), based on BMI (2011) data that indicate that out of the 154,988 skilled and educated native Germans, who left Germany in 2009, 8.9 percent went to the United States. While the Confederation of German Trade Unions (DGB) asserts that skills shortage exist because of a lack of educational reform (as cited in Bellmann \& Hübler, 2014), education and training have a big role to play in light of demographic changes causing bottlenecks (Bellmann \& Hübler, 2014). With that said, Constant and Tien (2011) report that at the time, "there [was] no clear methodology in Germany determining whether there is skilled labor shortage or not... [except the IAB, to be] the only method" (p. 27).

Demand. The demand for skilled labor in MINT fields may be closely linked to the discussion about skills shortages. While Brenke (2012a; 2012b) sees that there is no shortage in sight, the question of demographics is quickly raised and articulated around predicted declines in the STEM (MINT) sectors due to an ageing population. In the Information and Communications Technology (ICT) sector, for example, "Germany lacks a general and comprehensive e-skills strategy covering both for IT user and ICT practitioner skills" (European Commission, 2014, p. 9). The report goes on, stating that the current growth rates of university graduates will be inadequate to meet the demand.

Breznitz (2013) observes that Germany recognizes the importance of skills training and the benefits it brings to learning advanced technologies and enhancing innovation and productivity. In light of demographic changes, trends for further 
education and training of older individuals (50+) will likely require measures for companies to address demand. While demand is difficult to predict for highly competitive science- and technology-driven industries, demand is expected to grow by almost 8 percent until 2025 for STEM professionals and associate professionals (CEDEFOP, 2014). In light of a shortage of the 210,000 so-called MINT specialists reported by the Cologne Institute for Economic Research (IW) in April 2012, the upper house of the German Parliament passed the Blue Card in 2012 to allow the entry of skilled workers from non-EU countries (Bräuninger, 2012). Associated with issues about non-EU nationals, the recruiting of qualified workers may be related to how ambiguous the definition of skill shortage is (Green, Machin, \& Wilkinson, 1998 as cited in Bellmann \& Hübler, 2014). However, recruitment problems could be directly associated with skill gaps in being able to satisfy current demand. Nonetheless, there are other means to remedy a shortage of skilled workers, and it raises the question as to what happens when companies will engage in "outsourcing (often offshoring) to address the current needs of about 38,000 vacancies for IT professionals", for example (European Commission, 2014, p. 4).

\section{Market indicators.}

Wages and unemployment rates. Wages in Germany began to soar after the reunification with the German Democratic Republic (GDR) in October 1990. Unions in Germany would soon be faced with tight wage restraints, associated with the Schröder government labor reforms in 2003, known as the 'Agenda 2010' (The Economist, 2013). With the increased flexibility in the labor market and the concept of free market becoming more real, German companies were also moving their operations to East 
Germany, thus adding more restraints to wage growth. As a result, wages have been stagnant (Breznitz, 2014) or are just too low while the firm's hiring standards are too high, as reported by the unions (DGB, 2011 as cited in Bellmann \& Hübler, 2014). For example, The Economist (2013) reported that "German wages rose by an average of just $1.1 \%$ a year in nominal terms, leaving them flat in real terms [between 2001 and 2010]" (para 12). With that said, Brenke (2012b) does not see the issue of low wages to coincide with shortages even though it is a problem, while wage increases would be expected in case of shortages similar to opinions shared by several authors in the United States. Similarly, authors presented in Neubecker (2014) do not all agree; however, Karl Brenke's opinion makes one raises the question why the framing of the rhetoric about MINT (STEM) shortages would omit to include the free movement of workers in the debate, and play down the role of industries in negotiating the acquisition of human capital.

According to the German Federal Statistics Office, Germany's unemployment rate was 4.5 per cent in December 2015 vs 5.3 per cent in 2013. For STEM fields, the report by the Directorate General for Internal Policies in March 2015 shows a consistently low unemployment rate in many member states, as low as 2 per cent for EU28 in 2013, "below the total unemployment rate since the beginning of the 2000s" (Caprile, Palmen, Sanz, \& Dente, 2015, p. 6). Brenke (2012b) states that the unemployment rate of engineers and skilled labor had been higher before the economic crisis in 2008 .

Demographics. Dobson (2015, p.19) states that demographic patterns will be a cause for shortages in STEM workforce, including retirement age of baby-boomers, in part, and the lower proportion of young generations electing STEM disciplines. However, 
demographic changes are not necessarily taken into consideration in the assessment of future shortages and how the labor force is defined, given that the labor market does not operate on its own (Neubecker, 2014). Comparing men and women and their employment by sector of the economy indicates that fewer women are employed in R\&D and knowledge-intensive sectors, including MINT fields. However, highly qualified women tend to be employed in fields like health care, education or social affairs (Belitz et al., 2008, p. 92). The German national STEM policy is also supported by the National Pact for Women in MINT or “Go MINT!". The latter was launched as a partnership in 2008, at the instigation of the Federal Ministry for Education and Research. In the German Center for Research \& Innovation, Dr. Ulrike Struwe, Executive Director of Go Mint describes:

Go MINT! [as] part of the federal government's Qualification Initiative... was launched in 2008 at the instigation of the Federal Ministry for Education and Research with the aim of increasing young women's interest in scientific and technical degree courses and attracting female university graduates to careers in business. (para 1).

Besides the representation of women in MINT workforce, the German Federal Statistical Office (Statistisches Bundesamt), for example, presented a vivid picture of a transformed population in Germany, projecting an older workforce in the next years. However, not everyone shares that opinion as the making of long-term projections raises skepticism and should be used cautiously (Brenke, 2012b).

\section{Political Framework}

Industry. While Osborne \& Dillon (2008) see that "local shortages can be addressed by filling posts from the global supply" (p. 15), there is the notion that a stronger link between German universities and the industry could help promote the 
practical industrial value from applied research, for example, the "Fraunhofer's model is a classic government-industry partnership" (Wiessner, 2013, para 12), where Fraunhofer institutes are linked with German universities. At the same time, Bellmann and Hübler (2014) comment on different measures that could help alleviate skill shortages; for example, the lack of reform in the educational system that the unions see as responsible for such shortages. Other considerations could be to train older workers and hire women. At the same time, the expanding business or service sector has somewhat been changing the traditional approach to STEM skills, in that STEM skills per se may no longer suffice. As in Australia and the U.S., soft skills are becoming more important. However, it raises the question whether the education and further training system are responding to the requirements of the labor market; Kalhenberg and Spermann (2012) assert that they have not yet responded appropriately.

Programs and education. In 2012, the share of graduates in Germany was more than 27 per cent. Brenke (2012b) had reported that a sharp increase in graduates was expected, which could also create a bottleneck in the labor market. Bottlenecks are detected in academia too, where the number of academics 55 years old and above has increased from 15.1 per cent in 2000 to 18.8 per cent in 2009 (Bosch, 2011). At the same time, Bellmann and Hübler (2014) report that the Chamber of Commerce and Industry, that stresses "the responsibility of unions and employers at the policy and the firm level" (p. 8) advocated for more permeability between vocational training and the university as a measure to cut shortages. Powell \& Solga (2011) confirm there is low permeability and mobility to higher education despite the heavily export nature of the German economy. 
Immigration. It was in the early 2000s that Germany was officially recognized to be an immigration country (Constant $\&$ Tien, 2011). This relatively recent development occurred when the Schröder government passed a new immigration bill. While the green card regulation, which was launched in February 2000 by Chancellor Gerhard Schröder, aimed to attract highly skilled foreign professionals, with IT background primarily, the ambitious labor policy did not turn out to be as successful as expected. With that said, other countries such as the USA and Australia were competing for high skilled immigrants at the same time, and got them first (Constant \& Tien, 2011).

Bräuninger (2012) reports based on data from the Cologne Institute for Economic Research (IW) that there was "a shortage of around 210,000 so-called MINT specialists, i.e. mathematicians, engineers, scientists and IT specialists, in the German economy" (para 2). Although the current skill shortage is only seen as cyclical, the number of retirements is increasing each year, estimated at about 40,000 engineers (excluding IT specialists). This forecast raises serious concerns in light of an aging population that would be in need of greater medical and nursing attention in the coming decades. At the same time, an influx of migrants from southern European Economic and Monetary Union (EMU) states has happened. In light of those demographic changes, new legislative measures like the Blue Card have permitted to alleviate skill shortages for three years (The information portal for foreign professional qualifications, 2013). The Blue Card was passed by the German Parliament in 2012 to allow more non-EU residents to gain access to the German labor market. Nonetheless, Bräuninger (2012) sees additional limitations like language and high taxes and duties will deter skilled immigrants from entering the German labor market. The wave of young Europeans from the south, for example, could 
help prevent bottlenecks in the market. Still, Bräuninger (2012) states "the absolute figures of around 16,800 and 11,600 migrants were much lower than during the great wave of immigration in the 1960s" (para 5). Basically, the low number of highly qualified immigrants per capita in Germany is largely a question of integration. Although Germany may have shown the will to create a new foundation with respect to immigration, the main question is about social integration of immigrants (Zimmermann, Bonin, Fahr, \& Hinte, 2007), given that their integration needs to be mutually inclusive at both the national level and local level in Germany. On the whole, the issue of public acceptance is of fundamental importance and it forces us to ask how the welcoming of thousands of refugees within the last year will turn out.

Lack of cogent data. In light of a rapidly changing global knowledge economy, the rhetoric about skills shortages in MINT fields can best be appreciated with fit data to most adequately analyze human capital and skills in the context of innovation (Del Sorbo \& Hervas, 2013). However, in the absence of a statistically sound method to accurately measure supply and demand (Brenke, 2012b), Constant and Tien (2011) comment on the fact that the IAB is recognized as the established single authority for tracking labor market trends and shortages. It raises the question as to how the lack of comparable official datasets could not be a handicap to policymaking. That said, the question of reliable projections could be raised once more. In Neubecker (2014) and Kalhenberg and Spermann (2012), the study by the Swiss research institute, Prognos seems to indicate two different figures of a shortage of millions of highly skilled personnel by 2030, should no variation in the labor market occur or the net immigration per year remains the same during that time period. Nonetheless, the gap in the labor force would be around 5.2 
million to 5.5 million high skilled workers. Bellmann and Hübler (2014) report on the study, pointing out at a projected " 25 percent [gap] of the academic jobs ... [by] 2030 if no measures are taken" (p. 6).

\section{Summary}

Germany is a leading economy in Western Europe, yet the rhetoric of skill shortages is very much debated between proponents and researchers despite the absence of a statistically sound method to accurately measure supply and demand (Brenke, 2012b). The rhetoric of skill shortages in Germany may not be limited to the issues of an imminent lack of supply; it is also whether Germany could attract highly skilled immigrants.

\section{Conclusion}

In their response to the shortage of skilled labor in STEM or MINT-related fields, both Australia and Germany are faced with the dilemma of consistent and uniform data against the claims on shortages. Despite some similarities, solutions for each country will be in response to the national context, inclusive of regional and global forces. While Australia is in close proximity of the South Asian market, it still does not have a coherent national strategy and the funding of higher education has been fluctuating in the last 60 years. By contrast, Germany has a national strategy supported by MINT, however it exhibits a low permeability and mobility to higher education despite the heavily export nature of its economy. Lastly, Germany is not as much a destination for immigrants to settle in as opposed to Australia and the United States. 


\section{CHAPTER VI \\ DISCUSSION AND IMPLICATION}

In this final chapter, I begin by summarizing the document analysis, supported by interviews, alongside discussants' viewpoints on the narrative of STEM shortages in the United States, Australia and Germany. The narrative about shortages has been a continual theme since the 1950s; it is articulated as a bipartisan theme in public policy discussions and divided across the aisle between proponents of STEM shortages and researchers, who disagree. Coupled with scientific and technological transformations in the last decades, the political discourse is basically grounded on the two fundamental economic principles of supply and demand. Despite the plethora of publications that support the narrative, the ongoing debate over shortages in STEM skilled workers in the United States, Australia and Germany today, is expressed in relatively similar terms, in that the discourse is heavily framed in terms of the human capital side of science and technology with respect to the political, economic and social context of each nation within the larger context of a more integrated competitive global knowledge economy. This study focuses on STEM workers with at least a bachelor's degree or higher, which permits to align the discussion with educational requirements placed on $\mathrm{H}-1 \mathrm{~B}$ skilled workers. While policy reports on labor market shortages are very much reflecting individual employers' accounts of the hiring problems of qualified skilled workers in STEM fields (Lowell \& Salzman, 2007), two major points of contention emerge from the study in light of formulating 
recommendations directed at the bipartisanship in public policy discussions that is currently divided across the aisle between proponents of STEM shortages and researchers in order to develop a dialogue around STEM. First, the lack of a clear definition of STEM -a social construct- is a hindrance to being able to frame the policy discourse in its appropriate context beyond national boundaries in order to have proponents and researchers working together under a common analytical framework. While it has already been agreed upon that STEM, for example, is heterogeneous in its nature and representation (Freeman, Marginson, \& Tytler, 2015; Xue \& Larson, 2015), STEM represents multiple labor markets. Deborah Corrigan, associate professor at Monash University sees that a flexible definition can be adapted to serve one's political agenda. Second, the lack of consistent and substantiated data about the claims that proponents of shortages are making remains a challenge to best set the public policy, where either side could be right until it is possible to formalize a more comprehensive and unbiased definition of STEM within reasonable boundaries despite a few gray areas in STEM workers' skills and competencies. This approach would engender a greater sense of transparency and truth informing the public about the rhetoric that surrounds the shortage of high-skilled STEM talents despite political and economic agendas.

Next, I explain why the policy study is significant with respect to higher education both in terms of human capital and the nature of the labor market within the global knowledge economy. Next, I provide implications for practice and research, followed by recommendations that could help frame the discourse on STEM shortages in order to set a public policy grounded on a common analytical framework at the federal and state levels within the global setting. Next, the list of recommendations has informed 
the researcher with possible future research studies that vary in scope. Some of the suggested future research initiatives would more than likely require significant funding and may be best addressed by a group of researchers engaging in such studies in

light of their scope. Lastly, I conclude on how the document analysis and interviews have informed my policy study.

In the attempt to dissect the current rhetoric shaped around several studies and their underlying datasets, I aimed "to satisfy the need for pertinent information and thoughtful, impartial assessments in the policy process" (Kraft \& Furling, 2004, p. 103). Alongside the theoretical perspective, I provide greater "culturally derived and historically situated interpretations" (Crotty, 1998, p. 67) on the findings derived from document analysis and interviews. Most importantly, I took a critical look where the current beliefs lie, placing them in their national context with respect to political and economic advocacy that may directly impact the objectivity of any information relative to shortages of STEM or MINT skilled workers.

The purpose of the study was to examine the current rhetoric of a shortage in STEM scholars and employees in the United States, including Australia and Germany as frames of reference in order to contextualize the role played by their national values in the context of the global STEM conversation.

\section{Research Questions}

1. What is the history of STEM education, beginning with an examination of American science since the early 1920s and including a historical outline on the perspective of science in Australia and Germany?

2. What is meant by STEM education and does a definition of STEM exist? 
2a. How does its interpretation differ based on national context?

3. What are the major tenets of the rhetoric of a shortage in STEM scholars and employees in the United States?

4. How does the rhetoric of a STEM workforce shortage play out in the United States from the perspective of the U.S. economy and its dependence on STEM workers to keep its vibrancy and the bipartisan theme in public policy discussions?

4a. How much leverage does this claim have with research suggesting there is little shortage in STEM occupations in the United States?

5. What are the main characteristics that surround the debate of the shortage of skilled workers in Australia and Germany?

6. What critical implications and recommendations can be drawn out from the current discourse on STEM shortage in the United States with consideration to Australia and Germany?

\section{Summary of Evidence}

The narrative that surrounds the shortage of workers in STEM fields has led to a plethora of publications. Although the ongoing debate over shortages in STEM skilled workers in the United States, Australia and Germany is expressed in relatively similar terms, information sources tend to be more tied to the government and organizations.in Australia and Germany while there tends to be a greater mix of information sources in the United States. Marginson et al. (2013) remind us that "programs, policies and professional practices in relation to STEM are nested in 'thick' and complex social, economic and policy contexts" (p. 54). Despite differences in the way the rhetoric may be articulated in each country, the assertion that there are too few STEM skilled workers can 
be summarized as follows:

In the United States, the discourse is supported by most policymakers, industry groups, university leaders and professional associations, who concur that the nation is facing a crisis in high-skilled talents (Hira, 2010; Salzman, 2013). Industry groups and trade associations are lobbying for more graduates in STEM fields and a greater number of H-1B workers to the United States. By contrast, there are researchers and pundits who reject the rhetoric of a STEM shortage that frames the need for increasing enrollments in STEM education programs These researchers maintain that no clear evidence can substantially support those claims in the absence of substantiated and consistent data; that more scientists and engineers graduate from U.S. universities than positions can guarantee their employment (Atwater \& Jones, 2004; Teitelbaum, 2008, 2014a, 2014b). That said is there a clear answer to how many engineers are needed in the United States?

In Australia, industry groups, unions and employers are expressing the difficulty to recruit qualified STEM labor. These groups have been exaggerating the problem of a shortage (Richardson, 2007), engendering tensions around the immigrant labor force, when claims about STEM shortages may not always be empirically substantiated. However, Panizzon et al. (2015) assert that "unless the specific areas of need are clearly communicated to the populace and stakeholders, the government and industry rhetoric that there is a shortage across the board does little to address any 'real' gaps that very likely exist in the STEM workforce" (p. 73).

In Germany, the rhetoric of skill shortages is supported by a group of labor market experts, politicians, ministries, employer associations or unions, who express a significant shortage in MINT professionals (Brenke, 2012a; 2012b; Neubecker, 2014). In 
April 2012, the Cologne Institute for Economic Research (IW) reported "a shortage of around 210,000 so-called MINT specialists, i.e. mathematicians, engineers, scientists and IT specialists, in the German economy" (Bräuninger, 2012, para 2). With that said Bosch (2011) sees that such complaints continue to be used for political purposes. Justifiably, Brenke (2012b) asserts that in the absence of a statistically sound method to accurately measure supply and demand such claims are not sound. Although the issue of low wages is a problem in Germany, Brenke (2012b) does not see it coincide with shortages as wages would be expected to increase in case of shortages; an opinion that is shared by several authors in the United States. Additionally, the narrative of skill shortages in Germany is associated with the migration of foreign workers and the issues of social integration that remains critical.

The current discourse is not a new phenomenon; it dates back to the 1950s and its context is now embracing new global dimensions. To the extent that so many resources are being allocated to STEM education at both the $\mathrm{P} 12^{12}$ and higher education level despite the disagreement in the global discourse, the critical issue of whether such delegation of finite resources is defensible remains to be answered. Associated with the lack of reliability in projecting future demands (Freeman, 2006b), well knowing that making "labor-market projections for scientists and engineers [is] ... notoriously difficult ...” (Teitelbaum, 2003, p. 46), the United States, Australia and Germany are inevitably facing a critical challenge in guiding policies and programs that surround STEM (or

\footnotetext{
${ }^{12}$ The focus of this study is on higher education, with STEM graduates with at least a bachelor's degree or higher. STEM education is also an issue for P12 and could be an excellent topic for future study.
} 
MINT) education.

The current beliefs that are founded on the economic principles of supply and demand, articulated across a political framework in relation to occupational sectors, are being grounded on a lack of consistent and cogent evidence and presented to the American public through a plethora of information that contributes to shaping the national policy (Benderly, 2012). As science, technology and innovation are more integrated globally under the umbrella of a global knowledge economy, proponents from industry claim that H-1B workers are "the best and brightest" (Matloff, 2013a); university leaders and highly ranked government officials are also shaping the rhetoric of shortage in the public sphere with foreign students, who are competing for space with domestic students. Along those lines, the United States, Australia and Germany recognize the issue related to demographics due, in part, to an ageing population, but also in the representation of women and underrepresented minorities in STEM workforce. That said, demographic changes may not always be taken into account in the assessment of future shortages, for example, due to the lack of clear guidelines in the policy-making process (Kalhenberg \& Spermann, 2012).

Other factors come into play. The most obvious market indicator, wages, has not been bid up in all three nations (Breznitz, 2014; Shierholz, 2014), which would indicate there is not a shortage. However, there are always exceptions, such as, in petroleum engineering in the United States, for example. The rhetoric is also articulated around the tendency to aggregate data, which may afford certain groups to have stronger representation in lobbying "because the larger STEM is, the more important it becomes relative to other disciplines" (N. Smith, personal communication, September 29, 2015). 
However, by aggregating data, it may mask what the accurate picture of the STEM labor market is and affect results highlighting the challenge of conflicting data (Bell et al., 2014); shortages could exist in some specific occupations or industries (Lowell \& Salzman, 2007), skill shortages can also exist in a geographical area of a country or when the unemployment rate is very high (Cohen \& Zaidi, 2002), thus raising the question as to whether the rhetoric of a general shortage in STEM is valid or exaggerated.

The fundamental issue that seems to be at stake in all three nations represented in the study is how STEM and MINT are defined and delineated. Although it might be possible to draw reasonable boundaries in defining STEM or MINT, a thorough understanding of the nature of each acronym is absolutely necessary in order to have a debate on similar terms and formulate a most accurate policy analysis. However, there is no consensus on how STEM is defined and defining it remains a challenge (NSF, 2015). That said, the contemporary discussion around STEM, MINT, skills shortages and skills mismatches is articulated within an analytical framework that tends to differ across the political spectrum; it is almost a case-by-case matter, where programs play out in specific ways and may even be adapted in other international contexts ${ }^{13}$.

Despite beliefs that there are too few Bachelor's degrees or higher in science and engineering (Teitelbaum, 2014a, 2014b), the cost associated with an education in STEM programs tends to be the most expensive (AIR, 2013). However, not all programs under STEM do require the same number of credit hours as well as an education up to a PhD. Despite these differences, STEM education programs at colleges and universities are

\footnotetext{
${ }^{13}$ The researcher will return to these issues in the recommendations section of this final chapter
} 
incentivized by the federal government at the graduate and postdoctoral levels to produce more graduates in high-demand fields (Kuenzi, 2008; Mckeown-Moak, 2013). The production of human capital in STEM fields raises intriguing questions in light of conflicting interests between providing a public good and meeting the politically-driven agendas that call for increasing the supply of STEM graduates, forcing students in the role of investors of their own education and faculty as entrepreneurs.

\section{Significance of Evidence}

Determining whether there is too little STEM workforce in the United States, and for that matter in Australia and Germany, is our ultimate goal. The policy study is significant for different reasons. It is of the utmost importance to education administrators in light of the large amount of federal funding that have been directed toward STEM programs, and continues to be today. It is critical for understanding the human capital side of STEM, and more importantly how it transpires through the production of STEM graduates at colleges and universities, which directly impacts national policy. It is strategic because it places into perspective how important the changing nature of the labor market and rapid technological developments that have emerged from globalization and the introduction of other markets, including China and India, have fundamentally contributed to the current rhetoric that surrounds the shortage of skilled workers in STEM (or MINT). Lastly, it broadens the perspective of the current narrative presenting an authorship that extends beyond the political establishment in the United States and Germany by including the viewpoints of economists, for example, and brings an international lens to the discussion by framing the policy discourse on STEM shortage beyond national boundaries, in that it is not an isolated phenomenon. 
Placing the study in its historical context is important (H. Salzman, personal communication, September 29, 2015; Marginson et al., 2013; R. Hira, personal communication, October 6,2015$)$ in order to understand how the narrative about shortages has been a continual theme since the 1950s. By and large, the narrative has been driven by a combination of industry groups (H. Salzman, personal communication, September 29, 2015). The study brings in evidence of the transformative nature of that narrative since the years following World War II, when both the Bush and Steelman reports confirmed that the human resource capacity for science and engineering needed to increase, particularly due to war losses. At the time, "the availability of trained personnel was clearly the main limiting factor to developing research and development activities" (President's Scientific Research Board, 1947a). Science and technology developments were seen as essential to assuring national security and public perceptions toward science, and the role of scientific knowledge in society (DeBoer, 2000) played a critical role in sustaining the hegemonic position of the United States in the world. While the NDEA was instrumental in "encourag[ing] the expansion and improvement of educational programs to meet critical national needs," (Public Law 85-864, p. 1581), the inspiration of people toward science grew. It raises the question whether that could have been a trigger in how nations began to address the human capital side of STEM in response to an increasingly "research-reliant society" (Killian, 1964) that was progressively facing an emerging competitiveness on the global stage, as the role of science was becoming more visible to the world.

Recalling the critical times in history when German scientists migrated to Australia or the United States, the human resource capacity in STEM in the twenty-first 
century is now negotiated under a very different philosophy. Undeniably, the immediacy of services across the globe has transformed global communication and exchange of human capital across nations. The pseudo removal of national borders in some respect has likely impacted the conceptualization of national STEM policy framed in human capital terms. R. Hira (personal communication, October 6, 2015) states that the human capital side of STEM is more important today from a policy perspective than it may have been in the past because US workers tend to be much less mobile than corporations are. R. Hira (personal communication, October 6, 2015) adds that corporations are much less tied to nation for taxation purposes, for example. When a corporation, like Pfizer Inc., for example, a giant drug company with headquarters in the U.S. had decided to move its headquarters to Ireland in late 2015 -U.S. regulations were tightened to prevent the merger deal with Allergan, Plc- it would have been more than likely that not every worker was able to move. Although some STEM qualified workers may be unable to move, they may divert to non-STEM occupations in light of greater prospects and earnings; they can also be under-employed or unemployed depending on the local industry needs. At the state level, companies may move their headquarters to other states that offer corporate tax incentives. For example, the American company State Farm with its headquarters in Bloomington, Illinois has progressively been moving its workforce to other states like Georgia, Texas and Arizona. It is very likely that the 30 percent corporate tax increase in January 2011 in Illinois raised questions about competition and taxation. All in all, it makes one ponder the question of the societal benefit of STEM education and the cost associated in producing human capital in STEM fields. While the industry used to be more prone to providing training or subsidizing continuing education 
at a local college or university, for example, companies are acting more rationally today with a more flexible labor market, particularly in technology (R. Hira, personal communication, October 6,2015$)$. Workers may not stay in one company as many years as they used to, and it could be part of the problem. However, it forces us to ask if it is the problem -that the United States is under-investing in training (R. Hira, personal communication, October 6, 2015)- when the industry claims that too many older workers available for work have not updated their skills (Matloff, 2013b). All in all, the argument raises the question whether training, for example, is simply a distraction to the real problem of a STEM shortage.

The rhetoric of STEM shortages has very much driven the debate in the H-1B visa program. R. Hira (personal communication, October 6, 2015) thinks that "it is a misguided debate because you don't need to demonstrate there is a shortage to hire an $\mathrm{H}$ 1B worker." While the America COMPETES Act aimed to increase the number of STEM graduates at colleges and universities, it is important to keep in mind that it is a market system and there is a lag to produce STEM graduates, who will have the skills and competencies for the labor market. However, the push for H-1B visa holders by corporations, hence with legislation that resembles the Immigration Innovation Act of 2015 (or I-Squared Act of 2015) to increase the supply of guest workers to new levels is likely to provide plenty of workers, but is also a way to bypass training and to pay those workers a lower wage -a mechanism that is taking advantage of many legal loopholes (Matloff, 2013a; Salzman, 2016) despite the requirement to pay workers "at least the actual or prevailing wage for their occupation, whichever is higher" as indicated by U.S. Citizenship and Immigration Services. It is also undermining the value of American 
education and taking away aspirations in science from graduates, who have invested large amounts of money in their STEM education. That said, the cost of education in STEM programs at colleges and universities tends to often be the most expensive (AIR, 2013), with the exception of a few applied and liberal arts fields.

\section{Implications}

The assertion of the shortage of skilled scholars and employees in STEM-related fields has a long history; it dates back to at least the late 1950s. Reinforced by the making of predictions at different times since then, the rhetoric has been debated on different fronts, framed around "the underlying theme ... that the United States is losing its dominance in science and engineering" (Stephan, 2012, p. 165). Whether or not this is actually the case, the debate is ongoing. Debates on STEM (or MINT) shortages are not limited to the United States. Those issues are being discussed in Australia and Germany as well. The discussion includes a series of critical implications that focus on global competitiveness, effectiveness of federal STEM programs, definition of STEM, transparency in the reporting of data coupled with the lack of evidence, H-1B labor, cost of education in STEM fields, and accountability related to vested interest and public perspective. The discussion is also taking into account the level of subjectivity from my interviews with six individuals in the field, who kindly accepted to participate to my questionnaire.

Contextually different nationally and internationally, the narrative strives to report how critical shortages in STEM fields are constructing a rhetoric that reflects much subjectivity. In the United States, N. Smith (personal communication, September 29, 2015) sees this as the reality, nonetheless. Basically, it is a political debate with economic 
and social nuances. While economics has a lot to do with science (Stephan, 2012), for example, when "government science-funding agencies may find wages problematic insofar as they result in increased costs for research" (Teitelbaum, 2003, p. 19) and the cost of educating STEM graduates, what counts as STEM is also built on a socially constructed argument. To quote Teitelbaum (2003) on the fact that "[the] public discourse is mired in paradox" (p. 51) there are two sides to the argument. On one side, there are proponents of STEM shortages, who may act as spokespersons of large organizations or reputable think tanks, demonstrating a vested interest in representing industry groups that are shaping the narrative. It forces us to ask what happens when long reports are published and whether a vetting process is in place, counting on the reputability of the organization or think tank. In short, who might take the time to dissect those reports, and can the data analyses be replicated? On the opposite side, there are researchers and scholars, who would argue on the lack of empirical evidence of those claims. To quote R. Hira (personal communication, October 6, 2015):

The shortage argument can't be separated from the political and economic interest, it does not stand on its own; it's being promoted by special interest groups that have a huge conflict of interest, benefiting directly from politicians accepting or believing that there is a shortage.

At the same time, claims are made that the United States is outcompeted by China by producing more engineers; but China is also doing more engineering work and construction (H. Salzman, personal communication, September 29, 2015). Although shortages may exist in some specific areas, there is a lot of skepticism of claims made about shortages, and if there were a shortage, wages would go up; yet they have not recovered since 2000 (H. Salzman, personal communication, September 29, 2015; R. Hira, personal communication, October 6, 2015). Similarly, Shierholz (2014) retrieved no 
indication of a wage increase indicating a shortage of STEM supply. Stepping back to the 1980s up to the early 2000, a philosophical shift has happened in that the difference between the interest of the company and the interest of U.S. workers has changed; for example, Intel or IBM have not been as tied to the U.S. workforce as opposed to the years of the competitive debate with Japan and the auto industry. Corporate inversion, for example, has direct implications for STEM workers, who are not or may not be as mobile as corporations are, thus affecting geographical areas in the country. As U.S. workers tend to be less mobile, R. Hira (personal communication, October 6, 2015) recommends that the United States should be investing more in geographically 'sticky' type of investments.

Similar to Dobson (2015) in his report on seven European countries on existing solutions to the STEM skills shortages, there seems to be many similarities in the problems at play and recommendations to address those problems. Although specific measures may be sought out, the main issue is to being able to address the "difficult[y] to measure the long-term impact of any reform or group of reforms" (Dobson, 2015, p. 4). Essentially, the issue at stake has a close resemblance to the lack of coordination among STEM program and agencies in the United States. One direct implication to the decentralization of STEM programs (Kuenzi 2008) is the inability to thoroughly assess the effectiveness of federal investments in STEM education. It raises obstacles to collect data to adequately measure long-term student outcomes (U.S. Department of Education, 2007). It also removes the sense of cohesiveness across the programs by adding a level of complexity in the evaluation processes, thus neglecting objectivity and preventing the reporting of an accurate picture of the intended outcomes. 
While the human capital side of science and technology is critical to U.S. policy, the way STEM is defined in constructing research studies leads to believe in a lack of consistency in the research process across organizations. Without a common analytical framework that includes a clear definition of STEM taking into consideration differences among disciplines, the purpose of running studies where interpretations can vary greatly from subjectively designed large datasets raises questions about comparing datasets and the interpretation of these studies if STEM is not clearly defined in the first place.

Metcalf (2011) asserts that "what counts as science and engineering, and who counts as a scientist and engineer is highly socially constructed" (p. 180). To quote H. Salzman (personal communication, September 29, 2015) "STEM is an acronym that has a political meaning rather than scientific or policy meaning ... the way we count it is not tied to the way it is being used". All in all, how to define STEM depends on, "what's your purpose" H. Salzman (personal communication, September 29, 2015) adds. There is one immediate implication to this. If there is no coherent definition to STEM, we must ask ourselves why the current debate continues about what STEM is, how it influences and impacts our lives, hence being in short supply to ensure the United States scientific and technological innovation in face of global competitiveness. That said, it makes one ponder the question whether there seems to be a myopic approach to STEM, a lack of perspective and representation coupled with subjectivity that undervalue a greater need for communication and respect for different perspectives to come to a constructive debate. To some extent, an analogy could be made to the story of the blind men and an elephant that originated from the Indian subcontinent. The study is about a group of blind men, who touch an elephant to learn what it is like. Each of the men touches only one part of 
the elephant. After doing so, it turns out that they are disagreeing about the part they felt. In this scenario, the parable could reveal the notion that the truth about STEM is absolutely conjectural and contextual as each government body, industry group or researcher in a particular nation develops its own interpretation of what STEM is about. Because STEM is heterogeneous (Freeman et al., 2015; Xue \& Larson, 2015), all the more reason that it is difficult to settle on a definition. For example, there is the question whether medical professionals should be included; some do include them, some don't. Panizzon et al. (2015) state that "the inclusion or exclusion of medicine and the health sciences in the field of STEM varies in Australia" (p. 72). In light of a lack of international standards about STEM -MINT in Germany- it seems that it is more about what one makes of STEM and adapts it to fit a particular discourse. For example, ' $\mathrm{T}$ ' in STEM accounts for over 50 per cent; it includes several sub-occupations to which education backgrounds and educational levels vary. However, it forces us to ask how ' $\mathrm{T}$ ' is leveraged within the larger picture. H Salzman (personal communication, September $29,2015)$ sees that the reality is that there is no standard definition for STEM, that STEM is defined according to one's purpose. That said it makes it more difficult to frame the current debate in the absence of reliable statistical data even though subjective reports about shortages can easily be publicized in press releases or the media. Benderly (2012) questions why proponents of shortages choose press releases while researchers publish in scholarly papers. That said, press releases or media that depend on advertising push more immediately accessible articles to readers on the internet, for example, and those articles are likely more publicized with an appeal that draws attention, hence readership. Along those lines, the media contributes greatly in the shaping of policy; it steers the message of 
proponents of shortages and at the same time shapes the public attitude.

Besides the issue about defining STEM, aggregating data is commonly used by organizations. The time constraints to separate STEM would be another issue, N. Smith (personal communication, September 29, 2015) adds, in that "people want to group it together, because the larger STEM is, the more important it becomes relative to other disciplines and therefore they can lobby for better representation as a bigger group". For example, ' $T$ ' gets more representation; but by disaggregating STEM, it would weaken its impact (R. Hira, personal communication, October 6, 2015). Along those lines, J.

Rothwell (personal communication, October 28, 2015) states:

There are practical reasons why you'd want to group and why you'd want to separate them, depending on the context ... that for policy, for broad understanding of labor market issues, it's convenient to group them together because many of the same issues apply across the board looking at all the disciplines in terms of relative high wages, relatively good job prospects.

H. Salzman (personal communication, September 29, 2015) continues and states that "If you can't define the purpose you can't come up with a coherent definition".

Inevitably, it seems that STEM can be handled arbitrarily to build a narrative that serves a particular agenda, divulged through long reports, including data analyses that may not be vetted by other experts in the field.

The debate on STEM shortage will more than likely continue; however, the lack of consistent and reliable empirical data remains a challenge to best set the public policy, where either side could be right until a more comprehensive and unbiased definition of STEM can be established within reasonable boundaries to more clearly inform the public about the lack of STEM talents and its impacts on society. For example, a recent news release by the American Competitiveness Alliance in February 2016 gives the sense that 
American businesses will be facing hard times as $\mathrm{H}-1 \mathrm{~B}$ visa fees are doubling, and that larger companies may have a way out, regardless, as "[they] may relocate operations outside the U.S., where a large base of skilled talent is readily available to ensure [those companies] remain globally competitive" (ACAlliance, 2016, para. 4). This message resembles the current rhetoric, underlining a vested interest that is sponsored by large corporations not referencing any sources to substantiate the evidence. Nonetheless, while American firms are acting more rationally in terms of providing training to workers, with a more flexible labor market, especially in technology, maintaining the internal human capital capacity raises critical questions about long term investments, prosperity and innovation.

The lack of evidence coupled with the lack of data as proponents of STEM shortages are lobbying for H-1B workers and increased enrollments in STEM programs create huge implications for the future of STEM. The statement by H. Salzman (2016) before the United States Senate Judiciary Committee in February 2016 reinforces the increasing disharmony between the immigration policy and guest worker programs that clearly intends to reduce the cost of doing business for industry despite evidence of questionable claims of shortages. To quote R. Hira (personal communication, October 6, 2015), "the justification for more STEM is on very shaky ground, if any ground at all." While it is important to differentiate the current belief with empirical evidence (Salzman, 2013; Shierholz, 2014; Teitelbaum, 2014a, 2014b), it forces us to ask what the message is behind the projections of future demands, even more so, when reflecting on the scrutinized 'looming shortages' announced by the NSF in the 1980s.

The H-1B visa program presents another ongoing debate. Foreign workers are in 
general younger workers in their 20s or early 30 s and while hired under an H-1B visa, many may be working for the same employer as they are waiting for the green card (NRC, 2001). At the same time, there are legal loopholes that allow mainstream firms to pay foreign workers a lower wage compared to American workers with comparable skills (Matloff, 2013a). Not everyone would agree and to quote J. Rothwell (personal communication, October 28, 2015), who "tends to disagree with the most vocal, oppositional critic of the $\mathrm{H}-1 \mathrm{~B}$ program, who have claimed that most $\mathrm{H}-1 \mathrm{~B}$ workers are paid below the market price, undercutting American workers", it forces us to ask what is the main motivation for hiring H-1Bs. Similarly, to quote S. Ezell (personal communication, October 2, 2015), in that “we're graduating only as many [computer science] graduates as we did a decade ago" raises another question of data reliability. Prominent think tanks and organizations get a lot of funding from multinational corporations. That said, Stephan (2012) would argue that "shortages are often predicted by groups who have a vested interest in attracting more students to graduate school and into careers in science and engineering" (p. 165). For the same reason, it might also explain why in my series of interviews with researchers and experts, N. Smith (personal communication, September 29, 2015), J. Rothwell (personal communication, October 28, 2015), S. Ezell and A. Nager (personal communication, October 2, 2015) all stated that there was a shortage, in most instances with a focus on IT workforce. When asked whether the STEM shortage was general or specific to some occupational fields, they agreed that there were shortages in spot areas. It forces us to ask whether the narrative about shortages is exaggerated to some degree. It raises suspicion asking how much of it is governed by vested interests in pushing for more STEM graduates and for hiring 
foreign workers with $\mathrm{H}-1 \mathrm{~B}$ visas, for example. A direct implication for workers in tech fields is that H-1Bs are suppressing wage growth (Matloff, 2013a; Stephan, 2012) and increasing the age discrimination for workers over age 35 (Matloff, 2013a; 2013b). The implication of foreign worker programs in IT fields is an "internal brain drain" (Matloff, 2013a, p. 223) of the American best and brightest, which could have dire consequences in the long run as the human capital stock of skilled human resources will require time to be replenished at some point in time. However, N. Smith (personal communication, September 29, 2015) would argue that because there is a shortage in STEM capabilities and STEM credentials the duration of their stay after graduation should be reevaluated and extended, if they are in fact such an asset. Similarly, A. Nager (personal communication, October 2, 2015) and N. Smith (personal communication, September 29, 2015) see that foreign students are a huge win for the U.S., and they are being sent back after graduating. To quote A. Nager (personal communication, October 2, 2015), these are "huge national resources that we should be taking advantage of" (A. Nager, personal communication, October 2, 2015).

While the assertion of a tech labor shortage creates a misguided debate founded on no evidence, engineers in the United States do a double-take, they don't understand why there is a shortage even though some engineers think there is (H. Salzman, personal communication, September 29, 2015; R. Hira, personal communication, October 6, 2015). That said Dr. William J. F. Hunter, Director of the Centre for Mathematics, Science and Technology at Illinois State University reports otherwise, in that the Illinois Department of Transportation has partnered with the Illinois Mathematics \& Science Partnership to recruit students into engineering. Coincidentally, the average age of that 
engineering workforce is 56 years old. Along those same lines that shortages in STEM are not evident, Dr. Hunter adds that Cummins Inc, ComEd - a unit of Chicago-based Exelon Corporation -, and Rolls Royce are offering internships to engineering students, where nearly 80 percent of those interns are able to get permanent employment offers. Although shortages may exist in some specific areas of expertise, how can the narrative and the evidence about shortages of STEM talents be reconciled in order to get an accurate picture of the real phenomenon that transpires from the difficulty employers have and are frustrated about by not able to recruit workers with sufficient experience and specific technical skills?

The implication that derives from the lack of indicators of a shortage and how the narrative on shortages has been able to push for more STEM and shape the public attitude makes one ponder the question as to why some proponents of STEM shortages would want foreign students to stay in the United States, while American students are leaving STEM and H-1B workers are serving the on-demand needs of the industry. To quote A. Nager (personal communication, October 2, 2015), "a lot of time, the industry does not realize what they need, hard to know what the capabilities of an engineer are". However, Americans are also displaced at the PhD level, where the number of post-docs has been increasing, including in engineering. H. Salzman (personal communication, September $29,2015)$ questions, "What do we do with too many PhDs and lousy career prospects?" With $\mathrm{PhD}$ scientists having a 15 to 45 per cent chance to becoming a scientist and earning an annual wage of less than $\$ 50 \mathrm{~K}$ with student loans to pay back, it seems to cast a gloomy vision about STEM in the United States and its citizenry. In the meantime, career prospects are veering toward a more prominent service sector of the economy, including 
the finance industry, for example, which is a huge consumer of STEM (A. Nager, personal communication, October 2, 2015). The biggest problem, S. Ezell (personal communication, October 2, 2015) notes is when students switch out to non-STEM fields, causing a leaky pipeline in STEM education programs, where "about 50 per cent [of the students choosing STEM programs] do not graduate with a STEM major.” In broader terms, the human capital capacity seems to be eroding under the full power of politics and economics. While domestic policies in the United States recognize a shortage and try to respond to it by creating incentives for STEM graduates (N. Smith, personal communication, September 29,2015), it forces us to ask if policies are really addressing the problem when short-term gains seem to supersede many of the conversations that recognize the huge potential that women, under-represented populations and older workers may bring to meeting workforce demand. Indeed, inconsistencies in defining STEM may give the impression that women are well represented; however, this may be skewed by the fact that health disciplines are included in STEM in Australia. Women account for almost 80 per cent in health disciplines in Australia (Freeman, 2015). In Germany, for example, women are largely represented in health care as well and in education or social affairs (Belitz et al., 2008).

To dovetail on the inconsistencies in defining STEM, the complexity in defining STEM and clearly delineating it since STEM tends to be more and more woven into subject areas, including technology and engineering, for example, not all researchers and scholars agree that there is too little STEM workforce in the United States. They note that shortages exist in occupational groups that may or may not always require a bachelor's degree, such as in service, production, transportation and other occupations. Regardless 
of whether a bachelor's degree is required or not to do the job, how do STEM-related occupations at the sub-bachelor's level can be part of the STEM shortage equation? One direct implication that emerges from this level of complexity is how granular can the definition of STEM be for those four de facto core disciplines, known as Science, Engineering, Technology, and Mathematics, that are heterogeneous in nature and representation by most jurisdictions, internationally (Freeman, Marginson \& Tytler, 2015) in order to still be understood, in part, by all stakeholders, from policymakers, industry groups, professional associations, unions, researchers and scholars? What happens when industry seeks to recruit a qualified workforce that is not available and coordinates its efforts with the local college or university? The industry may be looking to recruit workers, who install, calibrate, wire, and maintain solar panels; who build and use spreadsheets to determine appropriate financial forecasts and production level; who determine the correct composition and spreading of fertilizer in a field of corn. Can all those individuals be categorized as STEM workers? R. Hira (personal communication, October 6, 2015) would respond that a production worker is not typically a STEM worker, that a welder is not a STEM worker by anyone's definition, “otherwise, you can't do any analysis, if you can't draw any boundary." This raises a fundamental question that is how broad can the definition of STEM be in order to still make sense for every stakeholder to be able to have a debate based on a common analytical framework? ${ }^{14}$ Indeed, the more precise STEM can be defined and delineated could help better answer what the adequacy of STEM skills is vs STEM-related vs non-STEM skills. The

\footnotetext{
${ }^{14}$ The researcher will return to these issues in the recommendations section of this final chapter
} 
infiltration of STEM skills in non-STEM fields is likely going to muddy STEM, which is already confusing to practitioners in its meaning and context (Koehler et al., 2016; Sanders, 2009). The direct implication to this changing nature of the labor market is to be able to evaluate how much of STEM plays out in these types of occupations that are more tangential compared to occupations that fit within a reasonably bound definition.

Nonetheless, as the main objective is to increase the number of STEM graduates, the United States is largely a market economic system and while the short-term rationale may be to produce more engineers, is there a clear answer to how many engineers are needed? Does the United States run the risk to end up with too many engineers (R. Hira, personal communication, October 6, 2015)? By and large, the study has indicated spot shortages in STEM fields within specific areas of expertise rather than general shortages. Such spot shortages can be in the semiconductor sector or in specific engineering and technology that may be highly cyclical in the United States or in specific engineering such as mechanical or electrical engineers with a combined knowledge in software development in Germany, for example. Marginson et al. (2013) refers to 'episodic' shortages in Australia that exist in engineering and computing.

In light of the America COMPETES Act, which included provisions to increase the number of STEM graduates, federal incentives for STEM programs have filtered down to colleges and universities. As the cost in education in STEM programs tends to be the most expensive (AIR, 2013) to teach, to pay faculty higher wages, to run and maintain laboratories, etc., it makes one ponder the question when the cost of education in STEM fields will be out-of-reach for U.S. students, if it is not already. Placed within the context of STEM shortages, claims may not help in attracting students into STEM 
and so do wages not being bid up, highly cyclical engineering employment, the long years of doctoral studies, followed with more frequent post-doctoral work, for example. All of these factors may not align with U.S. students' aspirations from pursuing a career in science. To become a research scientist may not be for everyone; however, colleges and universities' buy-in in 'pushing out' graduates to drive the economy (MckeownMoak, 2013) raises the question about how sustainable those practices are in light of the moral responsibility (Osborne \& Dillon, 2008) that education systems have in the formation of the societal benefit that derives from STEM education. With greater cost in educating STEM graduates, it forces us to ask how the advocacy role of career services and accountability at colleges and universities respond to the challenges and expectations of the 'real world'. Along those lines, how are advising best practices coordinated with the curriculum and choices of electives? R. Hira (personal communication, October 6 , 2015) tells his students to plan their career very carefully and to engage professionally.

Although human capital is even more important today for U.S. policy, in terms of workers' mobility, for example, the narrative about STEM shortages in engineers that large corporations are advocating for is one thing, it is another thing for U.S. government officials to present information objectively to millions of Americans, including teachers, parents and students of different ages to portray STEM as a promising career endeavor, well knowing that the "real opportunity requires every American to get the education and training they need to land a good-paying job" (White House, 2016, para 21); it remains puzzling how people can believe in that opportunity in acquiring "the skills today's employers are looking for to fill the jobs that are there right now and will be there in the future" (White House, 2013b, para 45) after totaling the cost of their education. 


\section{Recommendations}

"A coordinated strategy begins with the development of a coherent framework that everyone understands" (Baker \& Vogel, 2004, p. 8). These recommendations are directed at proponents of STEM shortages, researchers and pundits, who share different viewpoints ${ }^{15}$ on the current and ongoing debate over STEM shortages. Recommendations are suggesting how further actions about STEM could be taken at the federal and state level within the global setting.

1. There is an urgent need to better define what STEM means and whether the grouping of the four de facto disciplines, known as Science, Engineering, Technology, and Mathematics still make sense today.

Recommendation One would be to help formalize a more comprehensive and unbiased definition of STEM. From its origin in government policy in the early 1990s, STEM is still confusing to practitioners in its meaning and context (Koehler, Binns, \& Bloom, 2016; Sanders, 2009). While N. Smith (personal communication, September 29, 2015) describes STEM as being its own machinery, it makes one ponder the question about its meaningfulness - it is largely political- as STEM includes so many suboccupations under a grouping of disproportionally represented disciplines. Although STEM is more powerful as a group as N. Smith (personal communication, September 29, 2015) and J. Rothwell (personal communication, September 29, 2015) would argue, as opposed to having ' $\mathrm{T}$ ' by itself, how long can the debate continue without clearly

\footnotetext{
${ }^{15}$ It is important to note that individuals' viewpoint about this ongoing debate over STEM shortages is not clear cut; opinions may differ between professionals -engineers, for example- researchers and scholars.
} 
defining STEM or rather disregarding it entirely and advocate for supply and demand to be based on the discipline itself other than as a group? By and large, the definition of STEM seems elusive. STEM is heterogeneous in its representation and defining it might be a bit more complicated than it seems when faced with occupational skills that may not exactly fit the criteria set for a particular occupation since STEM tends to be more and more embedded in various subject areas. However, these occupations can also be the ones that employers are frustrated with, since they cannot find workers with adequate skills. While there is a need to define STEM within reasonable boundaries in order to set the public policy and run analyses on a commonly agreed framework, there could always be a few gray areas in STEM workers' skills and competencies, particularly when an occupation could define the possibility of a distinct labor market (Cohen, 1995) in light of rapid technological developments that emerge from globalization. For example, a welder is not a STEM worker by anyone's definition, R. Hira (personal communication, October 6, 2015) would comment. The same may be for someone, who installs, calibrates, wires, and maintains solar panels. In addition to educational level requirements, some occupations may be more tangential to how STEM is delineated; however, reaching out for a common understanding of this social construct -STEM - will definitively remain a challenge. Defining what STEM means is a priority in order to prevent any misleading interpretation of what shortages are about, in nature and in composition.

2. Engage in statistical analyses objectively to most accurately track how human capital is utilized by industry in alignment with STEM curricula.

Recommendation Two would help answer anecdotal opinions shared by STEM 
workers, who see the real STEM crisis being a lack of demand (Hira, 2010). The absence of a standard definition of STEM has a direct impact on data and how data are reported by various groups that have a vested interest. ' $S$ ' and ' $E$ ' account for about a third of STEM; 'T' accounts for over half. While determining whom is included in STEM and what disciplines count as STEM may be a matter of interpretation, it is nonetheless very much influenced by multinational corporations that fund non-profit organizations and think tanks. Teitelbaum (2003) recommends that researchers must "encourage objective appraisals of current career paths, as well as innovations in higher and continuing education" (p. 53). If federal incentives for STEM programs are predicated on the levels of enrollment at colleges and universities, how do those efforts translate when the deployment and utilization of STEM graduates' human capital by industry is not readily apparent from the data (Marginson et al., 2013)? Marginson et al. (2013) see that "the manner in which, and the extent to which, graduates' human capital is utilised at work, industry by industry, in the short- and long-term - remain largely a 'black box' for research" (p. 126).

3. Encourage the use of a vetting process for publications in STEM (or MINT). Recommendation Three would help instill transparency in reporting evidence, particularly when analysts who may have a vested interest muddy data to support the narrative of a shortage despite the absence of clear and consistent evidence. While it may take time to dissect long reports, do reports exhibit sufficient transparency to replicate analyses?

4. Invest in geographically 'sticky' type of investments (R. Hira, personal communication, October 6, 2015). 
Recommendation Four would help alleviate STEM shortages in regions where people are left behind, when corporations move their headquarters out of the area or overseas, for example. The human capital side of STEM is more important today from a policy perspective than it may have been in the past because U.S. workers tend to be much less mobile than corporations (R. Hira, personal communication, October 6, 2015). This recommendation aims to clearly bring in evidence that there is a conflicting interest between education as the supply source of human capital and industry as the demand for qualified workers.

5. Explore strength and relationships between career services, advising and the curriculum at colleges and universities.

Recommendation Five would be to explore methods and policies that would support the integration of career services with advising and the curriculum at colleges and universities in guiding students in their career path for employment readiness.

\section{Future Research}

The debate about STEM shortages is not unique to the United States. The study intended to bring contrasted views to the debate from two other OECD countries that share a common denominator -the Humboldtian model-associated with a common past with a vision of science and the migration of German scientists. Through the historiography of STEM and the programs and policies surrounding its development in higher education, in almost a century, future research topics can be identified.

Suggested topics for future study are as follows:

1. The discussion on the needs of technically trained personnel has been an important part of the study. The study has discussed the role of scientists from the early 
years of the twentieth century, when working as military personnel to the emergence of scientists from Europe before World War II and academic researchers, who were mobilized during the war to work on research and development projects at their institutions and remunerated for their service. Nonetheless, to quote R. Hira (personal communication, October 6, 2015), "the military aspect is much understated, because if [the United States] loses the electronic sector, technology superiority [is lost]". How does the role of the military transpire in protecting nationally critical technologies within a free trade and free market environment?

2. While the need to establish a coherent definition of STEM is fundamentally important to frame the policy discourse in its appropriate context and have proponents and researchers working together under a common analytical framework, reaching out for that common understanding of STEM would be key to formulate education policies and programs. The infiltration of STEM skills in non-STEM fields is likely going to muddy STEM, which is already confusing to practitioners in its meaning and context (Koehler et al., 2016; Sanders, 2009).

3. In the United States, the ' $\mathrm{T}$ ' part of STEM is a very specialized field that can be entered without a formal education. ' $\mathrm{T}$ ' also has the lowest credit STEM requirements of any STEM field (H. Salzman, personal communication, September 29, 2015). Although technology is embedded in almost every facet of one's life today, it can also be picked up very rapidly. How do the educational requirements for ' $\mathrm{T}$ ' translate within higher education and how do they exactly transpire despite political motivations?

4. Explore and analyze the demand side by developing a mixed method study conducted by interviewing employers in STEM areas, to inform how the current policies 
are aligning with practices and how the study could formulate revised or new policies and practices.

5. A study conducted on the formation of STEM skills and their utilization in industry sectors based on the demand of such skills could help better align supply and demand. The study could help better understand the drivers of industry demand for skills respective of how they fit within STEM and to anticipate future skills needs.

6. Lastly, extend the country comparison from United States, Australia and Germany by shifting the focus to countries that tend to most generally supply students and migrants workers in STEM fields, namely China and India.

\section{Conclusion}

The rhetoric of STEM workforce shortages in the United States has a direct impact on scientific and technological innovation and education. Similar concerns apply in Australia and Germany. In all three cases, the discourse is heavily framed in human capital terms despite contextual differences relative to the political, economic and social characteristics of each nation, operating within the larger context of a more integrated competitive global knowledge economy. Most importantly, the study has shown that STEM is a currency used to serve vested interests in support of the political discourse about STEM shortages. Associated with claims about a lack of supply in STEM workforce, with a focus on STEM graduates with at least a bachelor's degree or higher, the legitimacy of such claims has been questioned by researchers and pundits, who disagree with these claims, particularly due to the lack of empirical evidence that has been feeding the current belief of widespread labor market shortages in science and engineering occupations. Nonetheless, not all professionals -engineers, for example- 
researchers and scholars agree that there is too little STEM workforce. One parallel argument is the lack of reliable and consistent data coupled with the fact that there are many definitions of STEM, but no standard definition. To quote H. Salzman (personal communication, September 29, 2015), "STEM is an acronym that has a political meaning rather than scientific or policy meaning". How STEM is defined, and thus how empirical evidence is obtained and relevant to the real situation, particularly when an occupation could define the possibility of a distinct labor market (Cohen, 1995) adapting to rapid technological developments in a global setting, is at the core of the rhetoric.

In light of these uncertainties alongside a nebulous definition of STEM, the debate over STEM shortages is ongoing and tends to be polarized, namely with wages. By and large, the study has nonetheless indicated spot shortages in specific occupational STEM fields, niche markets, industry sectors and geographical areas rather than general shortages. That said lessons from the past about predictions emphasizing the lack of supply in STEM scholars and employees have not deterred proponents of shortages in their continuous efforts to publicize long-term labor-market projections for scientists and engineers. At the same time, demographic changes are a common concern for the United States, Australia and Germany. However, it is uncertain from the policy-side of STEM whether the participation of women, under-represented populations, and seniors has been fully assessed in their potential to increase a nation's talent pool. Extending the talent pool to the immigrant labor force, namely from China and India, the 'push' and 'pull' drivers of immigration (Salzman, 2013) have fueled the rhetoric of STEM shortages in all three countries as a means to suppress wages and drive economic growth. However, the migration of foreign workers is not as simple as it seems, as it has engendered tensions 
with unsubstantiated STEM shortages and issues of social integration that remain critical in places such as Germany, for example. Despite the plethora of reports and studies on STEM shortages in the United States, Australia and Germany, it may be difficult to clearly assess the long term impact of reforms. The discourse in Australia and Germany tends to be more tied to the government and organizations while there tends to be a greater mix of information sources in the United States, making the discourse harder to decipher.

As federal investments in STEM programs and initiatives aim to expand a STEM talent pool in the United States, it remains to be seen whether STEM education is well connected with the demand of a high-skilled STEM workforce in different sectors of the American economy. This ongoing debate will persist to be a challenge and while either side could be right, it is critical that bipartisan policy discussions be articulated on a common analytical framework to be able to frame the discourse in order to define and substantiate STEM and the values it brings to society. I believe that this is a contentious discourse. We need to all agree on what STEM is. This discourse may have no end in sight, it is nonetheless critical that "persuading young people to pursue careers in science without the evidence of demand [and a rationale based on a lack of consistent data and moveable labor markets across the globe] would be morally questionable" (p. 7). That said, can the United States sustain the myopic enterprise for greed by substituting the livelihood and aspirations of its people for science with on-demand labor practices? It is the responsibility of government officials to build public trust and provide solid objective data to inform people, if at all possible. 


\section{REFERENCES}

Adams, D. (2014, October). Is the 'skills gap' really a thing? By Sonari Glinton. National Public Radio.

Adams, J. D. (2010). Is the United States losing its preeminence in higher education? In

C. T. Clotfelter (Ed.), American universities in a global market (pp. 33-68). Chicago: University of Chicago Press.

Agar, J. (2012). Science in the twentieth century and beyond. Polity Press: Cambridge.

Alexander, F. K. (2000). The Changing Face of Accountability: Monitoring and Assessing Institutional Performance in Higher Education. The Journal of Higher Education, 71(4), 411-431.

American Institutes for Research. (2013a). How much does it cost institutions to produce STEM degrees? Center for STEM education \& innovation. Retrieved from http://www.deltacostproject.org/sites/default/files/products/Cost $\% 20$ to\%20Institut ions \%20of\%20STEM\%20Degrees.pdf

American Institutes for Research. (2013b). The road to the STEM professoriate for underrepresented minorities: A review of the literature. Retrieved from http://www.air.org/files/AGEP_Lit_Review_10-26-09.pdf

America COMPETES Act of 2007, P.L. 110-69 (121 STAT. 572). Retrieved from http://www.gpo.gov/fdsys/pkg/PLAW-110pub169/pdf/PLAW-110publ69.pdf

America COMPETES Reauthorization Act of 2010, P.L. 111-358 (124 STAT. 3982). Retrieved from http://www.gpo.gov/fdsys/pkg/PLAW-111publ358/pdf/PLAW111publ358.pdf

American Competitiveness Alliance. (2016). National survey: American businesses struggling to hire STEM talent due to increasing scarcity, higher costs and government fees. Accessible at http://www.prnewswire.com

Anft, M. (2013). The STEM crisis: Reality or myth? The Chronicle of Higher Education Retrieved from http://chronicle.com.libproxy.lib.ilstu.edu/article/The-STEMCrisis-Reality-or/142879/ 
Angier, N. (2010). STEM education has little to do with flowers. New York Times, pp. 13. Retrieved from http://www.nytimes.com/2010/10/05/science/05angier.html? pagewanted=all\&_r=0

Arrow, K., \& Capron, W. M. (1959). Dynamic shortages and price rises: The engineerscientist case. Quarterly Journal of Economics, 73(2), 292-308. doi: $10.2307 / 1883726$

Atkinson, R. C. (1990). Supply and demand for scientists and engineers: A national crisis in the making. Science, 248(4954), 425-432. doi:10.1126/science.248.4954.425

Atkinson, R. C., \& Blanpied, W. A. (2008). Research universities: Core of the US science and technology system. Technology in Society, 30(1), 30-48. doi:10.1016/j.techsoc.2007.10.004

Atkinson, R. D., Castro, D., Andes, S. M., Ezell, S. J., Hackler, D., \& Bennett, R. (2010). Innovation Policy on a Budget: Driving Innovation in a Time of Fiscal Constraint. SSRN Electronic Journal, 1-31. doi:10.2139/ssrn.1722870

Atkinson, R. D., \& Mayo, M. (2010). Refueling the U.S. innovation economy: Fresh approaches to science, technology, engineering and mathematics (STEM) education. Washington, DC: The Information Technology \& Innovation Foundation. Retrieved from: http://www.itif.org/files/2010-refueling-innovationeconomy.pdf

Atwater, M., \& Jones, A. (2004). Preparing for a future labor shortage: How to stay ahead of the curve. Graziadio Business Review, 7(2). Retrieved from http://gbr.pepperdine.edu/

Australian Academy of Science (2015). Position statement-Science priorities for Australian innovation. Accessible at https://www.science.org.au/supportingscience/science-policy/position-statements/sciencepriorities\#sthash.RRsf4vgj.dpuf

Australian Bureau of Statistics. (2014). Perspectives on Education and Training: Australians with qualifications in science, technology, engineering and mathematics (STEM), 2010-11. Qualifications paying off in science, technology, engineering and maths. Retrieved from http://www.abs.gov.au

Australian Bureau of Statistics. (2015). Average weekly earnings. Retrieved from http://www.abs.gov.au 
Australian Council of Learned Academies. (2013a). Compendium of reports for Australia's Comparative Advantage. Retrieved from

http://www.acola.org.au/PDF/SAF01/5.\%20Australias\%20Comparative\%20Adva ntage.pdf

Australian Council of Learned Academies. (2013b). STEM: Country comparisons.

PMSEIC Report. Retrieved from http://www.chiefscientist.gov.au/wpcontent/uploads/STEM-recommendations-for-PMSEIC.pdf

Australian Government, (2012a). Australia in the Asian Century [White Paper]. Retrieved from https://www.corrs.com.au/assets/thinking/downloads/Australia-inAsian-Century-Issues-Paper.pdf

Australian Government. Australia's Chief Scientist. (2012b). \$54 million commitment to mathematics, engineering and science. Retrieved from http://www.chiefscientist.gov.au/2012/05/54-million-committment-tomathematics-engineering-and-science/

Australian Government. Australian Research Council. (2015). \$86.9 million to promote industry-university linkages (Media Release). Canberra, Australia: The Hone Christopher Pyne MP

Australian Government. Department of Education and Training. (2016). Skilled Occupations List. Accessible at https://www.education.gov.au/

Australian Government. Department of Employment. (2015). Skill shortages - Statistical summary. Retrieved from

https://docs.employment.gov.au/system/files/doc/other/skillshortagesstatisticalsu mmary2015.pdf

Australian Industry Group. (2012). Lifting our Science, Technology, Engineering and Mathematics (STEM) Skills. Retrieved from http://www.aigroup.com.au/portal/binary/com.epicentric.contentmanagement.serv let.ContentDeliveryServlet/LIVE_CONTENT/Publications/Reports/2013/Ai_Gro up_Skills_Survey_2012-STEM_FINAL_PRINTED.pdf

Australian Industry Group. (2015). Progressing STEM skills in Australia. Retrieved from http://www.aigroup.com.au/portal/binary/com.epicentric.contentmanagement.serv let.ContentDeliveryServlet/LIVE_CONTENT/Publications/Reports/2015/14571_ STEM\%2520Skills\%2520Report\%2520Final\%2520-.pdf

Australian War Memorial. (1977a). Australia in the war of 1939-1945. Series 4: Vol. IV. War economy, 1942-1945. The search for manpower. (pp. 13-47). Retrieved from https://static.awm.gov.au/images/collection/pdf/RCDIG1070657--1-.pdf 
Australian War Memorial. (1977b). Australia in the war of 1939-1945. Series 4: Vol. IV. War economy, 1942-1945.Reconstruction - The manpower dimension. (pp. 680706). Retrieved from http://static.awm.gov.au/images/collection/pdf/RCDIG1070160--1-.pdf

Aynsley, B. (2015, June). Shortage of IT and communications tech talent costly to economy. The Australian Business Review. Accessible from http://www.theAustralian.com.au

Baker, P. J., \& Vogel, L. (2004). Leadership and school reform: Moving from contradictions to coherence. Paper presented at international conference Making educational reform happen: learning from the Asian experience and comparative perspectives. Bangkok, Thailand.

Bardach, E. (2012). A practical guide for policy analysis: The eightfold Path to more effective problem solving. Los Angeles: Sage.

Belitz, H., Clemens, M., Schmidt-Ehmcke, J., Schneider, S., \& Werwatz, A. (2008). Deficits in education endanger Germany's innovative capacity. German Institute for Economic Research, 14(4), 86-93. Retrieved from http://www.diw.de/documents/publikationen/73/diw_01.c.91488.de/diw_wr_2008 -14.pdf

Bell, J., Frater, B., Butterfield, L., Cunningham, S., Dodgson, M., Fox, K., ... Webster, E. (2014). The role of science, research and technology in lifting Australian productivity [Project 4]. http://www.acola.org.au/PDF/SAF04Reports/SAF04\%20Role\%20of\%20SRT\%2 0in\%20lifting\%20Aus\%20Productivity\%20FINAL\%20REPORT.pdf

Bellman, L., \& Hübler, O. (2014). Skills shortage before, during and after the Great Recession. http://www.ratswd.de/6kswd/style/praesentationen/D6KSWD_RatSWD_Bellmann-Huebler.pdf

Benderly, B. L. (2012, January). What scientist shortage? Columbia Journalism Review. Accessible at http://www.cjr.org/reports/what_scientist_shortage.php?page=all\&print=true

Benderly, B. L. (2015, February). Workforce 'smoke and mirrors' down under. Science. doi: 10.1126/science.caredit.a1500031

Bettinger, E. (2010). To be or not to be: Major choices in budding scientists. In C. T. Clotfelter (Ed.), American Universities in a Global Market (pp. 69-98). Chicago: University of Chicago Press. 
Birrell, B. (2015). Too few or perhaps too many STEM graduates. Australian Universities' Review, 57(2), pp. 71-78. Retrieved from http://issuu.com/nteu/docs/aur_57-02

Birrell, B. \& Healy, E. (2014). Immigration and unemployment in 2014. Retrieved from ttps://theaustralianpopulationresearchinstitute.files.wordpress.com/2015/01/birrell -healy-immigration-unemployment-august-2014.pdf

Bosch, G. (2011). Fachkräfte - das Geheimnis der deutschen Wettbewerbsfähigkeit. In Zeitgespräch im Fachkräftemangel: Scheinproblem oder Wachstumshemmnis? Wirtschaftsdienst. 9, 583-586. doi: 10.1007/s10273-011-1268-9

Bott, P., Helmrich, R., \& Zika, G. (2011). MINT occupations - claims of a skills shortage are often overstated. Analyses from the first BIBB-IAB Qualifications and major occupational field projection. BIB BWP Special Education, 9-13

Bowen, G. A. (2009). Document analysis as a qualitative research method. Qualitative Research Journal, 9(2), 27-40. doi: 10.3316/QRJ0902027

Bradley, D., Noonan, P., Nugent, H., \& Scales, B. (2008). Review of Australian higher education: final report [Bradley review]. Canberra: DEEWR.

Braue, D. (2015, August). Pollies' STEM sell is a generation too late. ABC Australia. Accessible at http://www.abc.net.au/news/2015-08-21/braue-pollies'-stem-sell-isa-generation-too-late/6714886

Bräuninger, D. (2012, May). New stimulus for Germany's skilled workers market. Deutsche Bank Research. Retrieved from http://www.dbresearch.com/servlet/reweb2.ReWEB?addmenu=false\&document= PROD0000000000288952\&rdShowArchivedDocus=true\&rwobj=ReDisplay.Start .class\&rwsite=DBR_INTERNET_EN-PROD

Bräuninger, D., \& Majowski, C. (2011). Labour mobility in the euro area. Deutsche Bank research. EU Monitor 85 . Retrieved from http://www.dbresearch.in/PROD/DBR_INTERNET_DEPROD/PROD0000000000278645/Labour+mobility+in+the+euro+area.pdf

Breiner, J. M., Johnson, C. C., Harkness, S. S., \& Koehler, C. M. (2012). What is STEM? A discussion about conceptions of STEM in education and partnerships. School Science and Mathematics, 112(1), 3-11.

Brenke, K. (2012a). Engineers in Germany: No shortage in sight. DIW Economic [Bulletin 5]. Retrieved from http://www.diw.de/documents/publikationen/73/diw_01.c.398792.de/diw_econ_b ull_2012-05-1.pdf 
Brenke, K.. (2012b). Gibt es in Deutschland einen Fachkräftemangel und wird es einen geben? Der unsichtbare Mangel. In: Bundesinstitut für Bau-, Stadt- und Raumforschung (BBSR) im Bundesamt für Bauwesen und Raumordnung (BBR) (Hrsg.). Fachkräftemangel. Ein neues, demografisch bedingtes Phänomen? Dezembertagung des Arbeitskreises ,Städte und Regionen" der DGD in Kooperation mit dem BBSR. BBSR-Online-Publikation, 02/2012, 4-13. http://www.bbsr.bund.de/BBSR/DE/Veroeffentlichungen/BBSROnline/2012/DL_ ON022012.pdf

Brenke, K.. (2012c). Hochschulabgänger decken den Bedarf. DIW Wochenbericht, Ingenieursberufe: Nachwuchs mittelfristig gesichert, 11, 9-10. https://www.diw.de/documents/publikationen/73/diw_01.c.394835.de/12-11.pdf

Breznitz, D. (2014, May). Why Germany dominates the U.S. in innovation. Harvard Business Review. https://hbr.org/2014/05/why-germany-dominates-the-u-s-ininnovation/

Brown, R., Brown, J., Reardon, K., \& Merrill, C. (2011). Understanding STEM: Current perceptions. Technology and Engineering Teacher, 5-10.

Bush, V. (1945). Science the endless frontier. Washington, DC: Government Printing Office. Retrieved from National Science Foundation website: http://www.nsf.gov/od/lpa/nsf50/vbush1945.htm

Business Europe. (2011, Spring). Plugging the skills gap - The clock is ticking. Retrieved from https://www.businesseurope.eu/sites/buseur/files/media/imported/201100855-E.pdf

Business Higher Education Forum (BHEF). (2011). Meeting the STEM workforce challenge: leveraging higher education's untapped potential to prepare tomorrow's STEM workforce. Retrieved from http://files.eric.ed.gov/fulltext/ED527257.pdf

Butz, W. P., Kelly, T. K., Adamson, D. M., Bloom, G.A., Fossum, D., \& Gross, M. E. (2004). Will the scientific and technology workforce meet the requirements of the Federal government? Retrieved from http://www.rand.org/content/dam/rand/pubs/monographs/2004/RAND_MG118.p df

Bybee, R. W. (2010). Advancing STEM education: A 2020 vision. Technology and Engineering Teacher, 70(1), 30-35. 
Camarota, S. A., \& Zeigler, K. (2014). Is there a STEM worker shortage? A look at employment and wages in science, technology, engineering, and math. Center for Immigration Studies. (pp. 1-34). Retrieved from http://cis.org/sites/cis.org/files/camarota-STEM.pdf

Cappelli, P. (2015). Skill gaps, skill shortages and skill mismatches: Evidence for the US (Working Paper 20382). Retrieved from NBER website:

http://www.nber.org/papers/w20382

Caprile, M., Palmen, R., Sanz, P., \& Dente, G. (2015). Directorate General for Internal Policies. Encouraging STEM studies: Labour Market Situation and Comparison of Practices Targeted at Young People in Different Member States. Available at http://www.europarl.europa.eu/studies

Carnevale, A. P., Cheah, B., \& Strohl, J. (2012). Hard times: Not all college degrees are created equal. Georgetown University: Center on Education and the Workforce. Retrieved from https://georgetown.app.box.com/s/og6p8y9x1yeacejk1ci0

Carnevale, A. P., Smith, N., \& Melton, M. (2011). STEM. Georgetown University: Center on Education and the Workforce. Retrieved from https://cew.georgetown.edu/

Charette, R. N. (2012, June). STEM education funding in the U.S. - Is more or less needed? IEEE Spectrum. Retrieved from http://spectrum.ieee.org/riskfactor/atwork/education/stem-education-in-the-us-is-more-or-less-needed

Chen, X., \& Weko, T. (2009). Stats in brief: Students who study science, technology, engineering, and mathematics (STEM) in postsecondary education. Washington, DC: US Department of Education NCES. Retrieved from http://nces.ed.gov/pubs2009/2009161.pdf

Chomsky, N. (2014). How America's great university system is being destroyed. AlterNet. Retrieved from http://www.alternet.org/corporate-accountability-andworkplace/chomsky-how-americas-great-university-system-getting? page $=0 \% 2 \mathrm{C} 2 \&$ paging $=$ off \&current_page $=1 \#$ bookmark

Clark, B. R. (1997). Foreword. In M. W. Peterson et al. (Eds.), Planning and management for a changing environment: A handbook on redesigning postsecondary institutions (pp. xiii-xviii). San Francisco: Jossey-Bass.

Cohen, A. M., \& Brawer, F. B. (2008). The American community college. San Francisco, CA: Jossey Bass. 
Cohen, A. M., Kisker, C. B, \& Brawer, F. B. (2013). The economy does not depend on higher education. Chronicle of Higher Education. Retrieved from http://chronicle.com/article/The-Economy-Does-Not-Depend-on/142641/

Cohen, M. S. (1995). Labor shortages as America approaches the twenty-first century. Ann Arbor, MI: The University Press of Michigan Press.

Cohen, M. S., \& Zaidi, M. A. (2002). Global skill shortages. Cheltenham, UK: Edward Elgar.

Commonwealth Scientific and Industrial Research Organisation (2015). CSIRO fund to support Australian start-ups. Accessible from http://www.csiro.au/en/News/News-releases/2015/CSIRO-fund-to-supportAustralian-start-ups

Conant, J. B. (1947). On understanding science - An historical approach. New Haven: Yale University Press.

Constant, A. F., \& Tien, B. N. (2011). Germany's immigration policy and labor shortages. IZA Research Report (Report No. 41) pp. 1-38. Retrieved from http://www.iza.org/en/webcontent/publications/reports/report_pdfs/iza_report_41. pdf

Cook, H. (2015, May). Christopher Pyne pushes for maths or science to be compulsory for year 11 and 12 students. The Sydney Morning Herald. Retrieved from http://www.smh.com.au/federalpolitics/politicalnews/christopherpynepushesform athsorsciencetobecompulsoryforyear11and12students20150526gh9kjv.html

Costa, D. (2012). STEM labor shortage? Microsoft report distorts reality about computing occupations (pp. 1-12). Retrieved from http://s1.epi.org/files/2012/pm195-stem-labor-shortages-microsoft-reportdistorts.pdf

Crotty, M. (1998). The foundations of social research: Meaning and perspective in the research process. London: Sage Publications.

Dawkins, J. (1987). Minister for employment, education, and training. Higher Education: A discussion paper. Canberra: Australian Government Publishing Service.

DeBoer, G. E. (2000). Scientific literacy: Another look its historical and contemporary meanings and its relationship to science education reform. Journal of research in science teaching, 37(6), 582-601. doi: 10.1002/1098-2736 
Del Sorbo, M., \& Hervás, F. (2013). Mind the Science and Technology Skills Gap. Retrieved from http://publications.jrc.ec.europa.eu/repository/bitstream/JRC83766/mind the gap.pdf

Denning, P. J., \& Gordon, E. E. (2015). Communications of the ACM, 58(3), 28-30. doi: $10.1145 / 2723673$

Dobson, I. R. (2015). STEM: Country comparisons - Europe ... a critical examination of existing solutions to the STEM skills shortage in comparable countries. Retrieved from http://www.acola.org.au/PDF/SAF02Consultants/Consultant\%20Report\%20$\%$ 20Western\%20Europe.pdf

Dunn, W. N. (1981). Public policy analysis: An introduction. Englewood Cliff, N.J.: Prentice-Hall.

European Center for the Development of Vocational Training. (2014). Rising STEMs. Retrieved from http://www.cedefop.europa.eu/en/publications-andresources/statistics-and-indicators/statistics-and-graphs/rising-stems

European Commission. (2014). e-SKILLS in Europe. Germany [Report]. Bonn, Germany: empirica Gesellschaft für Kommunikations- und Technologieforschung mbH.

European Commission. (2015). EC Skills Panorama glossary. Retrieved from http://euskillspanorama.cedefop.europa.eu/en/glossary

Eurydice. (2011). Science education in Europe: National policies, practices and research. Retrieved from http://eacea.ec.europa.eu/education/eurydice/documents/thematic_reports/133en.p df

Fallon, D. (2012). Europe inches forward on higher education reform, focus : Germany. Social Research, 79(3), 713-740.

Federal Ministry of Economics and Technology (BMWi) (2010). In focus: Germany as a competitive industrial nation: Build on strengths-overcoming weaknessessecuring the future. Retrieved from http://www.bmwi.de/English/Redaktion/Pdf/germany-industrynation,property $=$ pdf, bereich $=$ bmwi,sprache $=$ en, $r w b=$ true.pdf

Freeman, B. (2013). Science, Mathematics, Engineering and Technology (STEM) in Australia: Practice, policy and programs. Australian Council of Learned Academies. Retrieved from www.acola.org.au 
Freeman, B., Marginson, S., \& Tytler, R. (2015). Widening and deepening the STEM effect. In B. Freeman, S. Marginson, and R. Tytler (Eds.). The Age of STEM: Educational policy and practice across the world in science, technology, engineering and mathematics (pp. 178-200). London: Routledge Research in Education.

Freeman, R. B. (2006a). Does globalization of the scientific/engineering workforce threaten U.S. economic leadership? (Eds.). A. B. Jaffe, J. Lerner, \& S. Stern. Innovation policy and the economy (pp. 123-158). Cambridge, MA: The MIT Press.

Freeman, R. B. (2006b). Is a great labor shortage coming? Replacement demand in the global economy (Working Paper 12541). Retrieved from NBER website: http://www.nber.org/papers/w12541

Galama, T., \& Hosek, J. (2003). Is the United States Losing its edge in science. Retrieved from

http://www.rand.org/content/dam/rand/pubs/research_briefs/2008/RAND_RB934 7.pdf

Galama, T., \& Hosek, J. (2008). U.S. competitiveness in science and engineering. Retrieved from http://www.rand.org/content/dam/rand/pubs/monographs/2008/RAND_MG674.p df

German Center for Research \& Innovation. (2013). GCRI Interview. Dr. Ulrike Struwe. Retrieved from http://www.germaninnovation.org/shared/content/documents/interviews/DB41B8 62-2F25-E311-A37C-000C29E5517F.pdf

Goldin, C., \& Katz, L.F. (2007). The race between education and technology: The evolution of U.S. educational wage differentials, 1890 to 2005 (Working Paper 12984). Retrieved from NBER website: http://www.nber.org/papers/w12984.pdf

Gonzalez, H. B., \& Kuenzi, J. J. (2012). Science, Technology, Engineering, and Mathematics (STEM) education: A primer (CRS Report R42642). Retrieved from Federation of American Scientists website: http://fas.org/sgp/crs/misc/R42642.pdf

Griswold, J. (2006). What is the best yardstick to measure inflation? Trusteeship Magazine. Retrieved https://www.commonfund.org/CommonfundInstitute/HEPI/Pages/BestYardstickt oMeasureInflation.aspx 
Gunther, B. (2013). The cultural aspects of Mint recruitment: How to overcome the skills shortage by understanding graduates' needs. Hamburg, Germany: Anchor Academic Publishing.

Guralnick, S. M. (1979). The American scientists in higher education, 1820-1910. In N. Reingold (Ed.). The sciences in the American context: New perspectives (pp. 99141). Washington, D.C.: Smithsonian Institution Press.

Hagedorn, L. S., \& Purnamasari, A. V. (2012). A realistic look at STEM and the role of community colleges. Community College Review, 40(2), 145-164. doi: $10.1177 / 0091552112443701$

Harbinson, F. H., \& Myers, C. A. (1964). Education, manpower, and economic growth: Strategies of human resource development. New York: McGraw-Hill.

Harris, R. (2014, September). When scientists give up. National Public Radio. Retrieved from http://www.npr.org/blogs/health/2014/09/09/345289127/when-scientistsgive-up. Accessed 10 October, 2014.

Healy, J., Mavromaras, K. \& Zhu, R. (2012). Consultant report: Securing Australia's future STEM: Country comparisons. Retrieved from http://www.acola.org.au/PDF/SAF02Consultants/Consultant\%20Report\%20\%20Australian\%20Labour\%20Market.pdf

Hechinger Report. (2011). Timeline: Important dates in U.S. science education history. The Hechinger Report. Retrieved from http://hechingerreport.org/content/timeline-important-dates-in-u-s-scienceeducation-history_5063/

Hinsdale, B. A. (1898). Horace Mann and the common school revival in the United States. New York: Charles Scribner's Sons.

Hira, R. (2010). U.S. policy and the STEM workforce system. American Behavioral Scientist, 53(7), 949-961. doi:10.1177/0002764209356230

Holton, J. T. (2010). Science education curriculum, history of. In C. Kridel (Ed.), Encyclopedia of curriculum studies (pp. 768-769). Thousand Oaks, CA: Sage Publications, Inc. doi: 10.4135/9781412958806.n406

Home, R. (1995). Science as a German export to ninetheeth century Australia (Working Paper No. 104).Sir Robert Menzies Centre for Australian Studies: http://www.kcl.ac.uk/artshums/ahri/centres/menzies/research/Publications/Workin gpapers/WP104Home.pdf 
Jaschik, S. (2013). Study finds differential tuition can influence enrollment levels. Inside Higher Education. Retrieved from

https://www.insidehighered.com/news/2013/07/15/study-finds-differentialtuition-can-influence-enrollment-levels

Kalhenberg, C., \& Spermann, A. (2012). How Could Germany Escape the Demographic Trap? IZA. Retrieved from http://ftp.iza.org/pp48.pdf

Kehm, B. M. (1999). Higher education in Germany: Developments, problems, and perspectives. Wittenberg: Institute for Higher Education Research.

Kelly, T. K., Butz, W. P., Carroll, S., Adamson, D. M., \& Bloom, G. (2004). The U.S. scientific and technical workforce: Improving data for decisionmaking. Proceedings of RAND Corporation, USA, CF-194. Retrieved from http://www.rand.org/content/dam/rand/pubs/conf_proceedings/2005/CF194.pdf

Killian, J. R. (1964). Towards a research-reliant society: Some observations on government and science. In H. Woolf (Ed.), Science as a cultural force (pp. 9-34). Baltimore, MD: The Johns Hopkins Press.

King, C., \& James, R. (2013). Creating a demand-driven system. S. Marginson. (Ed.). Tertiary education policy in Australia (pp. 11-20). University of Melbourne: Center for the Study of Higher Education. Retrieved from https://cshe.unimelb.edu.au/research/policy_dev/docs/Tert_Edu_Policy_Aus.pdf

Koehler, C., Binns, I. C., \& Bloom, M. A. (2016). The Emergence of STEM. In C. C. Johnson, E. E. Peters-Burton, \& T. J. Moore (Eds.). STEM road map: A framework for integrated STEM education (pp. 13-22). New York: Routledge.

Kraft, M. E., \& Furling, S. R. (2004). Public policy: Politics, analysis, and alternatives. Washington, D.C.: CQ Press.

Kuenzi, J. (2008). Science, Technology, Engineering, and Mathematics (STEM) education: Background, Federal policy, and legislative action (CRS Report RL33434). Retrieved from San Diego Science Alliance website: http://www.sdsa.org/resources/publications/Congressional\%20report.pdf

Landivar, L. C. (2013). Disparities in STEM employment by sex, race, and Hispanic origin. American Community Survey Reports, ACS-24. Washington, DC: U.S. Census Bureau. Retrieved from http://www.census.gov/prod/2013pubs/acs-24.pdf

Lazear, E. P., \& Spletzer, J. R. (2012). The United States labor market: Status quo or a new normal? (Working Paper 18386). Retrieved from NBER website: http://www.nber.org.libproxy.lib.ilstu.edu/papers/w18386.pdf 
Li, I. W., \& Miller, P. W. (2013). The absorption of recent graduates into the Australian labour market: Variations by university attended and field of study. The Australian Economic Review, 46(1), 14-30. doi: 10.1111/j.14678462.2013.00713.x

Lingens, H. G. (1998). German higher education: Issues and challenges. International Studies in Education. Bloomington, IN: Phi Delta Kappa Educational Foundation.

Lowell, B. L., \& Salzman, H. (2007). Into the eye of the storm: Assessing the evidence on science and engineering education, quality, and workforce demand. Urban Institute. Retrieved from http://www.urban.org/UploadedPDF/411562_Salzman_Science.pdf

Lynn, L., Salzman, H., \& Kuehn, D. (2011). Dynamics of engineering labor markets: Petroleum engineering and responsive supply. Paper presented at U.S. Engineering in the Global Economy, Boston, MA. Retrieved from http://conference.nber.org/confer/2011/SEWPf11/Lynn_Salzman.pdf

Machlup, F. (1962). The production and distribution of knowledge in the United States. Princeton, N.J.: Princeton University Press.

Makwana, R. (2006). Neoliberalism and Economic Globalization. Share the World's Resources. Retrieved from http://www.stwr.org/globalization/neoliberalism-andeconomic-globalization.html

Marcus, J. (2011). Two years after Obama's college graduation initiative, major obstacles remain. The Hechinger Report. Retrieved from http://hechingerreport.org/content/two-years-after-obamas-college-graduationinitiative-major-obstacles-remain_5946/

Marginson, S. (2003). Higher education reform in Australia - an evaluation. In H. Eggins (Eds.), Globalization and reform in higher education (pp. 133-163). Glasgow, UK: Open University Press.

Marginson, S. (2013). Introduction. S. Marginson. (Ed.). Tertiary education policy in Australia (pp. 7-10). University of Melbourne: Center for the Study of Higher Education. Retrieved from https://cshe.unimelb.edu.au/research/policy_dev/docs/Tert_Edu_Policy_Aus.pdf

Marginson, S. (2015). What international comparisons can tell us. In B. Freeman, S. Marginson, and R. Tytler (Eds.). The Age of STEM: Educational policy and practice across the world in science, technology, engineering and mathematics (pp. 22-32). London: Routledge Research in Education. 
Marginson, S., Tytler, R., Freeman, B., \& Roberts, K. (2013). STEM: Country comparisons. International comparisons of science, technology, engineering and mathematics (STEM) education. [Project 2]. Australian Council of Learned Academies. Retrieved from http://www.acola.org.au/PDF/SAF02Consultants/SAF02_STEM_FINAL.pdf

Matloff, N. (2013a). Immigration and the tech industry: As a labour shortage remedy, for innovation, or for cost savings? Migration Letters, 10(2), 210-227. Retrieved from https://migrationfiles.ucdavis.edu/uploads/rs/files/2012/9/ciip/matloffimmigration-the-tech-industry.pdf

Matloff, N. (2013b). Are foreign students the 'best and brightest'? Data and implications for immigration policy (EPI Briefing Paper 356). Retrieved from Economic Policy Institute: http://www.epi.org/files/2013/outstanding-talent-high-skilledimmigration.pdf

McGrath, P. J. (2002). Scientists, business, and the state, 1890-1960. Chapel Hill, NC:University of North Carolina.

Mcintyre, S. (2009). The same under different skies: the university in the United States and Australia. Journal of Australian Studies, 33(3), 353-369. doi: 10.1080/14443050903079722

Mckeown-Moak, M. P. (2013). The "new" performance funding in higher education.Educational Considerations, 40(2), 3-10.

Metcalf, H. E. (2011). Formation and representation: Critical analyses of identity, supply, and demand in science, technology, engineering, mathematics (doctoral dissertation). Retrieved from http://hdl.handle.net/10150/145744

Microsoft Corporation. (2012). A national talent strategy: Ideas for securing U.S. competitiveness and economic growth. Retrieved from https://news.microsoft.com/download/presskits/citizenship/MSNTS.pdf

Miles, M. B., \& Huberman, A. M. (1994). An expanded sourcebook: Qualitative data analysis. Thousand Oaks: Sage Publications.

Monro, T. (2015, April). Why a national science strategy is good for Australia. The Conversation. Accessible at http://theconversation.com/why-a-national-sciencestrategy-is-good-for-australia-40254

Moon, J., \& Rundell Singer, S. (2012). Bringing STEM into focus. Education Week, 31(19), 24-32. Retrieved from http://www.edweek.org/ew/articles/2012/02/01/19moon.h31.html 
National Academy of Sciences. (2010). Rising above the gathering storm: Rapidly approaching category 5. Washington, DC: National Academies Press.

National Academy of Sciences, National Academy of Engineering, and Institute of Medicine. (2007). Rising above the gathering storm: Energizing and employing America for a brighter economic future. Retrieved from http://www.nsf.gov/attachments/105652/public/NAS-Gathering-Storm-11463.pdf

National Academy of Sciences, National Academy of Engineering, Institute of Medicine, and National Research Council. (1995). Allocating Federal funds for science and technology. Washington, DC: The National Academies Press.

National Archives of Australia. (2015). Commonwealth reconstruction training scheme administrative records - Fact sheet 178. Retrieved from http://www.naa.gov.au/collection/fact-sheets/fs178.aspx

National Commission on Excellence in Education. (1983). A Nation at risk: The imperative for educational reform. Washington, D.C.: U.S. Government Printing Office. Retrieved from http://datacenter.spps.org/uploads/sotw_a_nation_at_risk_1983.pdf

National Defense Education Act of 1958, P.L. 85-864 (72 Stat. 1580).

National Research Council. (2001). Building a Workforce for the Information Economy. Washington, D.C.: National Academies Press.

National Science Foundation. (2000). Science and Technology in Times of Transition: the 1940s and 1990s (Chapter 1). Retrieved from http://www.nsf.gov/statistics/seind00/pdf/c1/c01.pdf

National Science Foundation. (2010). Science and engineering indicators. Science and engineering labor force (Chapter 3). Retrieved from http://www.nsf.gov/statistics/seind10/pdf/c03.pdf

National Science Foundation. (2014a). Science and engineering indicators. Higher education in science and engineering (Chapter 2). Retrieved from http://www.nsf.gov/statistics/seind14/content/chapter-2/chapter-2.pdf

National Science Foundation. (2014b). Science and engineering indicators. Science and engineering labor force (Chapter 3). Retrieved from http://www.nsf.gov/statistics/seind14/content/chapter-3/chapter-3.pdf

National Science Foundation Act of 1950, P.L. 507-81 (64 Stat.149). Retrieved from https://www.nsf.gov/about/history/legislation.pdf 
National Science Foundation Act of 1950, amendment, P.L. 86-550 (73 Stat. 468).

Retrieved from http://www.gpo.gov/fdsys/pkg/STATUTE-74/pdf/STATUTE-74Pg256-3.pdf

National Science Foundation. Division of Science Resources Statistics. (2008). Survey of earned doctorates, 1998-2005. Arlington, VA: National Science Foundation.

National Science Foundation. STEM Education Data. (2014). What does the S\&E job market look like for U.S. graduates? Retrieved from https://www.nsf.gov/nsb/sei/edTool/data/workforce-03.html

Neubecker, N. (2014). Debating the shortage of skilled workers. DIW Roundup: Politik im Focus. Retrieved from http://www.diw.de/en/diw_01.c.434984.en/press/diw_roundup/debating_the_shor tage_of_skilled_workers.html

Office of the Chief Scientist (2012a). Health of Australian Science, Australian Government. Accessible at http:// www.chiefscientist.gov.au/2012/05/health-of australian-science-report-2/

Office of the Chief Scientist. (2012b). Mathematics, engineering \& science in the national interest. Australian Government, Canberra. Retrieved from http://www.chiefscientist.gov.au/wp-content/uploads/Office-of-the-ChiefScientist-MES-Report-8-May-2012.pdf

Office of the Chief Scientist. (2013). Science, technology, engineering and mathematics in the national interest: A strategic approach. Australian Government, Canberra. Retrieved from http://www.chiefscientist.gov.au/wpcontent/uploads/STEMstrategy290713FINALweb.pdf

Office of the Chief Scientist. (2014). Science, technology, engineering and mathematics: Australia's future. Australian Government, Canberra. Retrieved from http://www.chiefscientist.gov.au/wpcontent/uploads/STEM_AustraliasFuture_Sept2014_Web.pdf

Oregon Employment Department. (2012). The greening of Oregon's workforce: Jobs wages, and workforce. Retrieved from http://www.qualityinfo.org/pubs/green/greening.pdf

Organization for Economic Co-operation and Development. (2013). Education at a Glance 2013: OECD Indicators, OECD Publishing, Paris. doi: 10.1787/eag-2013table150-en 
Osborne, J. \& Dillon, J. (2008). Science education in Europe: Critical reflections http://efepereth.wdfiles.com/local--files/scienceeducation/Sci_Ed_in_Europe_Report_Final.pdf

Owen, G. T. (2009). Qualitative methods in higher education policy analysis: Using interviews and document analysis. The Qualitative Report, 19(52), 1-19. Retrieved from http://www.nova.edu/ssss/QR/QR19/owen52.pdf

Owen, L. (1997). Science in the United States. In J. Krige \& D. Pestre (Eds.), Science in the twentieth century. Amsterdam: Harwood Academic Press.

Panizzon, D., Corrigan, D., Forgasz, H., \& Hopkins, S. (2015). Impending STEM shortages in Australia: Beware the "smoke and mirrors". Procedia - Social and Behavioral Sciences, 167, 70-74. doi:10.1016/j.sbspro.2014.12.644

Parliament of Australia. The Senate (2014). Education and Employment Legislation Committee. Higher Education and Research Reform Amendment Bill 2014 [provisions]. Commonwealth of Australia. http://www.aph.gov.au/Parliamentary_Business/Committees/Senate/Education_an d_Employment/Higher_Education/Report/c02

Patton, C. V., Sawicki, D. S., \& Clark, J. (2016). Basic methods of policy analysis and planning. London: Routledge.

Perry, A. M. (2006). Substantive members should receive financial aid. Journal of Hispanic Higher Education, 5(4), 322-346. doi:10.1177/1538192706291140

Pick, D. (2008). Towards a 'post-public era'? Shifting frames in German and Australian higher education policy. Higher Education Quarterly, 62(1-2), 3-19. doi: 10.1111/j.1468-2273/2008.00383.x

Poirier, J. M., Tanenbaum, C., Storey, C., Kirshstein, R., \& Rodriguez, C. (2009). The road to the STEM professoriate for underrepresented minorities: A review of the literature. Washington, DC: American Institutes for Research.

Powell, J. J. W., \& Solga, H. (2011). Why are higher education participation rates in Germany so low? Institutional barriers to higher education expansion. Journal of Education and Work, 24(1-2), 49-68. doi:10.1080/13639080.2010.534445

President's Scientific Research Board. (1947a). Science and public policy: A program for the nation. Washington, D.C.: U.S. Government Printing Office.

President's Scientific Research Board. (1947b). Science and public policy: Manpower or research. Washington, D.C.: U.S. Government Printing Office. 
Rahn, L. (2013). Australia's science and technology global engagement. Australian Government. Department of industry, Innovation, Science, Research and Tertiary Education. Retrieved from

http://sites.nationalacademies.org/cs/groups/pgasite/documents/webpage/pga_084 199.pdf

Reif, F. (1965). The competitive world of the pure scientist. In N. Kaplan (Ed.), Science and society (pp. 133-145). Chicago: Rand Mc.Nally \& Company.

Reingold, N. (1979). Reflections on 200 years of science in the United States. In N. Reingold (Ed.), The sciences in the American context: New perspectives (pp. 920). Washington DC: Smithsonian Institution Press.

Reingold, N. (1981). Refugee mathematicians in the United States of America, 19331941: Reception and reaction. Annals of Science, 38, 313-338.

Richardson, S. (2007). What is a skill shortage? National Centre for Vocational Education Research. Retrieved from http://files.eric.ed.gov/fulltext/ED495918.pdf

Rochester Institute of Technology. (2007). Policymakers urged to address concerns about US science and technology workforce. Science Daily. Retrieved from http://www.sciencedaily.com/releases/2007/10/071017160531.htm

Rothwell, J. (2013). The hidden STEM economy. Brookings. Retrieved from http://www.brookings.edu/ /media/research/files/reports/2013/06/10 stem economy rothwell/thehiddenstemeconomy610.pdf

Rothwell, J., \& Ruiz, N. G. (2013). H-1B Visas and the STEM Shortage: A Research Brief. SSRN Electronic Journal. doi: 10.2139/ssrn.2262872

Rubin, H. J., \& Rubin, I. S. (2005). Qualitative interviewing: The art of hearing data. Thousand Oaks, CA: Sage.

Salzman, H. (2013). What shortages? The real evidence about the STEM workforce. Issues in Science and Technology, 58-67. Retrieved from http://policy.rutgers.edu/faculty/salzman/What\%20Shortages-Issues\%20S\&TSummer2013-Salzman-Final.pdf

Salzman, H. (2016). The impact of high-skill guestworker programs and the STEM workforce. Senate Committee on the Judiciary, U.S. Senate. Retrieved from https://www.judiciary.senate.gov/imo/media/doc/02-25$16 \% 20$ Salzman\%20Testimony.pdf

Sanders, M. (2009). STEM, STEM education, STEMmania. The Technology Teacher, 68(4), 20-26. 
Sapolsky, H. M. (1979). Academic science and the military: The years since the Second World War. In N. Reingold (Ed.), The sciences in the American context: New perspectives. (pp. 379-399). Washington DC: Smithsonian Institution Press.

Sarachan, S. (2013, February). Ask the experts: Skills gap. Need to know on PBS. Retrieved from http://www.pbs.org/wnet/need-to-know/economy/ask-the-expertsskills-jobs/16219/

Sargeant, Jr., J. F. (2014). The U.S. science and engineering workforce: Recent, current, and projected employment, wages, and unemployment (CRS Report R43061). Washington, DC: Congressional Research Service.

Schibuk, E. (2008). Re-looking undergraduate STEM education reform at Brown University: An undergraduate thesis in science and technology studies (Unpublished thesis). Brown University, Providence, RI. Retrieved from http://brown.edu/academics/science-and-technologystudies/sites/brown.edu.academics.science-and-technologystudies/files/uploads/E_Schibuk_thesis_final_1.pdf

Schramm, M, \& Fraunholz, U. (2012). Between the ivory tower and the industrial laboratory: Universities in the West German innovation system, 1945-1990. Historical Social Research, 37(2), 254-279. Retrieved from http://www.ssoar.info/ssoar/handle/document/37293

Shah, C., \& Burke, G. (2003). Skills shortages: Concepts, measurements and implications (Working Paper No. 52). Retrieved from the Center for the Economics of Education and Training: http://www.monash.edu.au/education/non$\mathrm{cms} /$ centres/ceet/docs/workingpapers/wp52nov03shah.pdf

Shapley D. (1973).White house foes: Wiesner target of proposal to cut M.I.T. funds, Science, 181(4096), 244-246. doi: 10.1126/science.181.4096.244

Shierholz, H. (2014). Is there really a shortage of skilled workers? Economic Policy Institute. Retrieved from http://www.epi.org/publication/shortage-skilled-workers/

Shierholz, H., Sabadish, N., \& Finio, N. (2013). The class of 2013: Young graduates still face dim job prospects (EPI Briefing Paper 360). Retrieved from Economic Policy Institute: http://s4.epi.org/files/2013/Class-of-2013-graduates-job-prospects.pdf

Stampen, J. O., \& Layzell, D. T. (1997). Tuition and student aid in public higher education: Searching for an organizing principle. New Directions for Institutional Research, 1997(95), 25-42. doi:10.1002/ir.9502

Statistisches Bundesamt. (1996). Bildung und Kultur, Prüfungen an Hochschulen. Fachserie 11, Reihe 4.2. Wiesbaden. 
Stephan, P. (2012). How economics shape science. Cambridge, MA: Harvard University Press.

Teaching Institute for Excellence in STEM (2015). What is STEM education? http://www.tiesteach.org/about/what-is-stem-education/

Teitelbaum, M. S. (2003, Fall). Do we need more scientists? The Public Interest, 153, 4053.

Teitelbaum, M. S. (2008). Is there really a shortage of technical professionals? ResearchTechnology Management, 51(2), 10-13. doi: 10.1080/08956308.2008.11657489

Teitelbaum, M. S. (2014a). Falling behind? Boom, bust, and the global race for scientific talent. Princeton, N.J.: Princeton University Press.

Teitelbaum, M. S. (2014b, March). The myth of the science and engineering shortage. The Atlantic. Retrieved from http://www.theatlantic.com/education/archive/2014/03/the-myth-of-the-scienceand-engineering-shortage/284359/

The Economist. (2013, June). Dissecting the miracle: The ingredients of German economic success are more complex than they seem [Special Report]. Retrieved from http://www.economist.com/news/special-report/21579145-ingredientsgerman-economic-success-are-more-complex-they-seem-dissecting

The information portal for foreign professional qualifications (2013). Germany introduces new legislation to attract skilled workers. Retrieved from https://www.bq-portal.de/en/aktuelles/germany-introduces-new-legislationattract-skilled-workers

The White House. Office of the Press Secretary. (2011). Remarks of the President in state of union address. Retrieved from https://www.whitehouse.gov/the-pressoffice/2011/01/25/remarks-president-state-union-address

The White House. Office of the Press Secretary. (2013a). Educate to Innovate. Retrieved from http://www.whitehouse.gov/issues/education/k-12/educate-innovate

The White House. Office of the Press Secretary. (2013b). Remarks of the President in state of union address. Accessible at https://www.whitehouse.gov/the-pressoffice/2013/02/12/remarks-president-state-union-address

The White House. Office of the Press Secretary. (2016). Remarks of the President in state of union address. Accessible at https://www.whitehouse.gov/the-pressoffice/2016/01/12/remarks-president-barackobama-\%E2\%80\%93-prepareddelivery-state-union-address 
Toner P., Turpin T., Woolley R., \& Lloyd C. (2011). The role and contribution of tradespeople and technicians in Australian research \& development: An exploratory study. Department of Education, Employment and Workplace Relations. Retrieved from http://industry.gov.au/skills/AssistanceForIndividuals/Documents/TradespeopleTe chnicians.pdf

Tyfield, D. 2012. A cultural political economy of research and innovation in an age of crisis. Minerva, 50(2), 149-167. doi:10.1007/s11024-012-9201-y

U.S. Census Bureau. (1970). Accessible at https://www.census gov

U.S. Census Bureau. (1980). Accessible at https://www.census gov

U.S. Census Bureau. (1990). Accessible at https://www.census gov

U.S. Census Bureau. (2000). Accessible at https://www.census gov

U.S. Census Bureau. American Community Survey. (2011). Accessible at www.census gov/acs/www

U.S. Census Bureau. American Community Survey. (2012). Accessible at www.census gov/acs/www

U.S. Census Bureau, American Community Survey. (2014). Census Bureau Reports Majority of STEM College Graduates Do Not Work in STEM Occupations (Release Number: CB14-130). Retrieved from http://www.census.gov/newsroom/press-releases/2014/cb14-130.html

U.S. Chamber of Commerce. (2005). Tapping America's potential: The education for innovation solution. Washington, DC: Business Roundtable. Retrieved from https://www.uschamber.com/sites/default/files/legacy/reports/050727_tapstateme nt.pdf

U.S. Congress. Joint Economic Committee (1964). Report on the January 1964 Economic Report of the President, $88^{\text {th }}$ Cong., $2^{\text {nd }}$ Sess., Senate Report. 931, p. 55.

U.S. Department of Education. (2007). Report of the Academic Competitiveness Council. Retrieved from http://coalition4evidence.org/wp-content/uploads/ACC-reportfinal.pdf

U.S. Department of Labor, Bureau of Labor Statistics. (2012). Attachment A: Options for defining STEM occupations under the 2010 SOC system. Retrieved from http://www.bls.gov/soc/Attachment_A_STEM.pdf 
U.S. Department of Labor, Bureau of Labor Statistics. (2013). Occupational Employment Statistics. Employment and wages by science, technology, engineering, and math (STEM) occupational groups and detailed occupations. Accessible at http://www.bls.gov/oes/2013/may/stem_groups.htm

U.S. Department of Labor, Bureau of Labor Statistics. (2014). Occupational Employment Statistics. Employment by type of STEM occupation. Accessible from http://www.bls.gov/oes/2014/may/stem_type.htm

U.S. Government Accountability Office. (1998). Information technology: Assessment of the Department of Commerce's report on workforce demand and supply (GAO/HEHS-98-106). http://gao.gov/assets/230/225415.pdf

U.S. Government Accountability Office. (2007). Higher education: Federal science, Technology, Engineering, and Mathematics Programs and related trends. In P. B. Richards (Ed.). Global Issues in Higher Education. (pp. 267-339). New York: Nova Science Publishers, Inc.

U.S. Government Accountability Office. (2012). Training, employment, and education: 31. Science, Technology, Engineering, and mathematics education (GAO-12342SP). Retrieved from http://www.gao.gov/assets/590/588818.pdf

U.S. National Research Council (2012). A framework for K-12 science education: Practices, crosscutting concepts, and core ideas. Washington, DC: National Academies Press.

U.S. State Department. (2012). Nonimmigrant Visa Statistics [spreadsheet]. http://www.travel.state.gov/xls/NIVIssuedFYs1987-2011

Ukeles, J. B. (1977). Policy analysis: Myth or reality? Public Administration Review, 37(3), 223-228.

University of Melbourne. (2008). Review of Australian higher education. The Bradley Review. Retrieved from https://www.unimelb.edu.au/publications/docs/2008bradleysubmission.pdf

Wallerstein, I. (1974). The rise and future demise of the world-capitalist system: Concepts for comparative analysis. Comparative Studies in Society and History, 16(4), 387-415.

Wiessner, C. W. (2013, November). How does Germany do it? ASME. Retrieved from https://www.asme.org/engineering-topics/articles/manufacturing-processing/howdoes-germany-do-it 
Wissenschaftsrat (Hrsg.). (1983). Zur Lage der Hochschulen Anfang der 80er Jahre. Textteil. Cologne: Wissenschaftsrat.

Wissenschaftsrat (Hg.) (1988). Empfehlungen des Wissensschaftsrates zu den Perspektiven der Hochschulen in den 90er Jahren. Cologne: Wissenschaftsrat.

Wissenschaftsrat (1996). Eckdaten und Kennzahlen zur Lage der Hochschulen. Stand 1996. Cologne: Wissenschaftsrat.

Xie, Y., \& Killewald, A. A. (2012). Is American science in decline? Cambridge, MA: Harvard University Press.

Xue, Y., \& Larson, R. C. (2015, May). STEM crisis or STEM surplus? Yes and yes. United States Department of Labor, Bureau of Labor Statistics. Retrieved from http://www.bls.gov/opub/mlr/2015/article/pdf/stem-crisis-or-stem-surplus-yesand-yes.pdf

Yanow, D. (2007). Qualitative-interpretive methods in policy research. In F. Fischer, G. J. Miller \& M. S. Sidney (Eds.), Handbook of public policy analysis: Theory, politics, and methods. (pp. 405-416). Boca Raton, FL: CRC Press, Taylor \& Francis Group.

Yin, R. K. (1994). Case study research: Design and methods. Thousand Oaks, CA: Sage.

Zimmermann, K. F., Bonin, H., Fahr, R, \& Hinte, H. (2007). Immigration policy and the labor market: The German experience and lessons from Europe. Berlin, Germany:Springer-Verlag. 


\section{APPENDIX A \\ INTERVIEW QUESTIONNAIRE}

1. In the U.S GAO (2007), it is noted that the United States "has long been known as a world leader in scientific and technological innovation" (p. 267), how critical is STEM (Science, Technology, Engineering and Mathematics) to the United States on the world stage competitiveness relative to investments in science, technology and education?

2. What are the U.S. concerns in terms of global positioning and scientific capital in sustaining its hegemonic power?

3. How does the rhetoric of a STEM workforce shortage play out in the United States from the perspective of the US economy and its dependence on STEM workers to keep its vibrancy and the bipartisan theme in public policy discussions?

4. Bush (1945) had expressed that "without scientific no amount of achievement ... can insure our health, prosperity, and security as a nation in the modern world" ( $p$. 11). With this in mind, corporate leaders, lobbyists, and universities are arguing that there are serious shortages of scientists and engineers in the United States, however researchers maintained that no clear evidence can substantially support those claims and that more scientists and engineers graduate from U.S. universities than positions can guarantee their employment. As a researcher, how do you approach these differences in opinion and what are the major tenets of these claims?

5. As of the $1920 \mathrm{~s}$, American science was marked by the "advent of science-based university and the professionalization of the scientific community" (Owen, 1997, p. 832). Although the scientific power was progressively shifting from Europe to the United States, the American industry would hardly meet any competition until the mid-1960s (Atkinson \& Blanpied, 2008), marked by an increasing competition from Europe and Japan. Also, the years of the Cold War raised a national interest for science in contrast to the argument that STEM is a 'leaking pipeline' today. 
a. Can we speak of fear or a defensive attitude extending to markets like China and India, for example the signing into law the America

COMPETES Act (2007) to improve STEM workforce and provide the capacity to expanding the talent pool?

b. Can we speak of a weakness in the fundamentals of STEM education and workforce in the United States (Galama \& Hosek, 2003)?

c. Can we speak of a generalization of STEM shortages, dismissing the predicated shortages in specific occupational fields?

6. Part of the literature review indicates an overemphasis of high-skilled workers and at the same time undermines the important role sub-bachelor's level STEM workers play in the US economy. Rothwell (2013) asserts that "vocational or practical training in science and technology" (p. 2) is not being assessed. Researchers have spoken of a dearth of evidence to differentiate accepted facts with empirical evidence. Are there any forces at play that prevent us from adequately addressing the evidence behind these claims?

7. While offshoring may be a relatively recent phenomenon, the hiring of foreign workers by US industrialists, who brought in European tradesmen in the early twentieth century is not too different from today's practices, including the incurred cost savings in labor while producing highly engineered products. How do you see those practices coincide with the behavior of those industries in terms of employment, when employers cannot fill positions with high skilled workers to meet demand in rapidly advancing STEM career fields, therefore feeding into the rhetoric of a STEM shortage?

8. How do these transformative models of doing business and negotiating education credentials in an era of globalization influence the rhetoric of a shortage in STEM workforce in the United States when compared with other labor markets like China and India and the hiring of H1-B visas for example?

9. Part of the literature review indicates that wages have not being bid up (Shierholz, 2014). Also, Camarota and Zeigler (2014) indicate that "over the entire period of 2000 to 2012, real hourly wages (adjusted for inflation) grew on average just 0.65 percent annually for those with only a bachelor's degree and 0.71 percent for all STEM workers" (p. 13; Figure 7). Could this indicate a pattern of a short supply of STEM workers in the United States?

10. Looking back at how STEM evolved from the NSF in the 1990s from the original acronym SMET, the four letters of STEM are also used interchangeably by different audiences, including the disciplines STEM includes. Is it possible that this compartmentalization of academic disciplines into a four-letter acronym fuels the biased rhetoric of a STEM shortage and remove the multidisciplinary benefits of integrated curricula "to studying grand challenges of our era" (Moon \& Rundell Singer, 2012, p. 31)? 
11. How much leverage could the ' $T$ ' in STEM have as "a defining driver of productivity in business and industry" (BHEF, 2011, p. 1) in supporting the rhetoric that feeds the public expectations for its standard of living, health and security?

12. How does the changing demographic distribution impact the workforce supply?

13. In light of becoming a scientist today, Teitelbaum (2003, 2014a, 2014b) speaks about the long years when a student foregoes earnings, for example, in biomedical research compared to non-STEM fields to which more students seem to rally to.

a. What does it take to become a scientist today? Has it become a profession of elites made of people willing to face low demand market offer and wage and be at risk, in part due to diminishing federal funding, in the pursuit of their dream*?

b. How can the status and appreciation of scientists be elevated in comparison to the cache that law, medicine, or high finance have?

c. How can the appeal or inspiration to pursue a career in a STEM field be of value in American society today and help alleviate the 'knowledge gap' that may contribute to the rhetoric of a skilled STEM shortage? 


\section{APPENDIX B \\ SEMINAL DOCUMENTS}

This appendix identifies a series of seminal documents, including reports, books and articles that have helped place the current narrative within the constructivist framework of this education policy study. These documents are organized by country, namely United States, Australia and Germany, respectively. For each country, documents pro et contra the narrative of STEM (or MINT) shortages are as follows:

\section{United States}

Two politically influential reports have played a pivotal role in structuring this discourse. Each of the two reports presents STEM shortages as critical for the United States.

\section{Reports}

Tapping America's Potential: The education for innovation solution (2005). The report was published in July 2005 by a coalition of industry associations led by the Business Roundtable. Addressed "To Leaders Who Care about America's Future", this resonated as alarming in that "the United States is in a fierce contest with other nations to remain the world's scientific leader" (p. 1).

Fourteen signatories were included in the formulation of this report, including influential business organizations such as the National Association of Manufacturers, Information Technology Industry Council and the Semiconductor Industry Association. 
The report makes use of ominous observations while recalling the Soviet Union's launching of Sputnik I in the 1950s, stating that "history is replete with examples of world economies that once were dominant but declined because of myopic, selfdetermined choices" (p. 5). Based on this state of panic, the brief report contains a series of recommendations addressed to federal, state, and local governments, along with business with the intent to boost the number of scientists and engineers entering the U.S. workforce by:

a) Building public support for making STEM performance a national priority

b) Motivating U.S. students and adults, including underrepresented populations to pursue STEM careers

c) Upgrading K-12 mathematics and science teaching to foster higher student achievement

d) Reforming visa and immigration policies to enable the United States to attract and retain the "best and brightest" STEM students from around the world to study for advanced degrees and stay to work in the United States

e) Boosting and sustaining funding for basic research, especially in the physical sciences and engineering

As the goal of the report had been to "Double the number of science, technology, engineering and mathematics graduates by 2015”, Tapping America's Potential now has a goal, that is to "Increase the annual number of U.S. science, technology, engineering and mathematics bachelor's-level graduates to 400,000." More information about Tapping America's Potential can be accessed at http://tapcoalition.org/ , including statistics from a revolving earth with the caption "Are we falling behind?" 
Rising Above the Gathering Storm (2005). This might be "one the most politically influential reports ever produced by a National Research Council committee" (Teitelbaum, 2014a, p. 19). An early draft was written and circulated in 2005. The draft was written on a very short timetable (within 10 weeks), which did not allow the committee to conduct a thorough analysis. A final hard copy was published in 2007 by the National Academies Press.

The ad hoc committee was chaired by Norman R. Augustine, former chairman and CEO of Lockheed Martin Corporation and former Under Secretary of the Army, was largely represented by industry leaders, presidents of major research universities, scientists or engineers, and several other highly influential individuals. In ten weeks, the Academies were asked for prompt responses to the following questions:

a) What are the top 10 actions, in priority order, that federal policy-makers could take to enhance the science and technology enterprise so that the United States can successfully compete, prosper, and be secure in the global community of the 21st Century?

b) What strategy, with several concrete steps, could be used to implement each of those actions?

In light of a very short timetable, the conclusions and recommendations drawn in the Gathering Storm report were quite similar to the other report from July 2005. Recommendations were as follows:

a) Increasing the U.S. talent pool, including America's teaching profession in K-12 science and mathematics education 
b) Sustain and strengthen the nation's traditional commitment to long-term basic research

c) Recruit and retain the "best and brightest" students, scientists, and engineers from within the United States and throughout the world

d) Ensure that the United States is the premier place in the world to innovate by providing tax incentives (doubling tax credit) and change intellectual-property laws that act as barriers to innovation in specific industries, for example, pharmaceuticals and information-technology for data and litigation While "the United States faces an enormous challenge because of the disadvantage it faces in labor cost", the committee sought out ambitious new public policies, in part, wanting to "institute a new skills-based, preferential immigration option". The push for "best and brightest" extends to "provid[ing] a 1-year automatic visa extension to international students who receive doctorates or the equivalent in [STEM], or other fields of national need at qualified US institutions to remain in the United States to seek employment.

At the same time, the committee sought to "increase the number of US citizens pursuing graduate study in "areas of national need" by funding 5,000 new graduate fellowships each year". Other incentives would be allocated for competitive undergraduate scholarships each year to US citizens attending US institutions. Lastly, another public policy called for greater federal investment in long term basic research by $10 \%$ a year over the next 7 years.

In concluding, the committee draws a negative outlook for America to compete for quality jobs, thus leading to the publication by the National Academies Press of the 
Rising above the gathering storm: Rapidly approaching category 5 - a metaphorical and sinister call to a situation that proved to have not being based on empirical evidence and careful analyses conducted by researchers and advocates that have shown no credible evidence to such alarming concerns.

\section{Books and articles}

The authors listed present different viewpoints. The STEM report by Carnevale, Smith, \& Melton (2011) presents STEM shortages as critical. The other leading experts on STEM shortages have steered the conversation in a slightly different direction, stating there are no general shortages of STEM workers, not excluding that shortages may exist in specific fields.

Anthony Carnevale, Nicole Smith, and Michelle Melton (2001). The report by Carnevale, Smith, and Melton (2011) at the Georgetown University, Center on Education and the Workforce is very often cited in U.S. debates about STEM workforce shortages. The report raises critical perspectives from a variety of angles, including higher education and sub-baccalaureate levels even though the latter may often not be part of STEM discussions and definitions. However, these broad perspectives could mask marked differences in growth and competencies among particular STEM occupations across levels that could lead to not being able to address the problem with the ideal solution. Most importantly and the report identifies this gap, is that what is really at stake in the current debate over the existence of quantifiable STEM shortages is an important question regarding a national strategy for sustaining economic innovation in the United States" (p.7). 
Hal Salzman. He has written several articles about STEM shortages. In the 2007 report, Into the eye of the storm: Assessing the evidence on science and engineering education, quality, and workforce demand, he and Lindsay Lowell have disputed that there are STEM shortages at the aggregate level and point to shortages only in specific fields or by minority groups. Salzman (2013) continues to question the narrative in his article, What shortages? The real evidence about the STEM workforce. Similar to my interview with him in September 2015, getting to understand the history of skill shortages is critical, particularly when the 2005 report by the NRC, Rising Above the Gathering Storm and the Category 5 five years later were able to shape the public opinion about STEM workforce shortages in the U.S. that can only be solved by increasing the flow of guest workers -it is nonetheless important to distinguish between immigration and guest workers.

Salzman (2013) maintains that "researchers have time and again examined such claims and failed to find much evidence to support them" (para 16) while "proponents of supply crisis claims push even further, arguing that STEM is a 'leaking pipeline"” (para 20). Lastly, looking at the supply crisis more broadly in that demand is not met, Salzman (2013) asserts that "the nation graduates more than two times as many STEM students each year as find jobs in STEM fields" (para 19).

Hal Salzman's work has led him to present before the United States Senate Judiciary Committee in February 2016. In his speech, he reinforced the fact that the increasing disharmony between the immigration policy and guest worker programs clearly intends to reduce the cost of doing business for industry despite evidence of questionable claims of shortages. 
Michael S. Teitelbaum. He has been very influential in setting the discourse in this study. His book, Falling behind? Boom, bust, and the global race for scientific talent has been a critical piece and quite comprehensive to understanding the current debate and guiding this education policy study.

Norman Matloff. He raises critical issues regarding the immigration of $\mathrm{H}-1 \mathrm{~B}$ workers, who are seen as the "best and brightest" in light of older American workers, who may be unprepared for the job since they have not kept up with their skills. Matloff (2013a; 2013b) speaks about the increasing age discrimination for older workers. Shared by other leading experts on the STEM workforce, training appears to be a distraction to the real problem as many legal loopholes exist to suppress wage growth by paying foreign workers less.

Paula Stephan (2012). She sets out to explain how economics has a lot to do with science. More specifically related to whether there are shortages of scientists and engineers, Stephan looks back at the "looming shortages" predicted by the NSF in 1989 before elaborating on the issues of shortages as they tend to be predicated by groups with a vested interest. Interestingly, Stephan (2012) notes that the Rising Above the Gathering Storm report "stressed measures that would enhance the demand for innovation and, by extension the demand for S\&E workers" (p. 165) as opposed to emphasizing on supply only. In that chapter, Stephan introduces an external perspective in that predictions of shortages are not limited to the United States, they occur in Europe as well, being subject to political events in Germany, for example, with the Berlin wall.

Richard B. Freeman. The United States has seen a declining number of science and engineering graduates as opposed to European and Asian universities, particularly 
from China. Not only the job market for young graduates in S\&E fields has changed -the job market is also no longer the same for older qualified STEM workers -, there has been a greater influx of immigrants. At the same time, there is the issue of income between low income countries and technologically advanced countries; a phenomenon that has been an attractive proposition for offshoring IT jobs to India, high-tech firms locating R\&D facilities in China and India and multinational corporations to set foot in developing countries to lower cost of production. However, the transition period to rebalance the spread of science and technological knowledge from other parts of the world in light of U.S. hegemony will likely take some time to recover. Freeman (2006a) states that comparatively to foreign nations where the number of scientists and engineers is increasing, "the U.S.'s comparative advantage in generating scientific and engineering knowledge and in the high-tech sectors and products associated with that knowledge will decline" (p. 148).

Looking back at the early 2000s, demographics changes had raised concerns about possible shortages of labor. The National Association of Manufacturing and the U.S. Chamber of Commerce, for example, stated that the lack of skilled workers and the increasing numbers of retiring baby boomers would lead to serious consequences. With that in mind, Freeman (2006b) sees that these concerns do not quite compare to the impact that the increased supplies of skilled labor in low wage countries will have on U.S. workers, in that "implications would go far beyond assuring that business obtains the labor it may seek 10 or 20 years down the road without incurring higher wages" (p. $3)$.

In sum, Freeman (2006b) concludes drawing from the perspective of three areas 
of focus that have fed into the discourse about labor shortage relative to a changing global economy.

1. The logic of labor shortage analyses is flawed as it is imperative to take into consideration the impact of global knowledge economy

2. Projections of future demands for skills lack the reliability to guide policies on skill development, including how technology has greatly influenced industry practices and handling of skilled workforce relative to earnings

3. Demographic changes have not historically been consistently associated with changes in labor market conditions

Ron Hira. As Hira (2010) states, "there is no need to belabor the importance of the STEM workforce ... [and] the critical role [it plays] in increasing our standard of living, ensuring national security..." (p. 949). The main dilemma is how the continuing rhetoric is articulated as a bipartisan theme, divided on one side of the aisle by corporations and university leaders, who share the consensus of a growing shortage of domestic STEM talent as a threat to national security and the like and on the other side leading experts like Ron Hira and several others who would disagree. Most importantly it is to see how much attention has been given to this topic by policymakers and the literature that ensued from those decisions, including very highly politically influential reports that have received very little scrutiny, yet have shaped public attitude about STEM shortages in spite of "deficient and stale data, untested theories, and poor predictions and often disregards distributional impacts" (Hira, 2010, p. 960).

Ron Hira's work has led him to present before the United States Senate Judiciary Committee in March 2016, in part, about the immigration of high-skilled workers in the 
U.S. in light of several corporations and universities "exploiting loopholes" regarding H1B rules in order to bypass the set cap.

\section{Yu Xie and Alexandra A. Killewald (2012). Is American Science in Decline?}

The authors find no evidence of a general shortage of scientists and engineers in the United States. Instead, they see a glut of young scientists with poor career prospects, which inevitably tends to lead to low wages and a lack of aspiration for science, contrary to the years following World War II. Globalization has had a profound effect on nations and has led to an increasing immigration of scientists to the United States. Nonetheless, globalization may benefit scientific progress in a collaborative fashion.

\section{Australia}

The authors listed present STEM from different perspectives. The AiGroup report resonates with a similar tone as the Rising Above the Gathering Storm, somehow. Simon Marginson presents stimulating international perspectives on STEM. His writings have been very insightful in guiding the education policy study on STEM.

\section{Report}

Australian Industry Group (2012). The AiGroup is a nonprofit group representing some 60,000 businesses in Australia. The report called for "a major re-think by Australian education at all levels and in all sectors" to increase participation in STEMrelated education and training. Survey results from the AiGroup (2012) indicate that the industry has difficulties to recruit STEM-skilled ready technicians and trade workers. The tone of the report raises concerns, simply by reporting on a comment made at a AiGroup focus group, that: 
In Australia you tend to get people that are experts in their field, but they can't see left and they can't see right of what they've actually done and the skills...in engineering you have to be able to look to the left and to the right to be able to put things together....And I think it's that part that's missing in the education sector. (p. 2)

Along those lines, concerns in secondary education are raised as well. That said, Vice-Chancellor Gavin Brown, University of Sydney stated in The Australian on March 10, 2010, "The state of maths and science at Australian schools and universities has deteriorated to a dangerous level."

That said the Australian Workforce and Productivity Agency (AWPA) joins the conversation about the low student participation in STEM. Interestingly, the AWPA developed the new Skills Occupation List (SOL) in 2010. The SOL was created for the Commonwealth government's Department of Immigration and Citizenship General Skilled Migration Programme.

The report continues with a Survey of Workforce Development Needs from 2012, emphasizing on primarily two inadequacies in recruiting qualified STEM workers, the lack of STEM skilled workers and their lack of workplace experience. One other category of relatively similar percentage is identified as "Not applicable."

In stating what needs to be done, the report references the AUS \$ 54 million the Australian Government had committed in 2012 to mathematics, engineering and science in light of harnessing STEM in its advantage.

The AiGroup expressed a sense of urgency with recommendations distributed across schooling, higher education and business and industry. While it is important to 
have school students experience STEM skills, the university-industry collaboration, including work-related experience is called for. This type of collaboration would extend to developing a national framework and grow models that support internships and work placements, thus engaging in training.

Despite these recommendations and observations made relative to government actions, it is nonetheless important to reiterate that Australia does not have a coherent national strategy to establish a constructive STEM framework (Braue, 2015; Marginson et al., 2013), which would help concretize the agenda set forth by the Office of the Chief Scientist.

\section{Books and articles}

Simon Marginson. He has a rich working achievement in the area of higher education, with several books and articles. For this study, his insights about higher education in Australia have supported the discourse I was looking for. From books and reports about STEM in Australia, including the 2015 book, The Age of STEM:

Educational policy and practice across the world in science, technology, engineering and mathematics helped confirm to have Australia in the study as a foil to frame the discourse in a global setting.

Although the Australian higher education system has gone through major reforms in the last 30 years or so, Australia has been struggling to put science and technology policy on the political agenda (Marginson, 2013). The lack of a coherent national strategy makes it more difficult to establish a constructive STEM framework (Braue, 2015; Marginson et al., 2013), which would help concretize the agenda set forth by the Office of the Chief Scientist. 


\section{Germany}

The authors listed present different viewpoints. The report by the European Commission reflects ideas and concepts from a private survey about ICT. Karl Brenke argues that there is no shortage in sight.

\section{Report}

European Commission, e-SKILLS in Europe (2014). This report on Germany was generated by empirica, based on a study by BITKOM in 2014. The report was written for the European Commission, Directorate General Enterprise and Industry with a focus on the supply and demand of Information and Communications Technology (ICT) practitioners. Claims are that "Germany lacks a general and comprehensive e-skills strategy" (p. 9) for IT and ICT in light of growing concerns of the ageing German population. The German ICT industry association sees that educating more young people and getting them interested in STEM professions to be a major objective. For example, the Go MINT!, the National Pact for Women in MINT, created in 2008, is a promising partnership to draw young women's interest in scientific and technical degree courses and attract female university graduates to careers in business. Another STEM Initiative is the MINT Zukunft schaffen (Making the Future). Also created in 2008, this initiative provides public awareness as well as data about the shortage of STEM professionals on Germany's labor market.

Lessons learned tend to be about striking the perfect balance with broad skillprofiles (soft skills) and specific technological knowledge. However, the "IT Professional" type of education system industry demand is facing a lack of broad acceptance of that system. 


\section{Articles}

Karl Brenke, German Institute for Economic Research. As an economist, Brenke (2012b) clearly states that the narrative on shortages in Germany seems to revolve around a consensus of no general shortages vs shortages in specific disciplines in MINT occupations. Indeed, opinions about shortages in Germany are also conflicting, when represented by the Association of German Engineers (Verein Deutscher Ingenieure VDI) or business associations, for example, exhibiting a vested interest. Here too, the issue about fit data is raised while major sources that can inform on the employment of engineers, demography and labor market tend to be more limited. As equally important, if not absolutely critical, Germany is faced with a 'brain drain' (Brenke, 2012b; Constant \& Tien, 2011). 